\title{
Public Health Care: Essays on Wait Times, Home Care, and the Public-private Mix
}

\author{
By
}

\section{Haizhen Mou}

\author{
A thesis submitted to \\ The Faculty of Graduate Studies and Research \\ In partial fulfillment of the requirements for the degree of \\ Doctor of Philosophy \\ Ottawa-Carleton Institute for Economics \\ Department of Economics \\ Carleton University \\ Ottawa, Ontario, Canada \\ May 2009
}


Library and

Archives Canada

Published Heritage

Branch

395 Wellington Street

Ottawa ON K1A 0N4

Canada
Bibliothèque et

Archives Canada

Direction du

Patrimoine de l'édition

395 , rue Wellington

Ottawa ON K1A 0N4

Canada

Your file Votre référence

ISBN: 978-0-494-52084-0

Our file Notre référence

ISBN: 978-0-494-52084-0

NOTICE:

The author has granted a nonexclusive license allowing Library and Archives Canada to reproduce, publish, archive, preserve, conserve, communicate to the public by telecommunication or on the Internet, loan, distribute and sell theses worldwide, for commercial or noncommercial purposes, in microform, paper, electronic and/or any other formats.

The author retains copyright ownership and moral rights in this thesis. Neither the thesis nor substantial extracts from it may be printed or otherwise reproduced without the author's permission.
AVIS:

L'auteur a accordé une licence non exclusive permettant à la Bibliothèque et Archives Canada de reproduire, publier, archiver, sauvegarder, conserver, transmettre au public par télécommunication ou par l'Internet, prêter, distribuer et vendre des thèses partout dans le monde, à des fins commerciales ou autres, sur support microforme, papier, électronique et/ou autres formats.

L'auteur conserve la propriété du droit d'auteur et des droits moraux qui protège cette thèse. $\mathrm{Ni}$ la thèse ni des extraits substantiels de celle-ci ne doivent être imprimés ou autrement reproduits sans son autorisation.
In compliance with the Canadian

Privacy A'ct some supporting forms may have been removed from this thesis.

While these forms may be included in the document page count, their removal does not represent any loss of content from the thesis.
Conformément à la loi canadienne sur la protection de la vie privée, quelques formulaires secondaires ont été enlevés de cette thèse.

Bien que ces formulaires aient inclus dans la pagination, il n'y aura aucun contenu manquant.

\section{Canadä}




\section{Dedication}

This dissertation is dedicated to my parents, Yaofeng Liu and Congwei Mou, and my loving husband, Xuetao Liu, without whose unconditional love and longstanding support I would have never accomplished this goal.

Translation from English:

慈将本文献给我的父母牟从威和柳热风, 以及我亲爱的丈夫, 柳雪涛。没有你们无 私的爱和恒久的支持, 我将不可能实现这一目标。 


\section{Acknowledgement}

I owe an immense debt of gratitude to my supervisor, Dr. Stanley L. Winer, from whom I learned how to do research. This dissertation would not have been possible without his sage advice, insightful guidance, and dedicated efforts. I am fortunate to have Dr. Stephen Ferris in my committee whose warm encouragements and helpful consultations were invaluable for my Ph.D. study. Gratitude is also given to Dr. Rose Anne Devlin and Dr. Frances Woolley who carefully reviewed the papers and provided very useful suggestions.

I want to thank the discussions with many faculty members at the two economics departments. In particular, Dr. Stefan Dodds offered collegial supports and helped at each stage of the thesis. Dr. Ingela Alger is always willing to share her expertise.

Deep appreciations go to my family members, friends, teachers, and my master thesis supervisor Yuexiang Lu in China who stood by me in the ups and downs of life.

I also want to thank my friends at Carleton U. and U. of Ottawa with whom I shared several memorable years. It is you who made my studies interesting and enjoyable.

Finally, I want to express my appreciation to the administration team at the department. Because of your professionalism and generosity, the department is like a home.

Thank you all!

Haizhen Mou

May 2009 


\begin{abstract}
This thesis investigates various health care policies in a framework that combines heath care financing, health expenditure, and public choice procedure. The health care policies studied include wait times for public health care, subsidy for home care for the elderly, and the public-private mix of health expenditure.
\end{abstract}

Chapter 1 investigates the determinants of wait times for public health care in a political economy framework. A public-private health system is modeled, where the longer wait for public care is the major difference between the public and private systems. Voters' preferences for health care vary according to their expected morbidity and by income. In the political equilibrium, wait times in the public system depend on demographics and morbidity. But they are independent of the distributions of income and of political influence, which affect only individual tax-transfer rates.

Chapter 2 studies analytically and with simulation the measurement of the net fiscal incidence of a program that subsidizes home care of the elderly, when both individual welfare and family structure matter. The definition of welfare incidence, the comparison of welfare-based incidence with budgetary incidence for non-cooperative and cooperative families, and the calculation of the shifting of program benefits between family members, some of whom may be altruistic, are key issues in the analysis.

Chapter 3 investigates the determinants of the public-private $\operatorname{mix}$ in health care expenditure in OECD countries over the 1981 - 2005 period. Estimating equations are 
based on an extension of Usher (1977)'s model of the collective decision to socialize private goods. The estimation results verify Usher's theory concerning the roles of incentives to redistribute and the losses from socialization of health care when preferences are diverse. In addition, we find that the general right-left ideological views of citizens play an important role in defining the boundary between public care and private care. Finally, the results indicate that population aging is likely to lead to increased spending on the public health care system rather than to greater relative reliance on private care. 


\section{Table of Contents}

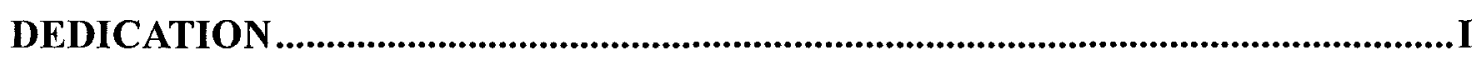

ACKNOWLEDGEMENT ............................................................................................ II

ABSTRACT .....................................................................................................

TABLE OF CONTENTS................................................................................ V

LIST OF TABLES...............................................................................................VIII

LIST OF FIGURES .................................................................................................................IX

PART I WAIT TIMES FOR PUBLIC HEALTH CARE: A POLITICAL

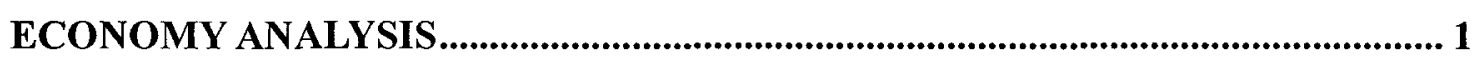

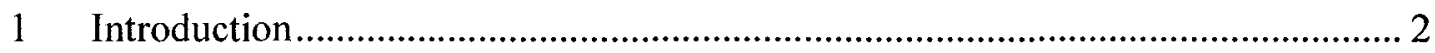

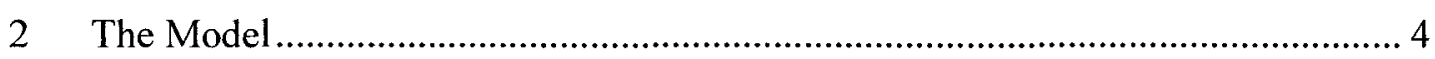

2.1 The relationship between public care and private care ................................ 5

2.2 The demand for individual private care................................................... 8

2.3 The wait time function ................................................................................

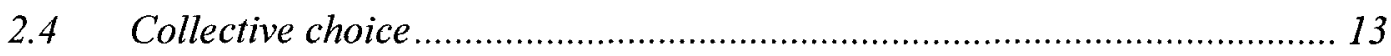

3 The Political Equilibrium.............................................................................. 17

3.1 Solving for the equilibrium policy platform ……………………………...... 17

3.2 The separation result and the single tax rate case........................................ 21

3.3 The role of actuarially fair insurance …………………………………..... 22

3.4 The role of single-mindedness in the equilibrium tax-transfer schedule ...... 24

4 The Impact of Aging on Equilibrium Wait Times............................................. 26

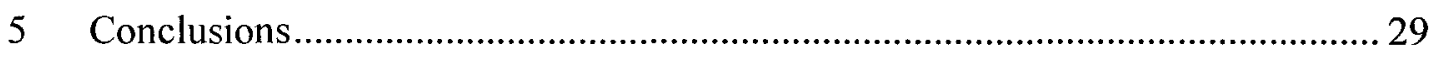

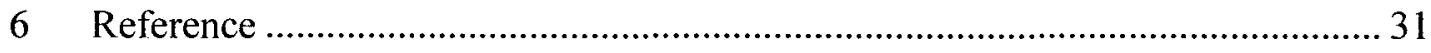

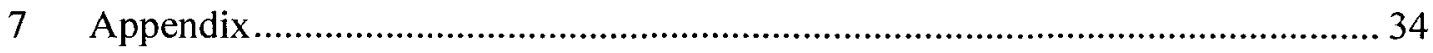

7.1 Solving for the Political Equilibrium under Alternative Assumption ............ 34

7.2 The Equilibrium Tax-Transfer Schedule and Its Properties.......................... 37

7.3 The Impact of Aging on Equilibrium Wait Times ...................................... 39 


\section{PART II FISCAL INCIDENCE WHEN BOTH INDIVIDUAL WELFARE AND}

FAMILY STRUCTURE MATTER: THE CASE OF SUBSIDIZATION OF HOMECARE FOR THE ELDERLY 42

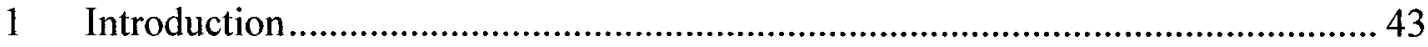

2 A Brief Guide to Incidence Analysis ................................................................. 46

2.1 The choice of a counterfactual experiment .................................................. 46

2.2 Observing the government budget in the counterfactual.............................. 47

2.3 Choice of a metric for incidence calculations ............................................. 48

2.4 Choosing a benchmark income for the purpose of defining an incidence

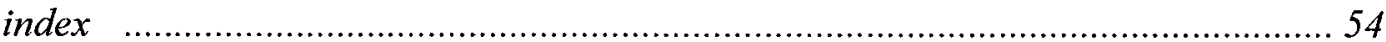

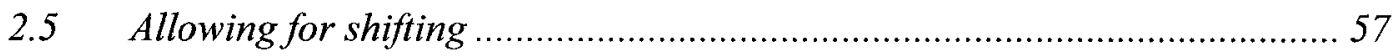

3 The Net Incidence of A Price Subsidy for Home Care When Children Are

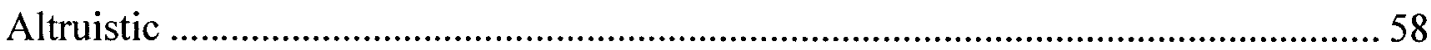

3.1 A basic model of a non-cooperative family ………………........................ 59

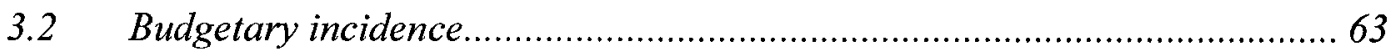

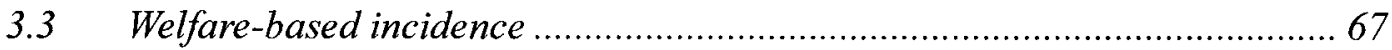

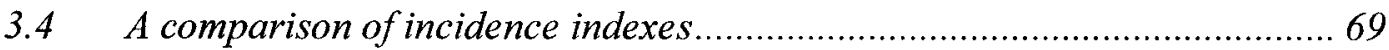

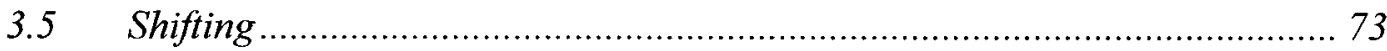

4 A Cooperative Family, and Simulation of Incidence Indexes for Both Family

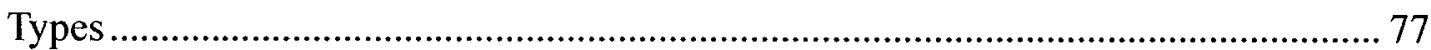

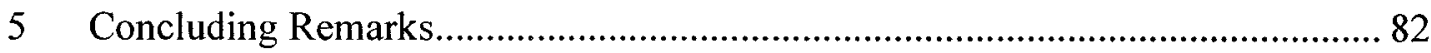

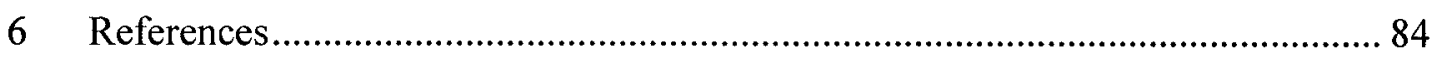

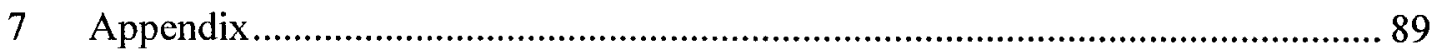

7.1 The cost-saving method of calculating budgetary fiscal incidence ............... 89

7.2 Differences between BFI and WFI over long and short horizons................. 90

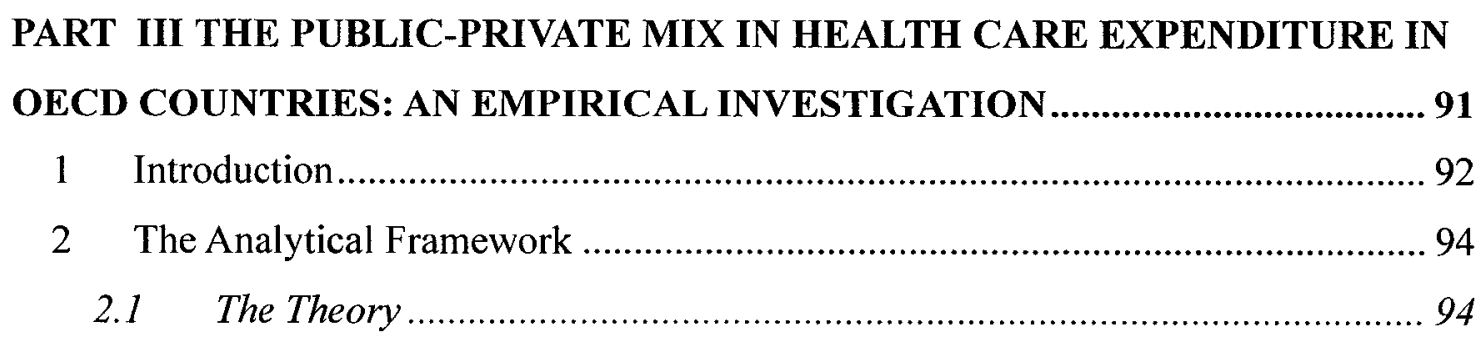


2.2 A Model and Basic Estimating Equation.

3 A Brief Review of Issues in Empirical Comparative Research ........................ 105

4 The Data and Estimation Strategy …................................................................ 110

4.1 Basic characteristics of the countries included in the estimation sample ... 111

4.2 The structure of the time-series, cross-section data...................................113

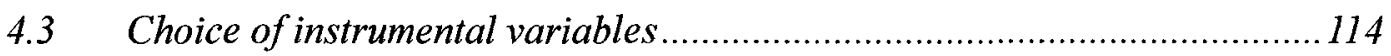

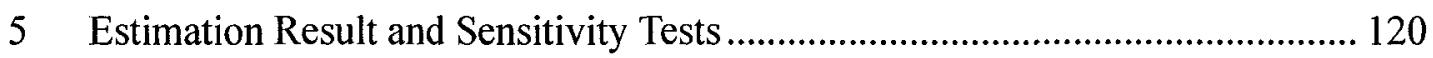

5.1 Re-estimating Besley and Gouveia's test of Usher Model ....................... 120

5.2 Extensions of Usher model to allow for private alternatives and supply side..

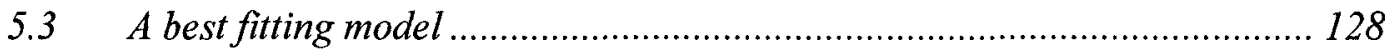

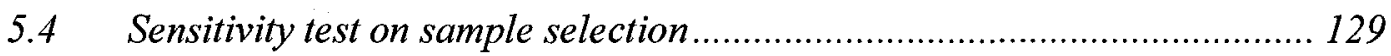

5.5 Testing for the effects of health care systems ....................................... 130

5.6 Further considerations concerning how the model may be improved........ 134

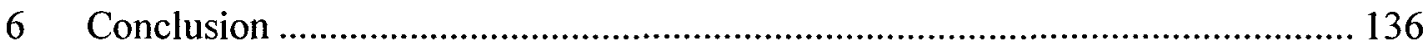

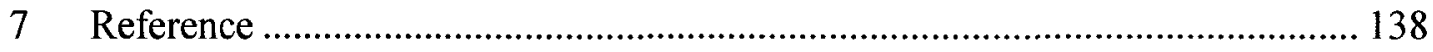

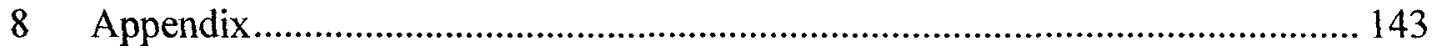

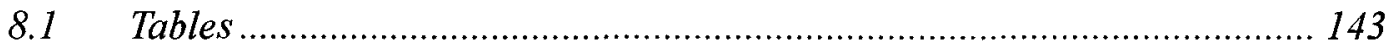

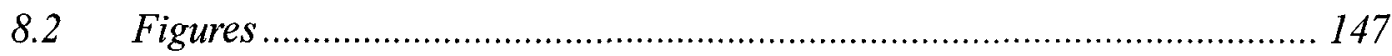

8.3 Testing for unit heterogeneity and time trend ..................................... 148

8.4 Testing for validity of instrumental variables ....................................... 148

vii 


\section{List of Tables}

Table I-1 Comparison of Assumptions about Public Care and Private Care ..................... 8

Table II-1 The Cost-Saving Measurement of Budgetary Fiscal Incidence...................... 89

Table III-1 Summary of Main Variables for 1981-2005 (five-year averages) ................ 112

Table III-2 Average Ideological Positioning of the Electorate in 1981-2005 ................. 117

Table III-3 Simple Correlation of Ideological Indexes and Related Regressors ........... 117

Table III-4 Estimation Results of Alternative Model Specifications ............................ 125

Table III-5 Summary of Estimation Results about Health Care Systems ...................... 134

Table III-6 Tax and Monetary Incentives for the Purchase of Private Care................... 143

Table III-7 Key Private Health Insurance Related Laws and Regulations .................... 144

Table III-8 Categorisation of benefits with a social purpose .................................... 145

Table III-9 Summary Statistics of Variables in 1981-2005 (5-year averages) ............... 145

Table III-10 Simple Correlation of Regressors ................................................... 145

Table III-11 Measurement of the Right-left Ideological Positioning of Political Parties 146

Table III-12 Summary of Estimation Results of Models with Alternative Regressors... 146

viii 


\section{List of Figures}

Figure I-1 The Determinants of the Discount Function for Public Care ........................... 7

Figure I-2 Vote Share of Political Parties in Voter Group i......................................... 16

Figure I-3 The Movement of Equilibrium Wait Times ............................................... 28

Figure II-1 Cost-saving Basis for Measuring Budgetary Fiscal Incidence..................... 66

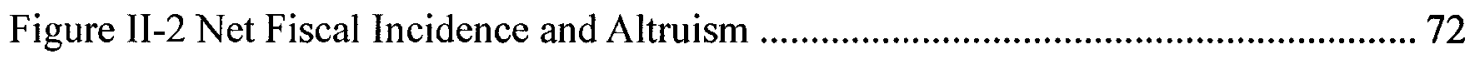

Figure II-3 Shifting of Program Benefits Using Welfare Indexes ................................ 76

Figure II-4 Shifting of Program Benefits Using Budgetary Indexes .............................. 77

Figure II-5 Net Fiscal Incidence and Family Structure................................................. 81

Figure II-6 Fiscal Incidence Index Based on the Cost-saving Measurement .................. 89

Figure III-1 Share of Public Health Expenditure in Total Health Expenditure .............. 112

Figure III-2 Patterns of Variations Across Units and Over Time ................................. 113

Figure III-3 Average Right-left Ideological Positioning of the Electorate in 1981-2005 117

Figure III-4 Health Care System and Share of Public Health Expenditure... 133

Figure III-5 Right-left Ideological Positioning of the Political Parties in Canada and in

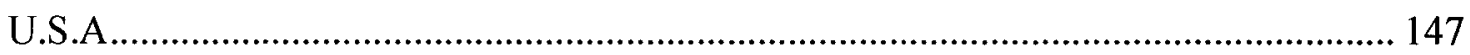

ix 


\title{
PART I
}

\section{Wait Times for Public Health Care: A Political Economy Analysis}

\begin{abstract}
This paper investigates the determinants of wait times for public health care in a multidimensional competitive political equilibrium. A public-private health system is modeled, where the longer wait for public care is the major difference between public and private systems. Voters' preferences for health care vary according to their expected morbidity and by income. In the political equilibrium, wait times in the public system depend on demographics and morbidity. But they are independent of the distributions of income and of political influence, which affect only individual tax-transfer rates. It is also shown that when the population ages, equilibrium wait times for public care may go up or down depending on the initial state of the health system.
\end{abstract}




\section{Introduction}

Population aging in advanced democracies has imposed severe strains on public health care systems, often being singled out as a key cause of health care queues. An aging population needs greater medical treatment, and longer wait times lead to deterioration in the satisfaction with the public health care system. The result is growing concern with the viability of public care, so much so that most competing political parties in countries with public health systems now treat health care as a prominent issue in their election campaigns.'

In contrast to the scholarly attention that has been given to the political viability of public pension systems when population ages ${ }^{2}$, few papers have studied the relationship between health care and aging in a political economy framework. There is a rich literature on wait times in the health economics literature; for example, Marchand and Schroyen 2005, Costaa and Garcia 2003, Hoel and Sæther 2003, López-Nicolás and Vera-Hernández 2002, and Jofre-Bonet 2000. But none of these works has investigated wait times in a political equilibrium ${ }^{3}$.The purpose of this paper is to begin to fill this gap.

We model wait times for public care in a competitive political system and explore the

\footnotetext{
${ }^{1}$ For example, in Canada, this has recently led to promises of a "wait time guarantee". (See the Canadian government's "Speech from the Throne" on April 4, 2006). Sweden and Spain also set up wait time guarantees (Gonzalez and Herrero, 2004).

${ }^{2}$ For some contributions to the literature of pension and population aging, see Weaver 2003, Banting and Boadway 1997, Disney 1996, and Meijdam and Verbon 1996.

${ }^{3}$ There are some literature on political economy of health care, see for example, Vogel 1999, Gouveia 1997 , Feldstein 1990, and Pauly 1988. Some works are on political economy of publicly provided private good in general, see for example, Blomquist and Christiansen 1999, Epple and Romano 1996 and Usher 1977
} 
impact of population aging and other factors on the political equilibrium. The research builds to some extent on Gouveia's (1997) model of health care with one important difference being that in this paper, the tax system is more complicated, distinguishing between groups of taxpayers according to their income, morbidity, and political influence. The complexity of policy here necessitates the use of a multi-dimensional spatial voting model, in contrast to the median voter model used by Gouveia.

In the framework we develop, health care is composed of two parts: a "free" but delayed public component, and a timely private component. Wait times in the public system are modeled using queuing theory, under the assumption that rationing in the public system inevitably leads to wait times that exceed those for private care.

The electorate consists of various groups - young and old (or healthy and sick), and rich and poor. Older voters prefer faster public care while younger and richer citizens do not want to pay for an expanded public health system. In the spatial voting model we develop, expected-vote maximizing parties propose multi-dimensional policy platforms, including a group specific tax-transfer system, to address the inherent conflicts among these groups.

Results of the investigation include the following. First, under well-specified conditions, equilibrium wait times in the public health system depend on the nature of the distribution of morbidity and on the technical factors that determine the length of the waiting queue for public care. But wait times are independent of the distributions of income and of political influence, which affect only group specific tax-transfer rates, even though senior citizens are more single-minded than others about health care when voting. Second, as the electorate as a whole ages, the equilibrium wait times may increase 
or decrease depending on factors such as the initial equilibrium state and the electorate's changing average preference for public care.

\section{The Model}

Assume that there are $I$ different groups of citizens who have inherently different average incomes, $y_{i}$, average rates of morbidity, $p_{i}$, as measured by the probability of becoming sick, with $p_{i} \subset(0,1)$, and average political influence, $s_{i}$, as measured by the sensitivity of voting to changes in welfare. Thus there are in the electorate a group of citizens who are old, poor, and politically influential, a group that is young, rich and of limited influence, and so on. Each group is of size $n_{i}$ and the total population or electorates of the country is $N=\sum_{i=1}^{I} n_{i}$.

Each individual has a common utility function. Because we are interested primarily in the health care consumption mix, we assume that the labor decision has already been solved and is independent of consumption. In each group, the representative citizen is assumed to earn a fixed level of income and spend all this income on a numéraire consumption good and on health care.

If any a citizen in group $i$ gets sick, he or she demands a level of health care, $h_{l i}{ }^{4}$ to be chosen in conjunction with a quantity of a numéraire consumption good, $x_{l i}$. The level of utility achieved by a representative citizen when sick is

\footnotetext{
${ }^{4}$ In this paper, health care includes only hospital treatment and physician services. Medical services such as dental care and vision care are not considered because in these specialties, waiting time is not a serious problem and there is not much interaction between public and private providers.
} 


$$
u_{1 i}=u\left(x_{1 i}, h_{1 i}\right)
$$

On the other hand, if the citizen is healthy, he will demand a level of numéraire consumption, $x_{0 i}$, and his health care consumption will consist only of some minimum level, $h_{0 i}$, that includes such features as an annual health check up and immunization. Then his utility when healthy is

$$
u_{0 i}=u\left(x_{0 i}, h_{0 i}\right)
$$

We assume that the level of health care consumption must be determined prior to knowing the probability of becoming sick or the position in a waiting queue for public care. The expected utility of a representative citizen in group $i$ is

$$
E u\left(x_{i}, h_{i}\right)=\left(1-p_{i}\right) u\left(x_{0 i}, h_{0 i}\right)+p_{i} u\left(x_{1 i}, h_{1 i}\right)
$$

\subsection{The relationship between public care and private care}

We assume a public-private mixed health care system ${ }^{5}$. Health care consumption of each citizen consists of two components. The government provides $g$ units of universal public care free of charge to each citizen ${ }^{6}$, independent of their risk group. In addition, the citizen can choose to purchase $m$ units of private care at price $q$ to supplement their public care entitlement. Initially we assume that private health insurance is available for citizens who wish to purchase private care, and there is no pay-from- the pocket private

\footnotetext{
${ }^{5}$ Australia, Belgium, France, Germany, Sweden, and United Kingdom all have universal public health care coverage and are also integrating private-sector involvement in health care delivery and financing (Cyrenne, 2004).

${ }^{6}$ Universality means that all the citizens are entitled to the same amount of public care.
} 
care option ${ }^{7}$.

In the presence of both public and private care, the health care consumption of a representative citizen in group $i$ is

$$
h_{1 i}=R\left(p_{i}\right)^{T} g+m_{i}
$$

where $h_{l i}$ is the total health care consumption when the citizen is sick; $g$ is the universal level of per-capita public health care consumption ${ }^{8}$; and $m_{i}$ is the units of private care consumption chosen by the citizen. $R\left(p_{i}\right)=\frac{1}{1+\delta\left(p_{i}\right)}$ with $0<R\left(p_{i}\right)<1$ is the discount rate for public care representing the dissatisfaction with delay in the public system, where $\delta\left(p_{i}\right)$ is the rate of time preference of the citizen, and $T$ is the number of periods that citizens have to wait for public health service. $\delta\left(p_{i}\right)$ depends on a patient's morbidity as well as his or her subjective preference for public care.

We assume that the patients with higher morbidity have a higher time preference for medical service, that is, the derivative of $\delta\left(p_{i}\right)$ with respect to $p_{i}$ is positive. Wait times affect groups with higher morbidity more negatively than others, so that groups with a higher morbidity have a lower assessment of the value of the public care, and hence will be more likely to buy supplementary private coverage ${ }^{9}$. For example, senior citizens use hospital and physician services more often than youths do because of their higher

\footnotetext{
${ }^{7}$ We initially exclude the pay-from-the-pocket option because this helps in focusing on the redistribution issue associated with public and private health insurance. This assumption is relaxed in section three.

${ }^{8}$ We do not distinguish between public care entitlement and actual public care consumption because on average, they have to be equal.

${ }^{9}$ Relaxing this assumption would not change any major result of the study.
} 
probability of becoming sick. As a result, seniors are more frequently allocated to waiting queues and have greater dissatisfaction with wait times in the public system. When private alternatives are available, seniors demand more than others, ceteris paribus, to supplement their entitlement of public care with private insurance ${ }^{10}$.

The discount function, $R\left(p_{i}\right)^{T}$ is illustrated in Figure I-1. $R\left(p_{i}\right)^{T}$ is the marginal value of public care in terms of private care for a citizen in group $i . R\left(p_{i}\right)^{T}$ is assumed to decline with morbidity $p_{i}$ for given $T$, and to shift downwards when $T$ increases, as shown in Figure I-1 . The horizontal line at 1 represents the "discount rate" of private care.

Figure I-1 The Determinants of the Discount Function for Public Care

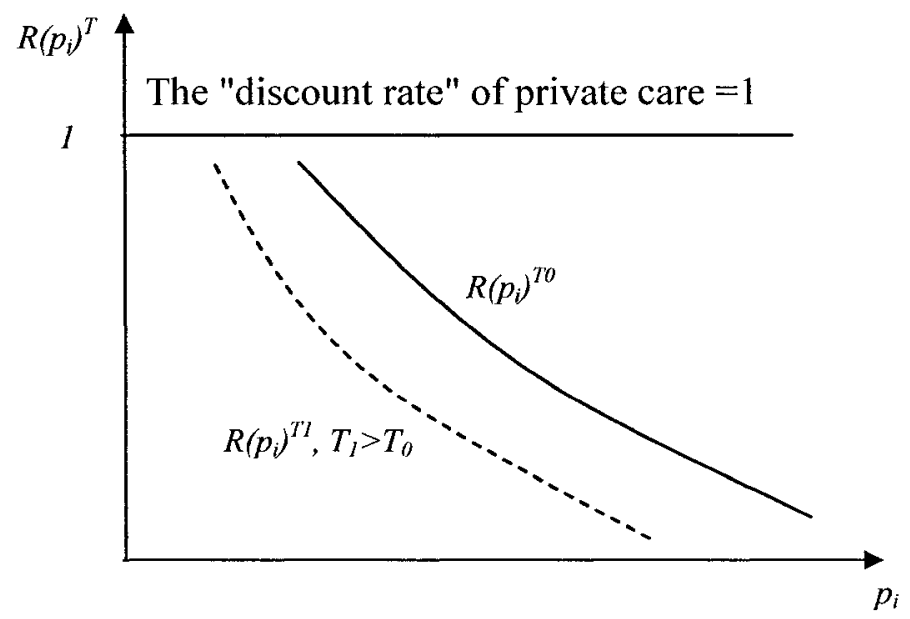

To support the public health system, each citizen pays income tax at a rate $t_{i}$, whether he or she purchases private care or not. These income tax rates differ across voter groups according to their income, morbidity, and political influence.

We have already distinguished between public and private care by assuming that there are

\footnotetext{
${ }^{10}$ This does not mean that seniors actually purchase more private insurance than youths because seniors are more likely to be screened out by private insurance providers.
} 
wait times in the public care system but no waiting in the private system. The other difference is that private health services are priced. But except for wait times and prices, we assume that the public and the private sectors offer the same coverage and quality.

For the readers' convenience, the similarities and differences between public and private care in the model are summarized in the table below:

\section{Table I-1 Comparison of Assumptions about Public Care and Private Care}

\begin{tabular}{lll}
\hline & Public care & Private care \\
\hline Service Coverage & same & same \\
Service Quality & same & same \\
Production Cost & same & same \\
Financing Source & tax revenue & insurance premium \\
Wait Times Length & $\mathrm{T}>0$ & $\mathrm{~T}=0$ (no wait times) \\
Price to Patients & tax payment & market price \\
Quantity & fixed at g & any non-negative value \\
Time Flexibility & Citizens cannot pay to jump the & no wait times \\
\hline
\end{tabular}

\subsection{The demand for individual private care}

We now specify in detail the individual demand for private care. We assume there is an actuarially fair private insurance scheme ${ }^{11}$. The representative citizen purchases $q m_{i}$ units of private insurance, where $q$ is the market price of private care, and pays a premium at rate $p_{i}$ because the insurance is actuarially fair. The price of the numéraire consumption $\operatorname{good} x$ is normalized to 1 .

The budget constraint of the citizen is independent of his or her realized health status, and is

\footnotetext{
"Adverse selection and moral hazard problems are important for a private insurance scheme but we will not deal with these problems in this paper.
} 


$$
x_{0 i}=x_{1 i}=y_{i}\left(1-t_{i}\right)-p_{i} q m_{i},
$$

where $t_{i}$ is the tax-transfer rate for a member in group $i$.

The representative citizen chooses the desired level of private care $m_{i}$ so as to maximize expected utility

$$
\underset{\left(m_{i}\right)}{E u_{i}}=\left(1-p_{i}\right) u\left(x_{0 i}, h_{0 i}\right)+p_{i} u\left(x_{1 i}, R\left(p_{i}\right)^{T} g+m_{i}\right)
$$

subject to the budget constraint in equation (5).

After substituting numéraire consumption $x$ out of the citizen's objective function by using the budget constraint in equation (5), we obtain the following:

$$
\underset{\left(m_{i}\right)}{E u_{i}}=\left(1-p_{i}\right) u\left(\left[y_{i}\left(1-t_{i}\right)-p_{i} q m_{i}\right], h_{0 i}\right)+p_{i} u\left(\left[y_{i}\left(1-t_{i}\right)-p_{i} q m_{i}\right],\left[R\left(p_{i}\right)^{T} g+m_{i}\right]\right)
$$

The first order condition for the choice of $m_{i}$ that maximizes expected utility is

$$
M R S_{x h}=\frac{u_{h}\left(\theta_{i}\right)}{u_{x}\left(\theta_{i}\right)}=q, \text { and } \theta_{i}=\left(y_{i}, t_{i}, p_{i}, q, R\left(p_{i}\right), T, g, m_{i}^{*}\right)
$$

This first order condition is to be used when solving the political equilibrium in section three.

\subsection{The wait time function}

Rationing through waiting lists is a common and necessary device of universal public health care systems because there is usually excess demand for the "free" public care. When competing political parties choose a policy platform composed of a level of public care, $g$, and tax-transfer rates, $\left\{t_{i}\right\}$, they must consider the effect of wait times on political 
support. Here we specify the wait time function.

To simplify, we assume the supply of health care is perfectly elastic ${ }^{12}$, but there is still rationing in the public health system since the government will trade off satisfying demands for rapid public care with demands for non health related public services. Because public care is provided at zero cost to consumers, consumers will use the public care up to the point where the marginal value to them falls to zero - beyond the point where marginal value equals marginal cost. In this sense, the public system will experience excess demand. A queue is the tool that the government uses to ration demands.

We use queuing theory to build the wait time function. In the waiting queue we will employ, patients enter the waiting queue for medical treatment randomly as a Poisson process $^{13}$; doctors treat the patients randomly and the service time of doctors follows a negative exponential distribution; patients receive treatments according to the rule of "first come, first served"; the system has an unlimited queue capacity and an infinite population of potential arrivals, so that a single patient has no effect on potential new arrivals; patients make decisions on joining the queue independently; and there are $d$ doctors serving potential patients.

In our analysis, patients enter public medical waiting queues according to need, which is in turn determined by their morbidity rates. The average rate of morbidity of a country,

\footnotetext{
${ }^{12}$ Relaxing the elasticity assumption is left for future research.

${ }^{13}$ In the waiting queue for public care, the number of patients is large so that a single patient has no effect on the performance of the system. Patients enter waiting queue randomly and act independently in making decisions. These characteristics can be approximated well by a Poisson process.
} 
$\bar{p}=\sum_{i=1}^{l}\left(n_{i} / N\right) p_{i}$, will be one of the major factors affecting the aggregate demand for public care. We use $\bar{p}$ to approximate the expected number of the patients entering the waiting queue per unit of time ${ }^{14}$.

The aggregate size of public care provision, $\mathrm{Ng}$, determines the serving capacity of the public health system. To capture the effects of scale, we use $d(N g)$ to approximate the number of doctors in the public health system. We assume the derivative of $d(\mathrm{Ng})$ with respect to $g, d_{g}^{\prime}$, is greater than zero. That is that a larger scale of provision requires more doctors. The derivative $d_{g}^{\prime}$ measures the extent to which one more unit of public provision expands team of doctors. $d_{g}^{\prime}$ is to be used to represent the expansion rate of team of doctors.

We let $\phi$ approximate the expected number of patients treated by one doctor per unit of time, where $0<\phi<1 . \phi$ represents the productivity of a doctor ${ }^{15}$. When there are $d$ doctors in the public care system, $\phi d$ is the expected average number of patients treated in the public system per unit of time, where $0<\phi d<1$.

Under the above circumstances, it can be shown that the function determining expected

\footnotetext{
${ }^{14}$ We ignore the substitution of private care for public care. Of course, when citizens use more private care, they may use public hospitals less. However, universal public care usually implies that everyone uses public care to some extent and private care is only a complement of public care. Citizens using private care still use public care and the best measure of demand for public care is the average morbidity of the population. The potential effect of private care on public care can be on the supply side when doctors and nurses migrate from the public system to the private system, which is left for future research.

${ }^{15}$ We can model $\phi$ as a function of $g$ and it will not affect the major conclusions.
} 
total wait times (including medical service time) is ${ }^{16}$

$$
T \approx \frac{1}{\phi d(N g)-\bar{p}}, T_{\bar{p}}>0, T_{\phi}<0, T_{d}<0 .
$$

For example, suppose patients enter a hospital at an average rate of $1 / 4$ patient per hour. A doctor treats 1 patient in one hour when the case is simple and $1 / 4$ patient in one hour when the case is complicated. On average, a doctor can treat $1 / 2$ patient per hour. Assume there is only 1 doctor in the system.

Following the wait time formula, in this example, the total wait time of the system is $T=\frac{1}{1 / 2-1 / 4}=4$ hours $^{17}$. Although on average a doctor's treatment of one patient is faster than the arrival of another patient, there is still 4 hours' average wait time because patients enter randomly and the treatment time of the doctor for one patient is randomly distributed as well.

Wait times thus depend positively on the average morbidity of the population and negatively on the level of the public care provision ${ }^{18}$. Given other parameters, expansion in public provision reduces wait times for public care while factors such as aging of the population prolongs wait times by increasing the average morbidity $\bar{p}$. Improving productivity of doctors helps reduce wait times as well.

\footnotetext{
${ }^{16}$ For queuing theory, see Gonzalez and Herrero 2004, Banks et al. 1999, Giffin 1978, and Gross and Harris 1974.

${ }^{17}$ It has to be born in mind that the parameters are all averages. On average, the treatment speed, $\Phi d$, has to be larger than the arrival rate, $p$. Otherwise, the waiting queue will go infinity and the public health system will break down.

${ }^{18}$ The definition of wait time is rough, measuring the generalized average wait times across all specialties. It will be interesting to investigate the wait time for treatment of a specific type of disease.
} 
Integrating the wait time function back into our analysis, the discount rate for the public care for a representative citizen in group $i$ becomes

$$
R\left(p_{i}\right)^{T}=R\left(p_{i}\right)^{\frac{1}{\phi d(N g)-\bar{p}}}
$$

Here, public care provision $g$ is the instrument that government will use to influence wait times.

\subsection{Collective choice}

We now describe a spatial voting model in which collective decisions about public care are made. There are two competing political parties, $\mathrm{A}$ and $\mathrm{B}$, both of which choose policies to maximize their expected vote or plurality. Voters are differentiated by their sensitivities to policy changes and by morbidity and income described above.

Policy platforms of political parties consist of a level of public care provision, $g$, and a separate income tax rate $t_{i}$ for each voter group, $w^{k}=w\left(g,\left\{t_{i}\right\}\right), k=A$ or $B$. The policy issue space thus is multi-dimensional. In much of the literature on political economy, the structure of income taxes is usually constrained to the "one-dimension policy" requirement of the median voter model. For example, in his median voter analyses, Usher (1977) uses a uniform income tax and Gouveia (1997) restricts policy to an average income tax schedule $\mathrm{e}^{19}$. In the real world, there is a universal level of public care but there

\footnotetext{
${ }^{19}$ Median voter model constraints number of tax instruments. The restrictions imposed by limited tax instruments in the public economics literature were recognized by Blomquist and Christianten (1999): "More recent articles like Epple and Romano (1996a), Gradstein and Justman (1996) and Gouveia (1997) are examples of voting models where the result that there is public provision of a private good is driven by severe restrictions on the tax instruments."
} 
are different groups of citizens, each of which receives a unique treatment through tax structure and special tax provisions such as deductions and exemptions. By using a group specific tax-transfer rate, the present analysis realistically allows for more dimensions of choice and so approximates more closely the actual policy structure used by modern democratic states ${ }^{20}$.

Following Profeta (2002), the decision of voters depends on two components: a systematic component depending on the difference in perceived utility from the platforms of the two opposing parties, and a non-systematic component independent of utility, but depending on the voters' perception of a party's leader or platform credibility. We assume the perceived utilities from the policy of political parties for a citizen in group $i$ are $v_{i}\left(w^{A}\right)$ and $v_{i}\left(w^{B}\right)$. The ideological bias in favour of party $\mathrm{A}$ of a voter in group $i$ is $\left(\psi+\xi_{i}\right)$, where $\psi$ is common to all voters and reflects the general preference for party A. $\xi_{i}$ is an idiosyncratic factor and is expressed as the difference between an individual voter's perception of party $\mathrm{A}$ and of party $\mathrm{B}, \xi_{i}=\xi_{i}^{A}-\xi_{i}^{B}$. The idiosyncratic bias towards party $\mathrm{B}$ is therefore $-\xi_{i}=\xi_{i}^{B}-\xi_{i}^{A} \cdot \xi_{i}$ can be of positive or negative value. $\xi_{i}$ is assumed to follow a uniform distribution on $\left(-1 / 2 s_{i}, 1 / 2 s_{i}\right)$ where $0<s_{i}<1 .-1 / 2 s_{i}$ and $1 / 2 s_{i}$ are the lower and upper bounds of the uniform distribution respectively, and $s_{i}$ is the density of the distribution.

If $D_{i}\left(w^{A}\right)$ is the representative voter's total perceived benefit from party $\mathrm{A}$, then

$$
D_{i}\left(w^{A}\right)=v_{i}\left(w^{A}\right)+\psi+\xi_{i}, \text { with } \xi_{i} \sim\left(-1 / 2 s_{i}, 1 / 2 s_{i}\right)
$$

\footnotetext{
${ }^{20}$ Of course, not all characteristics of each voter can be addressed uniquely due to administrative costs.
} 
The decision rule of a voter in group $i$ then can be written as

if $v_{i}\left(w^{A}\right)+\psi+\xi_{i}>v_{i}\left(w^{B}\right)$, the voter will vote for party A;

if $v_{i}\left(w^{A}\right)+\psi+\xi_{i}<v_{i}\left(w^{B}\right)$, the voter will vote for party B;

if $v_{i}\left(w^{A}\right)+\psi+\xi_{i}=v_{i}\left(w^{B}\right)$, the voter is indifferent between the two parties and is a

swing voter.

If a voter's idiosyncratic bias in favour of party $\mathrm{A}$ is very strong, he will vote for party $\mathrm{A}$ no matter what are the consequences of the two parties' proposed policy platforms on his welfare. In contrast, some voters have no established preference for any party, such as the swing voters described in equation (12). Such swing voters are very sensitive to welfare changes and are most inclined to change their votes according to their perceived benefits from a party's proposed policy bundle.

The swing voters' idiosyncratic bias in favour of party $\mathrm{A}, \xi_{i}^{s . v}$, is described in equation (12a) and will serve as a benchmark when computing voter shares of the two parties.

$$
\xi_{i}^{s . v}=v_{i}\left(w^{B}\right)-v_{i}\left(w^{A}\right)-\psi
$$

As shown in Figure I-2, a voter in group $i$ votes for party A when $\xi_{i}>\xi_{i}^{\text {s.v. }}$ and votes for party B when $\xi_{i}<\xi_{i}^{s . v .}$. Given the distribution of the idiosyncratic preferences of voters, the vote share of party $\mathrm{A}$ is the shaded area $a$, and the vote share of party $\mathrm{B}$ is the shaded area $b$. 
Figure I-2 Vote Share of Political Parties in Voter Group i

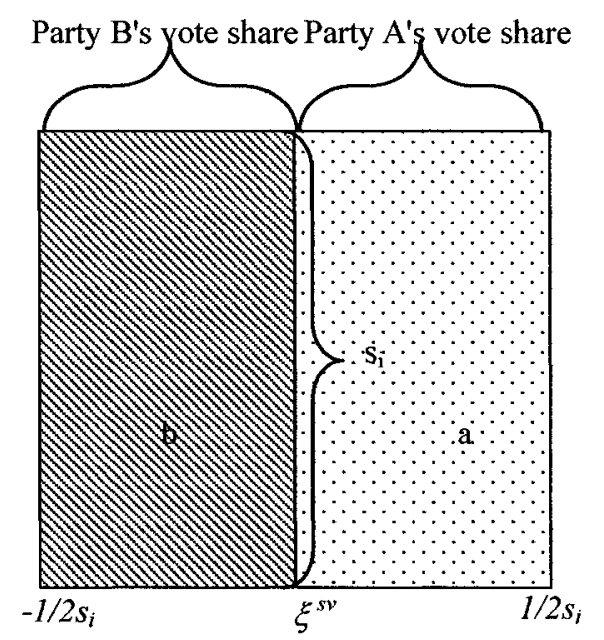

When $\xi_{i}>\xi^{v}$, voter group $i$ votes for party A;

When $\xi_{i}<\xi^{v}$, voter group $i$ votes for party $\mathrm{B}$.

Thus, party A's probability of obtaining support from group $i$ is

$\pi_{i}^{A}=\left(1 / 2 s_{i}-\xi^{s v}\right) /\left[1 / 2 s_{i}-\left(-1 / 2 s_{i}\right)\right]=1 / 2+s_{i} \xi^{s v}=1 / 2+s_{i}\left[v_{i}\left(w^{A}\right)+\psi-v_{i}\left(w^{B}\right)\right]$

and that for party $\mathrm{B}$ is just the residual, $\pi_{i}^{B}=1-\pi_{i}^{A}$.

The expected votes of party A from all the $I$ voter groups, $V^{A}$, is therefore ${ }^{21}$

$$
V^{A}=E\left(\sum_{i=1}^{I} n_{i} \pi_{i}^{A}\right)=\frac{1}{2} N+\sum_{i=1}^{I} n_{i} s_{i}\left[v_{i}\left(w^{A}\right)+\psi-v_{i}\left(w^{B}\right)\right]
$$

where

$$
\frac{\partial V^{A}}{\partial\left[v_{i}\left(w^{A}\right)+\psi-v_{i}\left(w^{B}\right)\right]}=n_{i} s_{i}
$$

\footnotetext{
${ }^{21}$ Since $N, \psi$ and $v_{i}\left(w^{B}\right)$ are constants, they are omitted when deriving the political support function of parties in section three.
} 
represents the "effective political influence" of voters in group $i$ towards the proposed policy platform of party A. The political influence of voters towards the platform of party B is defined analogously. We shall see that the welfare of voter groups with a larger size, $n_{i}$, or a higher density of swing voters, $s_{i}$, will be given greater weight in the political equilibrium. It is in the interest of the political parties that they offer favorable policies to the groups of greater political influence at the cost of the welfare of others.

\section{The Political Equilibrium}

In an election, competing political parties decide on their policy platforms, $w^{A}\left(g,\left\{t_{i}\right\}\right)$ and $w^{B}\left(g,\left\{t_{i}\right\}\right)$, by taking into account the interests and political sensitivity of voters. Given proposed policy platforms, citizens then decide on a level of private care and other consumptions.

The solution to this game requires the simultaneous determination of an equilibrium level of public care provision and a tax-transfer rate for each group of voters. The equilibrium wait times for public care are then determined by the aggregate demand for health care which is represented by average morbidity of the population, and the aggregate supply of public care determined in a political equilibrium.

\subsection{Solving for the equilibrium policy platform}

In the equilibrium of a spatial voting model, the platforms of the parties converge to one that maximizes a particularly weighted sum of the utilities of voters ${ }^{22}$, a result referred as

\footnotetext{
${ }^{22}$ We shall not prove the theorem formula here. The convergence can be proved by observing that the first order conditions are identical for the maximization of expected votes of both the parties.
} 
the Representation Theorem (see Hettich and Winer 1999, chap. 4 and Coughlin and Nitzan 1981).

We can find this equilibrium strategy $w^{A}$ or $w^{B}$ by solving the following maximization problem:

$$
\operatorname{Max} S^{A}=\sum_{i=1}^{I} n_{i} s_{i} v_{i}\left(w^{A}\right) \text { or } \operatorname{Max} S^{B}=\sum_{i=1}^{I} n_{i} s_{i} v_{i}\left(w^{B}\right)
$$

where $S$ denotes political support received by a party ${ }^{23}$.

These maximizations are subject to consumers' responses to government policy in equation (8), and subject to the government budget constraint ${ }^{24}$,

$$
\sum_{i=1}^{I} n_{i} y_{i} t_{i}=N c g
$$

where $c$ is the average cost of producing one unit of public care ${ }^{25}, g$ is the entitlement for public health care per capita, and $N c g$ is the total cost of providing public health care.

To solve for the political equilibrium, we substitute the first order condition of individual's maximization problem in equation (8) and the wait time function (9) into the political support function (15), and then solve the following problem.

\footnotetext{
${ }^{23}$ The political support function is derived from equation (14). It has to be noted that a political support function is not equivalent to a social welfare function. The weights of different citizen groups in a social welfare function are exogenously chosen, while in the political support function, the weights of different voter groups are endogenously determined by their voting behaviour. The weights in the political support function (15) are described in equation (14a).

${ }^{24}$ Without loss of generality, we leave out other public goods in the model.

${ }^{25}$ In the short run, the average cost of public care is subject to competition between public care and private care in the market for doctors, and other short run effects. These short run effects are not considered in this paper in which the focus is on long run equilibrium.
} 
$\operatorname{Max} \underset{\left(t_{t}, g\right)}{S}=\sum_{i=1}^{I} n_{i} s_{i}\left\{\left(1-p_{i}\right) u\left(\left[y_{i}\left(1-t_{i}\right)-p_{i} q m_{i}\right], h_{0 i}\right)+p_{i} u\left(\left[y_{i}\left(1-t_{i}\right)-p_{i} q m_{i}\right]_{i},\left[R\left(p_{i}\right)^{T(g)} g+m_{i}\right]\right)\right\}$,

subject to $\frac{v_{h}^{\prime}}{v_{x}^{\prime}}=q, T(g)=\frac{1}{\phi d(N g)-\bar{p}}$, and $\sum_{i=1}^{I} n_{i} y_{i} t_{i}=N c g$.

The first order conditions which describe the political equilibrium are

$$
\begin{gathered}
\frac{\partial L}{\partial t_{i}}=0 \Rightarrow n_{i} s_{i} y_{i} v_{x}^{i}-\eta n_{i} y_{i}=0, I \text { equations } \\
\frac{\partial L}{\partial g}=0 \Rightarrow \sum_{i=1}^{I} n_{i} p_{i} s_{i} v_{h}^{i} R\left(p_{i}\right)^{T(g)}\left[1+\frac{\partial T(g)}{\partial g} g \ln R\left(p_{i}\right)\right]-\eta N c=0 \\
\frac{\partial L}{\partial \eta}=0 \Rightarrow \sum_{i=1}^{I} n_{i} y_{i} t_{i}=N c g
\end{gathered}
$$

where $\eta$ is the Lagrange multiplier and. $i=1,2,3 \ldots \ldots I$.

After manipulating these first order conditions, the equilibrium public care provision $g^{*}$ is obtained by solving the following ${ }^{26}$ :

$$
\sum_{i=1}^{l} \frac{n_{i}}{N} p_{i} R\left(p_{i}\right)^{T\left(g^{*}, \phi, d, \bar{p}\right)}\left[1-d_{g}^{\prime} \phi T^{2}\left(g^{*}, \phi, d, \bar{p}\right) g^{*} \ln R\left(p_{i}\right)\right]=\frac{c}{q}
$$

Group specific tax-transfer rates, $t_{i}{ }^{*}$, are derived by the following to which we will return later:

$$
\eta=s_{i} v_{x}^{i}\left(g^{*}, t_{i}^{*}\right)
$$

By substituting $g^{*}$ into wait time function (9), we obtain equilibrium wait times $T^{*}$ as

\footnotetext{
${ }^{26}$ This equation itself is enough to solve for $g^{*}$. The second order conditions for this maximization are satisfied if assuming a well-defined utility function, see equation (15).
} 
follows:

$$
T^{*}=\frac{1}{\phi d\left(g^{*}\left(\frac{n_{i}}{N}, \bar{p}, p_{i}, R\left(p_{i}\right), \phi, d, d_{g}^{\prime}, c, q\right)\right)-\bar{p}} .
$$

We then have the following interesting proposition:

Proposition 1: Equilibrium wait times for universal public care are independent of the distributions of income and of political influence, when each type of voter is assigned a separate tax-transfer rate (The separation property).

Equation (21) and (23) show that wait times are a residual of decisions on public care provision. Once the level of equilibrium public care is determined, the equilibrium wait times are determined. The equilibrium wait times for public care also depend on the demographic distribution, represented by $n_{i} / N$, the average morbidity of the population, $\bar{p}$, the distribution of morbidity, $p_{i}$, and of the discount rate for public care, $R\left(p_{i}\right)$, the treatment speed of one doctor, $\phi$, the number of doctors in the public system, $d$, the expansion rate of team of doctors, $d_{g}^{\prime}$, the average cost of producing public care, $c$, and the price of private care, $q$.

Equations (21) and (23) indicate one important feature of wait times: the equilibrium wait times are independent of the distribution of income and political influence, which do not appear in either equation. This is because the group specific tax-transfer rates discriminate among different voters. Without a group specific tax schedule, the level of public care will depend on the income distribution, as shown in the single tax rate case in the next section. This separation result is analogous to the Atkinson and Stiglitz (1976) 
result concerning the desirability of a uniform consumption tax in the presence of a fully discriminating income tax, and is discussed further in what follows.

\subsection{The separation result and the single tax rate case}

To evaluate the equilibrium when the number of policy instruments is limited, we developed an equilibrium under the assumption that one uniform tax rate is assigned to all voters.

With a uniform tax rate, $t$, the government's budget constraint becomes

$$
t \sum_{i=1}^{I} n_{i} y_{i}=N c g
$$

Then working in a manner similar as the one used earlier, we obtain the equilibrium under the uniform tax schedule.

As shown in Section 1.1 of the Appendix, equilibrium public care $g^{* *}$ can be obtained by solving

$$
\sum_{i=1}^{I} \frac{p_{i} R\left(p_{i}\right)^{T\left(g^{* *}, \bar{p}, d, \phi\right)}\left[1-d_{g}^{\prime} \phi T^{2}\left(g^{* *}, \bar{p}, d, \phi\right) g^{* *} \ln R\left(p_{i}\right)\right]}{\left(y_{i} / \bar{y}\right)}=\frac{c}{q} .
$$

The equilibrium uniform income tax rate $t^{* *}$ then is

$$
t^{* *}=\frac{c g^{* *}}{\bar{y}}
$$

The implication of restricting tax instruments is found by comparing equation (21) and equation (25). When there is only one tax rate, the demographic distribution, represented 
by $n_{t} / N$, does not matter in determining $g^{* *}$ while the income distribution, represented by $y_{i} / \bar{y}$, does matter. As seen from equation (26), the tax rate is uniform across groups and does not distinguish among voters according to their income, morbidity, or political influence. What is going on here is that redistribution of income has to be carried out partly through the delivery of public care instead of exclusively through the tax scheme, in contrast to the earlier set up with a discriminative tax-transfer system. As a result, equilibrium public care provision $g^{* *}$ and wait times $T^{* *}$ now depend on the distribution of income.

The analysis shows that the assumption of a single tax rate, which is usually made to allow use of the median voter model, is misleading. A redistributive (i.e. group-specific) tax system removes pressure on the political parties to use public program like health care to redistribute income.

The Atkinson and Stiglitz (1976) result depends on the existence of a sufficiently sophisticated non-linear tax system and on assumption of additively separable utility. The latter is not essential here, but the number of tax instrument is crucial as we have shown. In the following section we show that actuarially fair insurance, which we have used as part of the framework, is the second necessary assumption underlying the separation result.

\subsection{The role of actuarially fair insurance}

When citizens pay for private care from their own pocket instead of purchasing insurance, the ex-post budget constraints of the citizen when he is healthy and when he is sick are 
different.

$$
x_{0 i}=y_{i}\left(1-t_{i}\right), \text { and } x_{1 i}=y_{i}\left(1-t_{i}\right)-q m_{i}
$$

The equilibrium public care $g^{p}$ can be obtained by solving the following equation (See Section 1.2 of the Appendix for detailed computations).

$$
\sum_{i=1}^{I} \frac{n_{i}}{N} p_{i} \frac{\left.v_{x}^{i}\right|_{x=x_{1}}\left(y_{i}, t_{i}, \ldots\right)}{\left[\left(1-p_{i}\right) v_{x \mid x=x_{0}}^{i}\left(y_{i}, t_{i}, \ldots\right)+p_{i} v_{x \mid x=x_{1}}^{i}\left(y_{i}, t_{i}, \ldots\right)\right]} R\left(p_{i}\right)^{T\left(g^{p}\right)}\left[1-d_{g}^{\prime} \phi T^{2}\left(g^{p}\right) g^{p} \ln R\left(p_{i}\right)\right]=\frac{c}{q}
$$

Since wait times depend on public care provision $g^{p}$, and in equation (28) $g^{p}$ depends on all of the indirect utilities $v_{i}$ s, wait times depend on the distribution of income, $y_{i}$, and the other factors determining individual utility.

Under the pay-from-the pocket assumption, the citizen pays for private care only when he is sick. When a citizen votes for the level of public care provision, he now has to take into account his income when he is sick and when he is healthy separately, whereas under actuarially fair insurance the payment of insurance premium is independent of health status.

When actuarially fair insurance is not available, a citizen faces the following trade-off. More public care implies a higher tax payment, which will reduce the citizen's disposable income in both health states. On the other hand, more public care means the citizen is able to spend less on private care when he is sick. Individuals with different income and tax-transfer rates will want to make different trade-offs between public care and post-tax income. Therefore, the distribution of income matters, and wait times will be determined simultaneously with the tax system. 
An implication of the separation result can be drawn from the discussion above: regulation of private health insurance market is important for the size of public care, and for the distribution of the tax burden of public health care system.

\subsection{The role of single-mindedness in the equilibrium tax-transfer schedule}

Taking a Cobb-Douglas utility $u(x, h)=a \ln x+(1-a) \ln h$ as an example of the implicit utility in the model, where $a$ is a taste parameter common across voter groups, we solve a more explicit equilibrium tax system.

The equilibrium tax-transfer rates in a model with a Cobb-Douglas utility is:

$$
t_{i}^{*}=1-\frac{\frac{s_{i}\left[a+(1-a) p_{i}\right]}{\bar{k}} *\left[\bar{y}+(q \bar{r}-c) g^{*}\right]-p_{i} R\left(p_{i}\right)^{T^{*}} q g^{*}}{y_{i}}
$$

where $\bar{y}=\sum_{i=1}^{l} \frac{n_{i}}{N} y_{i}, \bar{r}=\sum_{i=1}^{l} \frac{n_{i}}{N} p_{i} R\left(p_{i}\right)^{T(g)}, \bar{k}=\sum_{i=1}^{I} \frac{n_{i}}{N} s_{i}\left[a+(1-a) p_{i}\right]$ and $t^{\prime}>0, t_{s}^{\prime}<0$.

This tax system is progressive in income and regressive in political sensitivity. As shown in section two of the Appendix, political sensitivity affects tax-transfer rates with a greater elasticity than income does.

Before discussing the tax system in more detail, it is useful to outline the connection between political sensitivity and what we shall call the "single-mindedness" of seniors. Following Mulligan and Sala-i-Martin (1999) and Profeta (2002), we shall think of high 
political sensitivity as arising from "single-mindedness". ${ }^{27}$ "Single-mindedness" in the present context means that when individuals get older, they tend to become more concerned with health care when making voting decisions.

It is likely that seniors will change their votes based on which party provides them with the most beneficial health care, regardless of other issues. Thus, political sensitivity $s_{i}$ will be higher for seniors than for younger people, and for a given group size $n_{i}$, their weight in the expected vote function (14) that the parties attempt to maximize is larger.

As a result, the equilibrium tax schedule in equation (29) seems to discriminate in favour of single-minded voters. An extreme example is when there are two groups who have the same income but one is composed of senior citizens who are more single-minded on the issue of health care. In this case, the senior citizens will be assessed an effective taxtransfer rate lower than that for the young ones even though they have same income.

We can now state the following proposition:

Proposition 2: Voters who are single-minded on the issue of public health care will receive a relatively lower tax-transfer rate.

Single-mindedness is to be distinguished from population aging. We define the latter as an increase in the proportion of senior citizens in the population and we will explore its

\footnotetext{
${ }^{27}$ The theory of "single-mindedness" was introduced by Mulligan \& Sala-i-Martin (1999) who assumed that the elderly have more needs for leisure than the young and this necessity would explain why the elderly require (and obtain) generous pensions or transfers from government and why the social security expenditures in the U.S. have been increased so much over the last decades. They argued that the retired elderly concentrate on issues that relate only to their age such as the pension or the health care system while the young have to choose among age-related or occupation-related issues. The conclusion is that the elderly are more politically powerful because they are more single minded.
} 
role in what follows.

\section{The Impact of Aging on Equilibrium Wait Times}

One might expect that an aging population will demand lower wait times for public care. After all, public care and private care are equivalent (up to a discount factor) and the young citizens pay for the health care of the old. This is not the case in the present framework.

To simplify and focus on the cross-generational differences, suppose for the moment there are only two groups, youths, with an average income $y_{l}$, a morbidity rate $p_{l}$, and a group size $n_{1}$; and seniors, with an average income $y_{2}$, a morbidity rate $p_{2}$, and a group size $n_{2}$, where $N=n_{1}+n_{2}$. Seniors have a worse health status than youths, $p_{2}>p_{1}$. Income of the elderly can be higher, equal, or lower than that of the young ${ }^{28}$.

We assume as population ages, the ratio of seniors in the population, $n_{2} / N$, increases; among the aged population, as an individual becomes older (and sicker), he become more single-minded on health care and thus have a greater political influence, $s_{i}=s_{i}\left(p_{i}\right)$ and $s_{p}^{\prime}>0$

Equation (14a) implies that when population ages, seniors will possess even greater political power due to their enlarging group size. This has to be distinguished from individual aging in a life cycle, which implies an increasing single-mindedness, a greater

\footnotetext{
${ }^{28}$ Distribution of income does not matter for equilibrium wait times and thus will not be discussed further, see Proposition 1.
} 
political sensitivity, and a resulting lower tax-transfer rate ${ }^{29}$.

The following shows the impact of population aging, represented by an increasing ratio of seniors in the population, $n_{2} / N$, on equilibrium wait times.

$$
\begin{gathered}
\text { Define } \bar{r}_{T}=\sum_{i=1}^{2} \frac{n_{i}}{N} p_{i} R\left(p_{i}\right)^{T\left(g^{*}\right)} \ln R\left(p_{i}\right), \bar{r}_{T T}=\sum_{i=1}^{2} \frac{n_{i}}{N} p_{i} R\left(p_{i}\right)^{T\left(g^{\prime}\right)}\left(\ln R\left(p_{i}\right)\right)^{2}, \\
\underline{T}=-\frac{\bar{r}_{T}}{\bar{r}_{T T}}-\sqrt{\left(\frac{\bar{r}_{T}}{\bar{r}_{T T}}\right)^{2}+\frac{1}{\phi d_{g}^{\prime} g^{\prime}} \frac{\bar{r}_{T}}{\bar{r}_{T T}}} \text {, and } \bar{T}=-\frac{\bar{r}_{T}}{\bar{r}_{T T}}+\sqrt{\left(\frac{\bar{r}_{T}}{\bar{r}_{T T}}\right)^{2}+\frac{1}{\phi d_{g}^{\prime} g^{*}} \frac{\bar{r}_{T}}{\bar{r}_{T T}}} .
\end{gathered}
$$

As proved in section three of the Appendix, the following conclusions hold:

$$
\begin{gathered}
\text { When } 0<T^{*}<\underline{T} \text { or } T^{*}>\bar{T} \text {, we have } \frac{\partial T^{*}}{\partial\left(n_{2} / N\right)}>0 . \\
\text { When } \underline{T}<T^{*}<\bar{T} \text {, we have } \frac{\partial T^{*}}{\partial\left(n_{2} / N\right)}<0 .
\end{gathered}
$$

These results suggest that the movement of equilibrium wait times when a population ages depends on the initial equilibrium public care provision level and wait times, average marginal effects of wait times on discount rate for public care, $\bar{r}_{T}$ and $\bar{r}_{T T}$, the productivity of one doctor, $\phi$, the number of doctors, $d$, and expansion rate of team of doctors, $d_{g}^{\prime}$.

When the initial equilibrium wait times fall on a path where the marginal effect of wait time on the discount rate for public care implies that a longer wait time will increase political support, wait time will increase. Intuitively, distribution of net benefits from

\footnotetext{
${ }^{29}$ This is implied by equation (29).
} 
public care changes as population ages. When the initial wait times are very short or very long, $T^{*}<\underline{T}$ or $T^{*}>\bar{T}$, the interests of various voters can not be easily balanced politically through the public health system. The electorates as a whole prefer less public care and more disposable income, and the equilibrium wait times will increase, as shown in Figure I-3.

Figure I-3 The Movement of Equilibrium Wait Times

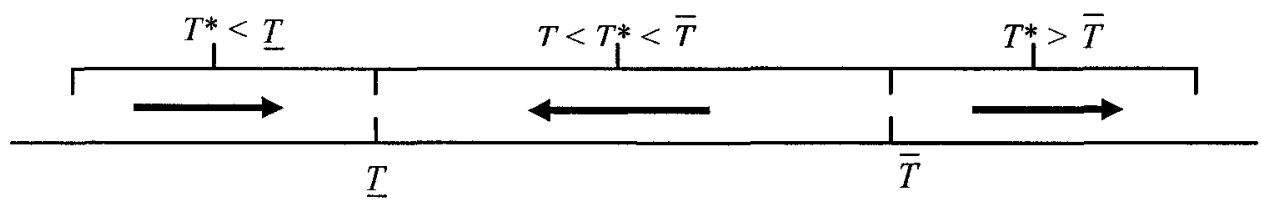

When the initial wait times fall in an intermediate range, $\underline{T}<T^{*}<\bar{T}$, in which the conflicts among heterogeneous citizens can be more easily addressed and shorter wait times can induce higher political support from the ageing population, more resources will be put into the public system, and wait times will decrease.

Equation (31) and (32) also show that the movement of wait times is independent of single-mindedness since symbol of single-mindedness, $s_{i}$, is not in the equations. Although citizens become more single-minded as they ages, seniors cannot influence the choice of public care by their political power due to single-mindedness. Singlemindedness only matters for income redistribution through tax-transfer schedule.

We summarize the preceding discussion with Proposition 3:

Proposition 3: When the population ages, it is possible that wait times may go up or down in a competitive political system, even though seniors are of relatively larger size and politically single-minded. 


\section{Conclusions}

An aging population challenges public health care systems, especially when there is a commitment to universal care. Health care policy becomes a critical field of political debate: seniors welcome rapid public care and affordable private care, and young healthy voters want to spend less on health system and have more private consumption. These conflicts and demands are balanced in a competitive political equilibrium where the interests of different groups of voters influence the allocation of resources to public health care and the redistributive nature of the fiscal system. In the political equilibrium modeled here, wait times turn out to be independent of the distributions of income and of political influence. Instead, wait times depend on voter group sizes, morbidity of the population, discount rate for public care, and the technical factors underlying medical waiting queues.

The model indicates that without empirical research, we cannot say what will happen as the population ages. It is possible that wait times will go up or down even though, in the present framework, seniors are politically more single-minded about health care than the young.

The model can be generalized in a number of directions. An alternative approach to dealing with an aging population is to subsidize private care with a tax credit. In this case, interesting questions arise about how the tax credit influences the boundary between public and private care, whether and under which conditions the tax credit helps to reduce wait times for public care, and whether the tax credit leads to an equilibrium as in Besley and Coate (1991) where the rich use private care and the poor use public care exclusively. 
It would also be interesting to extend the present model to analyze the short run situation when the supply of doctors is not perfectly elastic and a growing private sector draws resources from the public system. Including non-actuarially fair private insurance is another direction deserving consideration. We should expect, though, that in such an expanded model, the separation result will still hold if the public sector has sufficient policy instruments.

The research framework proposed in this paper is not specific to the public health care system. An investigation of the political economy of a publicly provided private good such as education and public housing may also be studied using a similar framework, particularly when public provision differs from private provision in terms of quality or timeliness. 


\section{Reference}

Atkinson, A.B., and J. E. Stiglitz (1976) "The Design of Tax Structure: Direct Versus Indirect" Journal of Public Economics Vol. 6, pp. 55-75.

Banks, Jerry, John Carson, Barry L. Nelson, and David Nicol (1999) Discrete-Event System Simulation, 4th Edition, Prentice Hall.

Banting, Keith G., and Robin W. Boadway (1997) (Eds.) Reform of Retirement Income Policy: International and Canadian Perspectives, Kingston, Ontario: Queen's University, School of Policy Studies.

Besley, Timothy and Stephen Coate (1991) "Public Provision of Private Goods and the Redistribution of Income" American Economic Review 81, pp. 979-984.

Bethencourt, Carlos and Vincenzo Galasso (2001) "On the Political Complementarity between Health Care and Social Security" CEPR Discussion Papers: 2788.

Blomquist, Soren and Vidar Christiansen (1999) "The political economy of publicly provided private goods" Journal of Public Economics 73, pp. 31-54.

Clark, J. Derek (1997) "Pressure and the Division of a Public Budget" Public Choice 93, pp. 179-195.

Costaa, Joan C. and Jaume Garcia (2003) "Demand for Private Health Insurance: How Important is the Quality Gap?" Health Economics 12, pp. 587-599.

Coughlin, Peter and Shmuel Nitzan (1981) "Electoral Outcomes with Probabilistic Voting and Nash Social Welfare Maxima" Journal of Public Economics Vol. 15, No. 1, pp. 113121.

Disney, Richard (1996) Can we afford to grow older? A perspective on the economics of aging, Cambridge and London: MIT Press. 
Epple, Dennis and Romano Richard E. (1996) "Public Provision of Private Goods" Journal of Political Economy Vol. 104, No. 1, pp. 57-84.

Feldstein, Paul J. (1990) "An Economic Perspective on Health Politics and Policy" Quarterly Review of Economics and Business vol. 30, No. 4, pp. 117-135.

Giffin, Walter C. (1978) Queuing: Basic Theory and Application, Grid Inc.

Gonzalez, Paula and Carmen Herrero (2004) "Optimal Sharing of Surgical Costs in the Presence of Queues" Mathematical Methods of Operations Research, Vol. 59, No. 3, Special Issue, pp. 435-446.

Gouveia, Miguel (1997) "Majority Rule and the Public Provision of a Private Good" Public Choice 93, pp. 221-244.

Gross, D. and C.M. Harris (1974) Fundamentals of Queuing Theory, New York: John Wiley and Sons, Inc.

Hettich, Walter and Stanley L. Winer (1999) Democratic Choice and Taxation---A Theoretical and Empirical Analysis, New York: Cambridge University Press.

Hoel, Michael and Erik Magnus Sæther (2003) "Public health care with waiting time: the role of supplementary private health care" Journal of Health Economics Vol. 22, No. 4, pp. 599-616.

Jacobson, Paul (2004) "Health care markets and the health care guarantee: baking a better loaf, or baking enough bread?" Policy Options/Options Politiques Vol. 25, No. 7, pp. 5058.

Jofre-Bonet, Mireia (2000) "Public care and Private Insurance Demand: The Waiting Time as a Link" Health Care Management Science 3, pp. 51-71.

López-Nicolás, Ángel and Marcos Vera-Hernández (2002) "Are Tax Subsidies for Private Medical Insurance Self-financing? Evidence from a NHS Outpatient Microsimulation Model" Working Papers of Research Center on Health and Economics 632, Department 
of Economics and Business, Universitat Pompeu Fabra.

Merchand, Maurice and Fred Schroyen (2005) "Can a Mixed Health Care System be Desirable on Equity Grounds?" Scandinavian Journal of Economics, Vol. 107, No. 1, pp. $1-23$.

Mulligan, C. B. and Sala-i-Martin (1999) "Social Security, Retirement and the SingleMindedness of the Electorate" NBER Working Paper 9691

Meijdam, Lex and Harrie A Verbon (1996) "Aging and Political Decision Making on Public Pensions" Journal of Population Economics Vol. 9, Issue 2, pp. 141-58.

Pauly, M.V. (1988) "Positive Political Economy of Medicare, Past and Future" in Pauly, M.V. and W.L. Kissick (Eds.), Lessons from the First Twenty Years of Medicare:

Research Implications for Public and Private Sector Policy, Philadelphia: University of Pennsylvania Press

Profeta, Paola (2002) "Retirement and Social Security in a Probabilistic Voting Model" International Tax and Public Finance 9, pp. 331-348.

The Fraser Institute $(2007,2006)$ "Waiting Your Turn: Hospital Waiting Lists in Canada" $17^{\text {th }}$ and $16^{\text {th }}$ Edition.

The Speech from the Throne, delivered ay by Her Excellency the Governor General on April 4, 2006. http://www.sft-ddt.gc.ca/default_e.htm

Usher, Dan (1977) "The Welfere Economics of the Socialization of Commodities" Journal of Public Economics 8, pp.151-168

Vogel, Ronald J (1999) Medicare: Issues in Political Economy, Ann Arbor: University of Michigan Press.

Weaver, R Kent (2003) "The Politics of Public Pension Reform" Working Paper of Center for Retirement Research, Boston College. 


\section{Appendix}

\subsection{Solving for the Political Equilibrium under Alternative Assumption}

\subsubsection{The single tax rate case}

With a single tax rate, the government budget constraint becomes

$$
N c g=t \sum_{i=1}^{I} n_{i} y_{i}=N t \bar{y}
$$

The political parties maximize political support by choice of a level of public care provision and a uniform tax-transfer rate.

$$
\begin{aligned}
& \operatorname{Max} \underset{\left(t_{i}, g\right)}{S}=\sum_{i=1}^{I} n_{i} s_{i}\left\{\left(1-p_{i}\right) u\left(\left[y_{i}(1-t)-p_{i} q m_{i}^{*}\right], h_{0}\right)+p_{i} u\left(\left[y_{i}(1-t)-p_{i} q m_{i}^{*}\right],\left[R\left(p_{i}\right)^{T(g)} g+m_{i}\right]\right\}\right. \\
& \text { subject to } v_{h}^{\prime} / v_{x}^{\prime}=q, T(g)=\frac{1}{d \phi(N g)-\bar{p}}, \text { and } N t \bar{y}=N c g
\end{aligned}
$$

The Lagrange problem is

$$
L=\sum_{i=1}^{I} n_{i} s_{i}\left\{\left(1-p_{i}\right) u\left(\left[y_{i}(1-t)-p_{i} q m_{i}^{*}\right], h_{0}\right)+p_{i} u\left(\left[y_{i}(1-t)-p_{i} q m_{i}^{*}\right],\left[R\left(p_{i}\right)^{T(g)} g+m_{i}\right]\right\}+\eta(N t \bar{y}-N c g)\right.
$$

The first order conditions include

$$
\begin{gathered}
\frac{\partial L}{\partial t}=0 \Rightarrow n_{i} s_{i} y_{i} v_{x}^{i}-\eta N \bar{y}=0 \Rightarrow \eta=s_{i} v_{x}^{i} \frac{n_{i}}{N} \frac{y_{i}}{\bar{y}}, I \text { equations } \\
\frac{\partial L}{\partial g}=0 \Rightarrow \sum_{i=1}^{I} n_{i} p_{i} s_{i} v_{h}^{i} R\left(p_{i}\right)^{T(g)}\left[1+\frac{\partial T(g)}{\partial g} g \ln R\left(p_{i}\right)\right]-\eta N c=0
\end{gathered}
$$




$$
\frac{\partial L}{\partial \eta}=0 \Rightarrow N \hbar \bar{y}=N c g
$$

Integrate (a3) into (a4), we obtain

$$
\sum_{i=1}^{I} n_{i} p_{i} \eta \frac{v_{h}^{i}}{v_{x}^{i}} \frac{N}{n_{i}} \frac{\bar{y}}{y_{i}} R\left(p_{i}\right)^{T(g)}\left[1+\frac{\partial T(g)}{\partial g} g \ln R\left(p_{i}\right)\right]-\eta N c=0
$$

Substituting the first order condition for private care $\frac{v_{h}^{\prime}}{v_{x}^{i}}=q$ into (a6), we obtain

$$
\sum_{i=1}^{l} \frac{p_{i} R\left(p_{i}\right)^{T(g)}\left[1+\frac{\partial T(g)}{\partial g} g \ln R\left(p_{i}\right)\right]}{y_{i} / \bar{y}}-\frac{c}{q}=0
$$

Replacing $\frac{\partial T(g)}{\partial g}$ by $\frac{\partial T(g)}{\partial g}=\frac{-d_{g}^{\prime} \phi}{[d \phi(g)-\bar{p}]^{2}}=-d_{g}^{\prime} \phi T^{2}(g)$ in equation (a7), we obtain equation (a8)

from which the equilibrium public care $g^{* *}$ can be solved for.

$$
\sum_{i=1}^{I}\left(\frac{p_{i} R\left(p_{i}\right)^{T\left(g^{* *}\right)}\left[1-d_{g}^{\prime} \phi T^{2}\left(g^{* *}\right) g^{* *} \ln R\left(p_{i}\right)\right]}{y_{i} / \bar{y}}\right)=\frac{c}{q} .
$$

The equilibrium wait times under uniform tax schedule, $T^{* *}$, is therefore

$$
T^{* *}=\frac{1}{\phi d\left(g^{* *}\left(\bar{p}, \phi, d, c, q, p_{i}, R\left(p_{i}\right), \frac{y_{i}}{\bar{y}}\right)\right)-\bar{p}} .
$$

From equation (a5), we then solve for the equilibrium uniform tax-transfer rate $t^{* *}$.

$$
t^{* *}=\frac{c g^{* *}}{\bar{y}} .
$$




\subsubsection{The pay-from-the pocket case}

When a citizen in group $i$ pays from his own pocket for private care, the budget constraints of the citizen when he is healthy and sick are respectively

$$
x_{0}=y_{i}\left(1-t_{i}\right) \text { and } x_{1}=y_{i}\left(1-t_{i}\right)-q m_{i} .
$$

After substituting $x$ out of the problem of optimizing individual utility by using the budget constraints described above, we obtain the following.

$$
\underset{(m)}{E u_{i}}=\left(1-p_{i}\right) u\left(\left[y_{i}\left(1-t_{i}\right)\right], h_{0}\right)+p_{i} u\left(\left[y_{i}\left(1-t_{i}\right)-q m\right]_{i},\left[R\left(p_{i}\right)^{T(g)} g+m_{i}\right]\right) .
$$

The first order condition for $m_{i}$ is

$$
M R S_{x h}=\frac{v_{h}^{\prime}}{\left.v_{x}^{\prime}\right|_{x=y(1-t)-q m}}=q
$$

The indirect utility function is

$$
\begin{gathered}
v_{i}^{p}=\left(1-p_{i}\right) u\left(y_{i}\left(1-t_{i}\right), h_{0}\right)+p_{i} u\left(\left[y_{i}\left(1-t_{i}\right)-q m_{i}^{*}\right],\left[R\left(p_{i}\right)^{T(g)} g+m_{i}\right]\right), \\
\text { with } \frac{v_{h}^{\prime}}{\left.v_{x}^{\prime}\right|_{x=y(1-t)-q m}}=q, v_{y}^{\prime}>0, \text { and } v_{p}^{\prime}<0 .
\end{gathered}
$$

To solve for the political equilibrium, we substitute the indirect utility function (a14) into the political support function (15) and then solve the following problem.

$$
\operatorname{Max} \underset{\left(t_{i}, g\right)}{S}=\sum_{i=1}^{I} n_{i} s_{i}\left\{\left(1-p_{i}\right) u\left(y_{i}\left(1-t_{i}\right), h_{0}\right)+p_{i} u\left(\left[y_{i}\left(1-t_{i}\right)-q m_{i}^{*}\right],\left[R\left(p_{i}\right)^{T(g)} g+m_{i}\right]\right\},\right.
$$




$$
\text { subject to } \frac{v_{h}^{\prime}}{\left.v_{x}^{\prime}\right|_{x=y(1-t)-q m}}=q, T(g)=\frac{1}{\phi d(g)-\bar{p}} \text {, and } \sum_{i=1}^{I} n_{i} y_{i} t_{i}=N c g \text {. }
$$

The first order conditions include

$$
\begin{gathered}
\frac{\partial L}{\partial t_{i}}=0 \Rightarrow n_{i} s_{i} y_{i}\left[\left(1-p_{i}\right) v_{x \mid x=y_{i}\left(1-t_{i}\right)}^{i}+p_{i} v_{x \mid x=y_{i}\left(1-t_{i}\right)-q m}^{i}\right]-\eta n_{i} y_{i}=0 \\
\frac{\partial L}{\partial g}=0 \Rightarrow \sum_{i=1}^{I} n_{i} s_{i} p_{i} v_{h}^{i} R\left(p_{i}\right)^{T(g)}\left[1+\frac{\partial T(g)}{\partial g} g \ln R\left(p_{i}\right)\right]-\eta N c=0 \\
\frac{\partial L}{\partial \eta}=0 \Rightarrow \sum_{i=1}^{l} n_{i} y_{i} t_{i}=N c g .
\end{gathered}
$$

Substituting (a16) into (a17) and rearrange the equation, we obtain:

$$
\sum_{i=1}^{I} n_{i} p_{i} \frac{v_{h}^{i}}{\left[\left(1-p_{i}\right) v_{x \mid x=x_{0}}^{i}+p_{i} v_{x \mid x=x_{i}}^{i}\right]} R\left(p_{i}\right)^{T(g)}\left[1+\frac{\partial T(g)}{\partial g} g \ln R\left(p_{i}\right)\right]-N c=0 .
$$

Substituting $\frac{v_{h}^{\prime}}{\left.v_{x}^{\prime}\right|_{x=y(1-t)-q m}}=q$ and $\frac{\partial T(g)}{\partial g}=\frac{-d_{g}^{\prime} \phi}{[d \phi(g)-\bar{p}]^{2}}=-d_{g}^{\prime} \phi T^{2}(g)$ into (a19), we obtain equation (a20) from which equilibrium public care $g^{p}$ can be solved for.

$$
\sum_{i=1}^{I} \frac{n_{i}}{N} p_{i} \frac{\left.v_{x}^{i}\right|_{x=x_{i}}\left(y_{i}, t_{i} \ldots \ldots\right)}{\left[\left(1-p_{i}\right) v_{x \mid x=x_{0}}^{i}\left(y_{i}, t_{i} \ldots \ldots .\right)+p_{i} v_{x \mid x=x_{1}}^{i}\left(y_{i}, t_{i} \ldots \ldots .\right)\right]} R\left(p_{i}\right)^{T(g)}\left[1-d_{g}^{\prime} \phi T^{2}\left(g^{p}\right) g^{p} \ln R\left(p_{i}\right)\right]=\frac{c}{q} \cdot(\mathrm{a} 20)
$$

\subsection{The Equilibrium Tax-Transfer Schedule and Its Properties}

The equilibrium tax-transfer rate for a citizen in group $i$ in a model with a Cobb-Douglas utility is

$$
t_{i}^{*}=1-\frac{\frac{s_{i}\left[a+(1-a) p_{i}\right]}{\bar{k}} *\left[\bar{y}+(q \bar{r}-c) g^{*}\right]-p_{i} R\left(p_{i}\right)^{T^{*}} q g^{*}}{y_{i}},
$$


where $\bar{y}=\sum_{i=1}^{I} \frac{n_{i}}{N} y_{i}, \bar{r}=\sum_{i=1}^{I} \frac{n_{i}}{N} p_{i} R\left(p_{i}\right)^{T(g)}$, and $\bar{k}=\sum_{i=1}^{I} \frac{n_{i}}{N} s_{i}\left[a+(1-a) p_{i}\right]$.

We then look at how income and political sensitivity affect the equilibrium tax-transfer schedule.

The first-order derivative of the equilibrium tax-transfer rate with respect to income is

$$
\frac{\partial t_{i}^{*}}{\partial y_{i}}=\frac{\frac{s_{i}\left[a+(1-a) p_{i}\right]}{\bar{k}} *\left[\bar{y}+\left(q \bar{r}_{p}-c\right) g^{*}\right]-p_{i} R\left(p_{i}\right)^{T^{*}} q g^{*}}{y_{i}^{2}}>0
$$

and the elasticity of equilibrium tax-transfer rate to change in income is

$$
\varepsilon_{t y}=\frac{\partial t_{i}^{*}}{\partial y_{i}} \frac{y_{i}}{t_{i}}=\frac{s_{i}\left[a+(1-a) p_{i}\right]\left[\bar{y}+\left(q \bar{r}_{p}-c\right) g^{*}\right] / \bar{k}-p_{i} R\left(p_{i}\right)^{T^{*}} q g^{*}}{y_{i}-\left\{s_{i}\left[a+(1-a) p_{i}\right]\left[\bar{y}+\left(q \bar{r}_{p}-c\right) g^{*}\right] / \bar{k}-p_{i} R\left(p_{i}\right)^{T^{*}} q g^{*}\right\}} .
$$

On the other hand, the first-order derivative of the equilibrium tax-transfer rate with respect to the indicator of political sensitivity, $s_{i}$, is

$$
\frac{\partial t_{i}^{*}}{\partial s_{i}}=-\frac{\frac{\left[a+(1-a) p_{i}\right]}{\bar{k}} *\left[\bar{y}+(q \bar{r}-c) g^{*}\right]}{y_{i}}<0
$$

and the elasticity is

$$
\varepsilon_{t s}=\frac{\partial t_{i}^{*}}{\partial s_{i}} \frac{s_{i}}{t_{i}}=\frac{-s_{i}\left[a+(1-a) p_{i}\right]\left[\bar{y}+\left(q \bar{r}_{p}-c\right) g^{*}\right] / \bar{k}^{*}}{y_{i}-\left\{s_{i}\left[a+(1-a) p_{i}\right]\left[\bar{y}+\left(q \bar{r}_{p}-c\right) g^{*}\right] / \bar{k}-p_{i} R\left(p_{i}\right)^{T^{*}} q g^{*}\right\}} .
$$

Equation (a22) and (a24) show that the tax system is progressive in income and regressive in political influence.

Comparing the elasticities in (a23) and (a25), we find that 


$$
\left|\varepsilon_{t y}\right|<\left|\varepsilon_{t_{s}}\right|
$$

That is, the elasticity of tax-transfer rates to income is lower than the elasticity of taxtransfer rate to political sensitivity. This implies that political sensitivity imposes a greater impact on tax-transfer rate than income does in terms of elasticity.

\subsection{The Impact of Aging on Equilibrium Wait Times}

Aging means that in a population, the proportion of seniors, $n_{2} / N$, is increasing relatively to that of youths. Assume that in an aging population the average morbidity of seniors is fixed at $p_{l}$ and the average morbidity of the young is fixed at $p_{2}$.

Define the equation for equilibrium public care, equation (21), as implicit equation $F($.$) .$

$$
F(.): \sum_{i=1}^{I} \frac{n_{i}}{N} p_{i} R\left(p_{i}\right)^{T\left(g^{*}\right)}\left[1-T^{2}\left(g^{*}\right) \phi d_{g}^{\prime} g^{*} \ln R\left(p_{i}\right)\right]-\frac{c}{q}=0
$$

According to the Implicit Function Theorem, we have

$$
\frac{\partial T^{*}}{\partial\left(n_{2} / N\right)}=-\frac{\partial F / \partial\left(n_{2} / N\right)}{\partial F / \partial T^{*}}
$$

Taking a partial derivation of equation (a26) with respect to the proportion of the seniors in the population, $n_{2} / N$, we obtain

$\frac{\partial F}{\partial\left(n_{2} / N\right)}=p_{2} R\left(p_{2}\right)^{T\left(g^{*}\right)}\left[1-T^{2}\left(g^{*}\right) \phi d_{g}^{\prime} g^{*} \ln R\left(p_{2}\right)\right]-p_{1} R\left(p_{1}\right)^{T\left(g^{*}\right)}\left[1-T^{2}\left(g^{*}\right) \phi d_{g}^{\prime} g^{*} \ln R\left(p_{1}\right)\right]$ 
Define $B_{i}$ as

$$
B_{i}=p_{i} R\left(p_{i}\right)^{T\left(g^{*}\right)}\left[1-T^{2}\left(g^{*}\right) \phi d_{g}^{\prime} g^{*} \ln R\left(p_{i}\right)\right]
$$

Substituting $B_{i}$ into (a28), we have

$$
\frac{\partial F}{\partial\left(n_{i} / N\right)}=B_{2}\left(p_{2}\right)-B_{1}\left(p_{1}\right)
$$

The elasticity of $B_{i}$ to $p_{i}$ is the following.

$$
\varepsilon_{B p}=1+p \frac{\partial R(p)}{\partial p}\left[\ln R(p)-\frac{T^{2}\left(g^{*}\right) \phi d d_{g}^{\prime} g^{*} \frac{1}{R(p)}}{\left[1-T^{2}\left(g^{*}\right) \phi d_{g}^{\prime} g^{*} \ln R(p)\right]}>1\right.
$$

Because $\frac{\partial R(p)}{\partial p}<0, \ln R(p)<0,\left[1-T^{2}\left(g^{*}\right) \phi d_{g}^{\prime} g^{*} \ln R(p)\right]>0$, we have $\varepsilon_{B P}>1>0$. Therefore, $p_{2}>p_{l}$ implies $B_{2}>B_{l}$.

We then have

$$
\frac{\partial F}{\partial\left(n_{i} / N\right)}=B_{2}-B_{1}>0
$$

To determine the sign of $\frac{\partial T^{*}}{\partial\left(n_{2} / N\right)}=-\frac{\partial F / \partial\left(n_{2} / N\right)}{\partial F / \partial T^{*}}$, we then calculate the first-order derivative of the implicit function $F($.$) to wait times, T$.

$$
\frac{\partial F}{\partial T^{*}}=\bar{r}_{T}\left(1-2 d \phi_{g}^{\prime} g^{*} T\left(g^{*}\right)\right)-d \phi_{g}^{\prime} g^{*} T^{2}\left(g^{*}\right) \bar{r}_{T T},
$$

where $\bar{r}_{T}=\sum_{i=1}^{2} \frac{n_{i}}{N} p_{i} R\left(p_{i}\right)^{T\left(g^{*}\right)} \ln R\left(p_{i}\right) ; \bar{r}_{T T}=\sum_{i=1}^{2} \frac{n_{i}}{N} p_{i} R\left(p_{i}\right)^{T\left(g^{*}\right)}\left(\ln R\left(p_{i}\right)\right)^{2}$. 
The sign of $\frac{\partial F}{\partial T^{*}}$ is ambiguous and $\frac{\partial F}{\partial\left(n_{i} / N\right)}>0$, so the sign of $\frac{\partial T^{*}}{\partial\left(n_{2} / N\right)}=-\frac{\partial F / \partial\left(n_{2} / N\right)}{\partial F / \partial T^{*}}$ is also undetermined.

However, we can find the sign of the function by making some assumptions:

If $0<T^{*}<-\frac{\bar{r}_{T}}{\bar{r}_{T T}}-\sqrt{\left(\frac{\bar{r}_{T}}{\bar{r}_{T T}}\right)^{2}+\frac{1}{d \phi_{g}^{\prime} g^{*}} \frac{\bar{r}_{T}}{\bar{r}_{T T}}}$ or $T^{*}>-\frac{\bar{r}_{T}}{\bar{r}_{T T}}+\sqrt{\left(\frac{\bar{r}_{T}}{\bar{r}_{T T}}\right)^{2}+\frac{1}{d \phi_{g}^{\prime} g^{*}} \bar{r}_{T T}}$, we will have $\frac{\partial F}{\partial T^{*}}<0$,

and therefore we will see

$$
\frac{\partial T^{*}}{\partial\left(n_{2} / N\right)}=-\frac{\partial F / \partial\left(n_{2} / N\right)}{\partial F / \partial T^{*}}>0
$$

On the other hand, when initial equilibrium wait times fall in a range such as

$-\frac{\bar{r}_{T}}{\bar{r}_{T T}}-\sqrt{\left(\frac{\bar{r}_{T}}{\bar{r}_{T T}}\right)^{2}+\frac{1}{d \phi_{g}^{\prime} g^{*}} \frac{\bar{r}_{T}}{\bar{r}_{T T}}}<T^{*}<-\frac{\bar{r}_{T}}{\bar{r}_{T T}}+\sqrt{\left(\frac{\bar{r}_{T}}{\bar{r}_{T T}}\right)^{2}+\frac{1}{d \phi_{g}^{\prime} g^{*}} \frac{\bar{r}_{T}}{\bar{r}_{T T}}}$, we will have $\frac{\partial F}{\partial T^{*}}>0$, and therefore

$$
\frac{\partial T^{*}}{\partial\left(n_{2} / N\right)}=-\frac{\partial F / \partial\left(n_{2} / N\right)}{\partial F / \partial T^{*}}<0
$$




\title{
Fiscal Incidence When Both Individual Welfare and Family Structure Matter: The Case of Subsidization of Home-care for the Elderly
}

\author{
(with Stanley L. Winer)
}

\begin{abstract}
In this paper, we investigate analytically and with simulation the measurement of the net fiscal incidence of a program that subsidizes home care, when both individual welfare and family structure matter. A secondary purpose of the paper is to contribute to incidence methodology. The definition of welfare incidence, the comparison of welfarebased incidence with budgetary incidence for non-cooperative and cooperative families, and the calculation of the shifting of program benefits between family members, some of whom may be altruistic, are key issues in the analysis. The integration of individual welfare, family structure and benefit shifting provides a fresh perspective on the study of the distributional consequences of home-care programs in particular, and on the theory of fiscal incidence generally.
\end{abstract}




\section{Introduction}

Demographic ageing in Western countries has increased pressure on the children of elderly parents to provide more care privately as an alternative to costly institutionalization. Home care programs cost less than nursing homes even for the elderly who are in need of extensive care (see for example, Hollander and Chappell 2002). But because personal contributions - in both money and time - of family caregivers is widely accepted as the key to the adequacy of long-term care, substitution towards home care only ameliorates a difficult situation. It is not surprising, then, that many OECD countries are increasing their program support for home care ${ }^{30}$. This allows them to maintain expenditures in other important policy areas to the extent possible, and to respond to the demands of increasingly burdened (adult) children.

While some papers have investigated the optimal structure of public policy in this context (for example, Pestieau and Sato 2004, and Balestrino 2004), there is very little work so far on the distributional impact of programs whose purpose is to subsidize the care of seniors who remain at home. In this paper, we investigate analytically and with simulation the measurement of the net fiscal incidence of a program that subsidizes home care, when both individual welfare (of children and parents) and family structure matter. A secondary purpose of the paper is to contribute to fiscal incidence methodology.

The definition of net fiscal incidence when the welfare of individuals matters, the

\footnotetext{
${ }^{30}$ Among OECD countries, Australia, Austria, Germany, Hungary, Luxembourg, Poland, Switzerland, and the United Kingdom provide cash subsidies to the elderly in need of home care. See the OECD Health Project by Manfred Huber, 2005, page 22, 23, and 40.
} 
importance of the structure of the family - whether it is non-cooperative or cooperative and the calculation of the shifting of program benefits between parents and altruistic children, are key issues in the analysis. The integration of individual welfare, family structure and benefit shifting provides a fresh perspective on the study of the distributional consequences of home-care programs in particular, and on the theory of fiscal incidence generally.

It may be noted that work on fiscal incidence when welfare matters has been sparse since the seminal contribution of Aaron and McGuire (1970). Early fiscal incidence studies, as well as most contemporary work, conveniently uses budgetary amounts as a metric, as for example, in the work of Gillespie (1964, 1980), Pechman (1974, 1985), Suits (1977), Vermaeten et al. (1995) and many others. This is so despite the work of Aaron and McGuire, Maital (1973), and Martinez-Vazquez (1982) that showed how the translation of budgetary incidence into welfare terms substantially affects incidence calculations. ${ }^{31}$

In this paper we pay special attention to the comparison of analyses that alternatively use welfare or budgetary amounts as a metric. Fiscal incidence is an important input into program evaluation and policy-design, and while welfare is theoretically superior as a metric, it would be much simpler to accumulate appropriate evidence if budgetary amounts (rather than welfare) could serve as a basis for assessing distributional impacts.

Shifting of taxes has, of course, been well-considered in the literature (surveyed recently by Zodrow 2005), following the seminal work of Harberger (1962) on the shifting of the

31 Welfare has been used as a metric in some computable general equilibrium (CGE) studies, which are referenced below. But these are computable models while, to the best of our knowledge, there remains a striking absence of analytical work on incidence when welfare matters. 
corporate income tax. On the other hand, the shifting of benefits, whether of services or subsidies, remains largely under researched with very few exceptions. (See, notably, Shoup 1988). In particular, there is little discussion in the literature about the nature of the short and long run horizons that must be distinguished in order to define shifting of benefits on the expenditure side of the government budget. In assessing the distributional impact of public subsidization of home care, where family structure is obviously involved, we think it is important to deal with the possibility that program benefits may be shifted between family members.

The paper proceeds as follows. We first summarize and review the key conceptual steps required for an incidence study. We then carry out these steps analytically in the context of an analysis of the incidence of a tax-financed (price) subsidy for home care for elderly parents, when the children are altruistic. ${ }^{32}$ Both welfare based and budgetary based incidence indexes are considered. Using simulations, we next consider the importance of behavioral assumptions about the degree of altruism and about family structure for the calculation of benefit shifting and for net incidence, in a manner analogous to the investigation of the role of such assumptions in the analysis of the incidence and shifting of a tax. A final section concludes. Ancillary calculations are provided in an Appendix.

\footnotetext{
32 One should note that the expenditure program we study does not involve provision of a public good. Nonetheless, we shall see that welfare and budgetary calculations differ systematically even when public goods are not involved. Moreover, the program consists of a policy that is designed to alter the price of a privately supplied good. The role of price changes as a result of public expenditure has, like individual welfare and expenditure shifting, been largely ignored in the net incidence literature, even though price changes have long been part of the study of tax incidence. Brennan (1976) and Browning (1978) have reminded us some time ago that a change in relative prices as a result of public policy may be an important element in net fiscal incidence calculations.
} 


\section{A Brief Guide to Incidence Analysis}

The conceptual steps required for a net fiscal incidence study have been acknowledged and, individually, have been discussed extensively in the literature at various points. But there does not appear to be any comprehensive summary of them that is readily available. In this section, we briefly outline the five key steps involved, and discuss the critical choices that must be made to complete each of them. In contrast to much of the literature, this overview allows for the use of welfare as a metric and for the analysis of the shifting of program benefits.

\subsection{The choice of a counterfactual experiment}

The first step is to choose a perspective, or counterfactual experiment, which effectively defines the policy or programs to be analyzed. We may examine a new program yet to be introduced, consider replacing an existing program or tax with another - in a differential incidence analysis - or analyze the implications of an existing tax, expenditure or fiscal system by comparing it to a pre-fisc situation in a balanced budget incidence analysis. A classic example of the differential approach is Pechman (1985). Gillespie (1964) provides the seminal balanced-budget analysis.

The choice between differential and balanced budget analyses is to some extent a matter of convenience when it is appropriately combined with an assumption about the counterfactual. When the return of funds to individuals, as part of a balanced budget study, is defined to be distributionally neutral in real terms, a differential analysis can be resolved into the combination of two balanced budget ones (Browning, 1978). The 
differential incidence effects of replacing tax or expenditure type A with type B will then be equal to the difference in the balanced budget incidence of $\mathrm{A}$ less that of $\mathrm{B}$, since the compensating policy changes in the latter two analyses are by definition distributionally neutral.

Of course the counterfactual can be defined in several ways and is a subject of debate. Vermaeten (1997) provides an especially useful survey of issues about the counterfactual. Browning and Johnson's (1979) controversial analysis of the incidence of the sales tax, for example, differs from others in the literature because they assume that all government revenue in the counterfactual is used to maintain the real value of transfers to the poor (Meerman, 1980). Moreover, the no-government or pre-fisc counterfactual of a balanced budget analysis is not really a world with no government, that is, without law and order.

As we shall see, the choice of the counterfactual has important implications for exactly how one acknowledges the existence of a government budget constraint (in step two), how a metric to measure changes in welfare is designed (in step three), how one defines a benchmark income (in step four), and the application of shifting (in step five) .

\subsection{Observing the government budget in the counterfactual}

Consistency requires that when a fiscal system is changed, the government budget constraint must be observed in designing the counterfactual. This is assured in a differential incidence study when the nominal revenue collected under each tax considered is identical, and that situation has become a standard part of the definition of a differential incidence study. 
In a balanced budget analysis, the change in revenue or expenditure as a result of the change in the fiscal system must be exactly allocated across individual citizens in the counterfactual. The welfare-based studies of Aaron and McGuire (1970) and Piggot and Whalley (1987), and the real budgetary based study of Vermaetan, Gillespie and Vermaetan (1995) are all examples of balanced-budget incidence studies.

There is a second element in this step, one which is of particular importance in an analytical incidence study. When the return of funds in a balanced budget study is done by altering tax ratios, this will require the assessment of additional behavioral adjustments consistent with the economic model underlying individual behavior. Or the funds can be dispersed lump sum. The lump sum assumption, as in Aaron and McGuire (1970), and many other empirical studies, avoids the necessity of incorporating behavioral changes in order to determine what happens in the counterfactual.

Altering tax rates is likely a more realistic alternative, though much more complicated. This assumption has been used in CGE studies such as that of Piggot and Whalley (1987) where behavioral adjustments can be allowed for through convenient assumptions about individual behavior and economic structure. For analytical work such as that conducted below, the lump sum disposal of public funds in accordance with the budget constraint is obviously a useful simplifying assumption.

\subsection{Choice of a metric for incidence calculations}

The third step is to choose a metric for the measurement of net benefits. Most fiscal incidence studies used budgetary amounts as a metric. Some, such as Browning (1978) or 
Vermaetan et al. (1995), do so more or less in real terms, partly as a way of acknowledging the importance of the difference between budgetary amounts and welfare as a metric.

A standard budgetary formula for the net benefit (NB) incident on group $i$ in a particular situation is 33

$$
N B_{i}=G_{i}+T R_{i}-T_{i}
$$

where $G_{i}$ is the monetary value of the public good or service received by group $i ; T R_{i}$ is the amount of the government direct transfer to group $i$; and $T_{i}$ is the amount of the total tax that the group pays.

This budgetary balance must in principle be measured in the initial (0) and in the counterfactual (1) situations, where the counterfactual may involve a balanced budget removal of an existing fiscal system (in a balanced budget analysis), or a replacement of an existing tax or program with another (in a differential incidence analysis).

Given a benchmark income, $y_{i}$ (to be discussed below), the fiscal incidence index for group $i$ in budgetary terms - or as we shall say for ease of exposition, the incidence for the group - is then defined generally as:

$$
B F I_{i}=\frac{N B_{i}^{0}}{y_{i}}-\frac{N B_{i}^{1}}{y_{i}} .
$$

\footnotetext{
33 This definition of net benefits is consistent with the "net residual" measurement in Musgrave and Musgrave $(1980,274)$. Another prevailing definition of the net benefit in budgetary terms is the difference between the pre-government income position and post-government income position (see, for example, Meerman 1980).
} 
To construct an overall incidence analysis of the usually reported type, these indexes are arranged to show their size by income class $\left\{y_{i}\right\}$, though here it proves useful to continue to study these indexes separately for each group. Suit (1977) has developed a well-used index to summarize the distribution of the incidence indexes. (See Chamberlain and Prante (2007) for a recent application.) Kim and Lambert (2009) applied Kakwani progressivity indices (Kakwani 1977, 1984) to measure the vertical impact of a tax or benefit. Another index, called "Relative Share Adjustment (RSA)", is suggested by Baum (1987) and has been employed in Dyck (2005) and Ruggeri et al. (1996).

In a differential budgetary tax incidence study, where $G$ is assumed to be fixed because total tax revenues are held constant, the calculation amounts to studying the differences in budgetary tax burdens across income groups normalized by some benchmark income. In a balanced budget analysis, $N B^{l}$ is effectively zero, since the counterfactual involves eliminating the program or fiscal system. In both differential and balanced budget cases, the benchmark income $y_{i}$ must be defined so that it is consistent with the nature of the counterfactual experiment (as discussed below).

Budgetary fiscal incidence studies often acknowledged the importance of welfare rather than monetary amounts as a metric, but they refrain from using it because of the difficulty of attributing values of public good to citizens. (See Musgrave and Musgrave (1980), Gillespie (1980), and Ruggeri et al. (1996) ${ }^{34}$.) Gillespie (1980) points out that:

\footnotetext{
${ }^{34}$ Ruggeri $(2003,121)$ states the standard argument: "In theory, the value of the benefits provided by pubic expenditures other than cash transfers is the dollar amount that individuals are willing to pay. However, this willingness to pay is not known in the case of publicly-provided goods and services, because there is no market for them."
} 
One could focus on the family unit's evaluation of the benefits received from the specific expenditure and attempt to allocate the 'benefits received' among the appropriate family units. One could, alternately, focus on the cost incurred by the government in providing specific expenditures for clearly delineated family units and attempt to allocate the 'cost incurred on behalf of' certain family units among them. The problems of estimating in the 'benefits received' approach are formidable. This has led investigators to adopt the 'cost incurred on behalf of' approach.

Gillespie (1980) and Ruggeri et al. (1996) implement the 'cost incurred on behalf of' approach in allocating benefits of specific expenditures in their study of Canada. Chamberlain and Prante (2007), for example, assume that all public goods and services are shared equally (and fully) by all households because of the non-rivalness of public goods.

One should note that the difference between welfare and budgetary amounts as a metric does not arise solely because of the presence of public goods. In general, these metrics will always differ even when analyzing only taxes and transfers, or expenditures on private goods.

The seminal work on the use of welfare as a metric in incidence studies is Aaron and McGuire (1970). They imputed the value of a public good as the product of the marginal rate of substitution between public and private goods and the amount of public goods received. The difference between the value of the public goods and the tax actually paid by an income group reflects the distributional effect of the fiscal system for the group. As 
pointed out by Aaron and McGuire (1970), this approach measures welfare at the margin and does not capture the intra-marginal effects which can only be captured by a consumer surplus measure of welfare. Maital (1973) improved the measurement of the marginal utility of income and Martinez-Vasquez (1981) applied Aaron and McGuire's approach to local government.

Piggot and Whalley (1987) measured net fiscal incidence as the distribution of equivalent variations in a computable general equilibrium model with a pure public good. The empirical, computable dynamic policy evaluation of Auerbach and Kotlikoff (1987) and their generational accounting (see for example, Auerbach et al. 1999, chap. 2) are also (total) welfare based.

The equivalent variation (EV) and the compensation variation (CV) are the two mostwidely used willingness-to-pay welfare-based measures. The EV is the amount of income that must be taken away from the consumer in lieu of price and income changes to leave the consumer as well off as with the change (where consumption adjustments are possible). (See, for example, Just et al. 2004, 158). The EV may be defined implicitly using the individual indirect utility function $V$ :

$$
V\left(p^{0}, y^{0}-E V\right)=V\left(p^{l}, y^{l}\right)=V^{l}
$$

Here, state 0 is the observable state with the existing program or tax, and state 1 is the counterfactual or hypothetical pre-fisc state without this program or tax. Price vectors $p^{0}$ and $p^{l}$ are for state 0 and state 1 , and $y^{0}$ and $y^{l}$ are the corresponding nominal incomes. ${ }^{35}$

\footnotetext{
${ }^{35}$ The EV may also be defined directly as: $E V=\left\{e\left(p^{0}, V^{0}\right)-e\left(p^{0}, V^{l}\right)\right\}$, where e (.) is the Hicksian or compensated demand function.
} 
The counterfactual implied by the use of the EV is the pre-fisc world without the observed policies (being studied) in place. In CGE work such as that of Piggot and Whalley, the EV is chosen over the $\mathrm{CV}$ because the EV always uses the observable current price vector $\left(p^{0}\right)$ as benchmark price while CV uses the hypothetical pregovernment price vector $\left(p^{l}\right) .{ }^{36}$ The $\mathrm{EV}$ is thus convenient if we are measuring the incidence of an existing benefit program, tax or fiscal system. We shall use the EV in what follows.

Welfare-based fiscal incidence (WFI), in contrast to budgetary net incidence, is the net benefit in welfare terms that a group receives from a fiscal program, relative to its benchmark income, or benchmark welfare, where net benefits are measured by the equivalent variations.

When a benchmark income is used in the denominator, the WFI for group $i$ is:

$$
W F I_{i}=\frac{E V_{i}}{y_{i}}
$$

Here the actual and counterfactual situations are embedded in the calculation of the EV. Interesting questions, ones that we shall pursue in our application, concern the conditions under which $B F I_{i}$ and $W F I_{i}$ are the same, and the sources of divergence in applied

\footnotetext{
${ }^{36} \mathrm{The} \mathrm{CV}$ is defined as the amount of income that must be taken away from a consumer (possibly negative) after a price and/or income change due to some program or tax to restore the consumer's original welfare level (where consumption adjustments are possible). The formula for the $C V$ is $V\left(p^{l}, y^{l}-C V\right)=V\left(p^{o}, y^{o}\right)=$ $V^{0}$, or $C V=\left\{e\left(p^{l}, V^{l}\right)-e\left(p^{l}, V^{0}\right)\right\}$. (See Just et al. 2004, 158).
} 
situations. $^{37}$

\subsection{Choosing a benchmark income for the purpose of defining an incidence index}

To implement either incidence measure, we must choose a benchmark income or level of welfare for the purpose of distributing net benefits across groups or income classes. Income is used as a benchmark for the purpose of defining beneficiary groups because it is thought to be relevant to the design and evaluation of public policies. Welfare has not been used in the denominator of the incidence measures so far, though doing so would be consistent with the use of welfare in the numerator. We consider this alternative later.

There are at least three choices for benchmark income $y_{i}$ that have been widely used in the literature. They are: pre-fisc income, post-fisc income, and a type of income lying between pre-fisc and post-fisc income referred to as broad income (Vermaetan et al. 1995). Pre-fisc income is private factor income in the absence of the fiscal system in question. Post-fisc income is the income observed in post-fisc state which includes transfer payments and the benefits of government purchases, and excludes the tax payment.

Broad income is basically pre-fisc income plus transfer payments. Vermaeten et al. (1995, 321) define broad income as a sum of market income, various additional sources of nonreported money income and non-money income, several adjustments to income for model consistency (such as backward-shifted payroll taxes), and government transfer payments

\footnotetext{
${ }^{37}$ One may note that the deadweight loss of a distortionary tax is the difference between the EV of the distortionary tax and the amount of wealth that a household would lose under an alternative lump-sum tax. (Mas-Colell et al. 1995, 84) This is essentially a differential analysis that captures the difference between the welfare impacts and the budgetary changes caused by the tax in question.
} 
received by families. The most important adjustments referred to here rely on the theory of tax-shifting, which we turn to in the next step, to estimate pre-fisc factor incomes, to which is added personal transfers to derive broad income.

The choice of benchmark income varies widely across fiscal incidence studies. (See the surveys of Kesselman and Cheung (2004) and Martinez-Vazquez (2001)). Ruggeri et al. $(1996,13)$ argue that post-fisc income is the most appropriate benchmark because:

It offers a more intuitive interpretation of ... incidence results and provides a more appropriate counterfactual... Actual post-fisc income provides an estimate of the standard of living, or potential consumption, of households in the period under consideration. The ratio of taxes paid to post-fisc income indicates the degree by which the current standard of living (including the benefits received when the tax revenue is spent) is reduced by the payment of taxes. The same interpretation applies to the ratio of the benefits of government spending to post-fisc income.

Pre-fisc income is not observed and must be estimated or calculated. In so doing, the calculations must be consistent with assumptions about behaviour and the shifting of taxes and expenditures when a program or tax is eliminated in setting up a balanced budget counterfactual. For example, if a tax is considered to be shifted backwards to labor, such as a corporate income tax in a small open economy, the tax actually collected must be imputed to factor incomes in order to derive pre-fisc factor income if that is used as the benchmark income concept. By way of contrast, when using post-fisc income, no such adjustment to private incomes is required to account for the consequences of eliminating taxes and expenditures. 
Broad income is chosen by Vermaeten et al. (1995) and others such as Okner and Pechman (1974). Vermaetan et al. (1995, 321) following Gillespie (1980) argue that personal transfers are widely regarded as part of individual income while the imputed value of public services is not. A tax policy, in his view, thus has to be evaluated based on an integrated tax/transfer system. The imputed value of public services is hard to measure and is usually not taken into account by citizens or policy makers in evaluating a public policy. Therefore, they say, "we believe it (broad income) to be of greater interest to both taxpayers and policy-makers than the other two." ${ }^{38}$

While it has never been used in analytical or empirical work, it also seems logical to allocate changes in welfare across groups in proportion to the total gain or loss in social welfare that occurs as a result of the public policy in question. In that case, WFI for group $i$ is:

$$
W F I_{i}=\frac{E V_{i}}{\sum_{i} E V_{i}},
$$

where the denominator is the aggregate change in welfare from the program in question. An obvious connection between incidence analysis and cost-benefit analysis is then apparent. The main difference is that incidence analysis is concerned primarily with the distribution of welfare gains or losses rather than with the bottom line which is the focus of a cost-benefit study. In this paper, we do not pursue definition (5) further.

\footnotetext{
${ }^{38}$ Gillespie apparently changed his use of the term "broad income" between his earlier work (1964, 1980) and his last and (in our view) best incidence study (1995). Previously, broad income was essentially equal to pre-fisc income.
} 


\subsection{Allowing for shifting}

As a final step, it is necessary to allow for the shifting of taxes and benefits. As already noted, this step may play an important role in calculations of the benchmark income if a pre-fisc or broad definition of income is used.

The analysis of the shifting of tax burdens has been at the center of tax incidence studies at least since Harberger's (1962) seminal work on the corporate income tax in general equilibrium. A tax initiates a chain of general-equilibrium reactions by economic agents which must be unwound in order to calculate pre-fisc factor incomes for the purpose of defining a benchmark income $y_{i}$ in the denominator of incidence indexes (2) and (4) above. The theory of tax incidence is well covered in standard public finance texts (see, for example, Rosen (2001) or Atkinson and Stiglitz (1980)), and need not be reviewed here.

By a similar logic, the distribution of benefits from an expenditure program must be unwound if they are to be allowed for in a comprehensive definition of pre-fisc income, or are to be included in the numerators of the incidence indexes defined earlier. But there is virtually no theory concerning the shifting of benefits, in large measure, one suspects, because it is thought that such a framework would be hard to actually apply, and the shifting of benefits is ignored in almost all incidence studies.

Shoup (1988) argued for, but did not provide, an analysis of the shifting of benefits. One of his examples concerns a city park constructed in the neighborhood of a rental residence. When the park is just constructed, the tenants living nearby receive the full 
benefit of the park. However, over time the benefit from the park leads to a rent increase. Thus, in the long run, part or all of the benefits from having the park is shifted from the tenants to the landlord. It would be a mistake, Shoup argues, if all the benefits from the park were to be allocated to the tenants.

To study the shifting of benefits, we need a theory of behavior and a counterfactual distinguishing incidence in the short and the longer run. Shifting is then defined as the difference in incidence over the two horizons. In a corporate income tax study, assumptions need to be made about adjustments in the capital stock in short and long runs in response to taxation. For example, the short run may be defined as a situation in which the capital stock is fixed and thus bears the full tax burden. Similar assumptions are needed in the study of expenditure incidence.

\section{The Net Incidence of A Price Subsidy for Home Care When Children Are Altruistic}

In this section we apply the steps outlined above to study the incidence of a public program that subsidizes home care for the parent when his or her child is altruistic. Here the relevant groups for the attribution of net benefits are generational in character namely children and their elderly parents - and the short run for the purpose of calculating the shifting of benefits involves a situation where the children cannot, or do not, adjust to a change in program benefits. In this analysis, alternative assumptions about the structure of the family are analogous to assumptions about the structure of the economy or the nature of the corporation in the analysis of a corporate income tax. 
In the following analytical incidence analysis, we assume a subsidy for home care is already in place, and we regard the situation when the home care subsidy is in place as the initial situation ' 0 ' for the purpose of calculating welfare changes. In the counterfactual, we hypothetically remove the subsidy and return the surplus tax revenue using a lump-sum transfer to taxpayers in proportion to his post-fisc or actual gross income (a balanced-budget situation). We define BFI and WFI taking post-fisc income as the benchmark income for the purpose of defining incidence across two groups: parent and his child. We then compare WFI with BFI in the short and longer runs analytically, and using simulations.

It should be noted that the situation we explore does not involve consideration of a public good. Nonetheless, BFI and WFI remain essentially different except in one very special circumstance described below.

\subsection{A basic model of a non-cooperative family}

We assume that all the families are identical and that every family is composed of an elderly parent and a child. Equivalently, we may think of the model as applying to a family of two parents and one or more children where there is no disagreement between the parents, and the children also always act cooperatively among themselves. ${ }^{39}$ For convenience, we proceed as if there was one parent and one child.

The parent is infirm and requires home care as a substitute for institutionalization. The home care required includes formal and informal care. The parent buys formal care from

\footnotetext{
39 Interested readers may wish to see Pezzin, Pollack and Schone (2006) or Knoef, Kooreman, and Kalmijn (2007) for an analysis of strategic interactions among siblings in arranging home care for elderly parent.
} 
market. The child is altruistic and spends time taking care of his or her parent, and also buys some formal care from the market to supplement the purchase of care by his parent $^{40}$. The parent prefers the company of the child, and purchased time is not a perfect substitute for the attention provided by the child. The government helps the parent with affordable care by granting him a subsidy proportional to his payment for formal care. The child's purchase of formal care is not eligible for the subsidy because the home care program targets the senior group.

We assume initially that the parent and the child act non-cooperatively to determine home care provision, and that the time horizon is long enough so that the child can adjust his behavior to allow for the existence of the government subsidy. We explore the difference a cooperative structure makes later.

It is important to understand why the non-cooperative case is relevant. At some point, the child would rather give money instead of spending more time with the parent, while the parent continues to prefer the child's attention to a money subsidy or transfer. We think that this disagreement is typical among families in developed countries and that in such a situation, a non-cooperative Nash model is appropriate.

Assuming utility is Cobb-Douglas, so that the income effect of a price change affects all components of agent choices, the utility of the parent $(p)$ then is:

$$
U\left(x_{p}, H=m+s, h\right)=a \log \left(x_{p}\right)+b \log (m+s)+c \log (h)
$$

\footnotetext{
${ }^{40}$ The altruism of the child may be driven by the possibility of receiving a bequest from the parent. We do not include bequest incentive in the model because we are focused on measurements of incidence of a public program.
} 
where $x_{p}$ is the numéraire consumption of the parent, $H$ is the total hours of formal care received by the parent, of which $m$ is purchased by the parent and $s$ is purchased by the child, and $h$ is total hours that the child spends on taking care of parent. As usual we assume that $a+b+c=1$. Parent's utility is maximized by choice of $\left(x_{p}, m\right)$ subject to the budget constraint

$$
y(1-t)=x_{p}+q\left(1-t_{s}\right) m
$$

where $y$ is the amount of the fixed pension income of the parent, the price of numeraire consumption is normalized to 1 , the price of formal care is $q$ per hour, $t$ is the uniform income tax rate, and $t_{s}$ is the rate of subsidy the government grants to the parent, when the subsidy is assumed to be non-taxable. With the government subsidy, the effective price of the formal care purchased by the parent is $q\left(I-t_{s}\right)$ per hour.

The utility of the child (c) is ${ }^{41}$

$$
U\left(x_{c}, l, x_{p}, m, h, s\right)=\left[(1-d) \log \left(x_{c}\right)+d \log (l)\right]+r U_{p}\left(x_{p}, m, h, s\right),
$$

where, $x_{c}$ is the numéraire consumption of the child, $l$ is the leisure enjoyed by the child, $U_{p}$ is the utility of the parent, and $r$ is the degree of altruism towards the parent. The part in the square bracket represents the felicity of the child per se. The child maximizes (8) by choice of $\left(x_{c}, h, s\right)$ subject to his budget constraint

$$
w(T-h-l)(1-t)=x_{c}+q s
$$

where $T=L+h+l$, with $T$ the child's total available time in a day, $L$ the child's working

\footnotetext{
${ }^{41}$ We do not differentiate among parents or children in order to focus on the central issue concerning distribution of incidence and shifting across generations in general.
} 
hours, $h$ the number of hours that the child provides home care to the parent, $l$ the hours of leisure enjoyed by the child, and $w$ the child's wage ${ }^{42}$.

The post-fisc solutions to the non-cooperative game, in the "long run" when the child fully incorporates the receipt of a subsidy by his parent include:

$$
\begin{aligned}
& m=\left[y(1-t) /\left[q\left(1-t_{s}\right)\right]-r a(1-t)\left[w T+y /\left(1-t_{s}\right)\right] /[(1+r) q],\right. \\
& s=r(a+b)(1-t)\left[w T+y /\left(1-t_{s}\right)\right] /[(1+r) q]-y(1-t) /\left[q\left(1-t_{s}\right)\right], \\
& H=m+s=r b(1-t)\left[w T+y /\left(1-t_{s}\right)\right] /[(1+r) q], \\
& h=r c(1-t)\left[w T+y /\left(1-t_{s}\right)\right] /[(1+r) w(1-t)], \\
& l=d(1-t)\left[w T+y /\left(1-t_{s}\right)\right] /[(1+r) w(1-t)], \\
& L=T-h-l=T-(d+r c)(1-t)\left[w T+y /\left(1-t_{s}\right)\right] /[(1+r) w(1-t)], \\
& x_{c}=(1-d)(1-t)\left[w T+y /\left(1-t_{s}\right)\right] /(1+r), \text { and } \\
& x_{p}=r a\left(1-t_{s}\right)(1-t)\left[w T+y /\left(1-t_{s}\right)\right] /(1+r)
\end{aligned}
$$

Substituting these solutions into utility functions (6) and (8), we obtain the indirect utilities of the parent and the child in state 0 in the long run, $V_{p}^{0}$ and $V_{c}^{0}$, that is, in the post-fisc situation where the subsidy is actually in place and fully adjusted to:

$V_{p}^{0}=\log \left[w T(1-t)+y(1-t) /\left(1-t_{s}\right)\right]+\operatorname{alog}\left(1-t_{s}\right)+Z_{p}$, where $Z_{p}$ is a constant, and $Z_{p}=-\log$ $(1+r)+\operatorname{alog}(r a)+b \log (r b)+c \log (r c)-b \log (q)-c \log [w(1-t)]$.

and $V_{c}^{0}=(1+r) \log \left[w T(1-t)+y(1-t) /\left(1-t_{s}\right)\right]+$ ralog $\left(1-t_{s}\right)+Z_{c}$, where $Z_{c}$ is a constant, and $Z_{c}$ $=-(1+r) \log (1+r)+(1-d) \log (1-d)+d \log (d)-(d+r c) \log [w(1-t)]+r Z_{p}$.

\footnotetext{
${ }^{42}$ Since women often stay at home taking care of elderly parents, the increases in women's wage rate and the increasing participation in labor force of women are of particular importance in determining distribution of benefits from a subsidy for home care.
} 
When the government budget is balanced, total tax revenue equals total expenditure:

$$
t\left(Y_{p}+Y_{c}\right)=t_{s} q m,
$$

where $Y_{p}$ and $Y_{c}$ are the taxable gross income of the parent and the child in the presence of the tax and the subsidy. ${ }^{43}$ Using this government budget constraint, we can derive the tax rate in the post-fisc situation with full adjustment in the long run (LR), $t^{L R}$, for later use:

$$
\begin{aligned}
t^{L R}=t_{s}\left(y /\left(1-t_{s}\right)-r a[w T+\right. & \left.\left.y /\left(1-t_{s}\right)\right] /(1+r)\right\} /\left\{t_{s} y /\left(1-t_{s}\right)-t_{s} r a\left[w T+y /\left(1-t_{s}\right)\right] /(1+r)\right. \\
& +(y+w T)(1+r-d-r c) /(1+r)\}
\end{aligned}
$$

\subsection{Budgetary incidence}

We now follow the five steps discussed before to calculate fiscal incidence indexes.

To define the budgetary incidence of the subsidy, we choose the post-fisc situation (state 0 ) as the initial one. We then assume the subsidy away and return the tax revenue released lump sum by a transfer, $R_{i}$. Our simulation data include the left-side quantities in (10) above. Of course we do not know the welfare optimization calculations that led to these behavioral outcomes: that is, we do not observe the right side of equations (10).

Let the lump-sum transfers, $R_{i}$, be proportional to the post-fisc taxable incomes, so that $R_{p}=f \cdot Y_{p}$ and $R_{c}=f \cdot Y_{c}$. To maintain the government budget when the subsidy program is assumed away, we must have $R_{p}+R_{c}=f\left(Y_{p}+Y_{c}\right)=t_{s} q m$ in the counterfactual situation, while also observing government budget balance: $t^{L R}\left(Y_{p}+Y_{c}\right)=t_{s} q m$. In this case, $f=t^{L R}$.

\footnotetext{
${ }^{43}$ Because all the families are identical, the number of families is omitted in the government budget.
} 
Therefore, $R_{p}=t^{L R} Y_{p}$ and $R_{c}=t^{L R} Y_{c}$, so that returning the subsidy lump-sum in proportion to income is equivalent to returning the actual tax payment. The assumption of lump-sum returns removes or at least mutes distributional effects in the counterfactual.

To allow for shifting using budgetary calculations, we shall assume that in long run, a part of the benefit from the subsidy is shifted from the parent to the child in proportion to his purchases of formal care when the subsidy is in place. ${ }^{44}$ The benefit to the parent in the long run then is $T R_{p}=t_{s} q m \cdot m /(m+s)$, and the benefit to the child in the long run is $T R_{c}=t_{s} q m \cdot s /(m+s)$. The tax paid by the parent is $t^{L R} Y_{p}$ and the tax paid by child is $t^{L R} Y_{c}$. The net benefits received by the parent and the child in the post-fisc situation in the long run are:

$$
\begin{gathered}
N B_{p}{ }^{0}=T R_{p}-T_{p}=t_{s} q m \cdot m /(m+s)-t^{L R} Y_{p}, \\
\text { and } \\
N B_{c}{ }^{0}=T R_{c}-T_{c}=t_{s} q m \cdot s /(m+s) .-t^{L R} Y_{c} .
\end{gathered}
$$

In the counterfactual state, neither the parent nor the child receives a subsidy. They both pay tax, and receive a lump-sum transfer equal to their tax payment. The net budgetary benefits in the counterfactual state (denoted by superscript 1) are zero.

The next step is to choose a benchmark income and define incidence across the two groups in the model. We shall use post-fisc income as the benchmark income relative to which net benefits are to be compared, because this is a natural choice for normalizing

\footnotetext{
${ }^{44}$ Note that we assume the subsidy program was intended to relieve the burden of the parent in the short and longer runs. Although altruism is not formally part of the budgetary model of incidence, we are explicitly taking it into account through the allocation of benefits to child in the long run.
} 
the welfare-based EV measure, and because we want to compare BFI and WFI. In this case, no adjustment to benchmark (observed post-fisc) income is required. We could use pre-fisc income or broad income as a benchmark, and in these cases eliminating the program would require that post-fisc income be adjusted in accordance with budget balance and a theory of shifting of benefits, so as to construct consistently the benchmark or counterfactual income.

The budgetary fiscal incidence index of the parent taking account of shifting of benefits and using post-fisc income as benchmark income then may be defined as:

$$
B F I_{p}^{L R}=\frac{N B_{p}}{Y_{p}}=\frac{t_{s} q m \times m /(m+s)-t^{\mathrm{LR}} Y_{p}}{Y_{p}^{p o s t-f i s c}},
$$

where the taxable income of the parent is $Y_{p}=y$, and the post-fiscal income of the parent is $Y_{p}^{\text {post-fisc }}=y\left(1-t^{L R}\right)+t_{s} q m$.

And the budgetary index of the child in the long run is:

$$
B F I_{c}^{L R}=\frac{N B_{c}}{Y_{c}}=\frac{t_{s} q m \times s /(m+s)-t^{\mathrm{LR}} Y_{c}}{Y_{c}^{\text {post }- \text { fisc }}},
$$

where, the taxable income of the child is $Y_{c}=w T-(r c+d)(w T+y) /(1+r)$, and the postfiscal income of the child is $Y_{c}^{\text {post-fisc }}=w T\left(1-t^{L R}\right)-\left(1-t^{L R}\right)(d+r c)\left[w T+y /\left(1-t_{s}\right)\right] /(1+r)$.

An alternative way to measure budgetary fiscal incidence is to define incidence according to the share of cost-saving on market hours purchased. ${ }^{45}$ Due to the subsidy, the parent and the child are able to spend less on formal care, and we may measure the

45 We thank Mel McMillan for suggesting this method of defining budgetary incidence. 
extent to which the family members save money when the subsidy is in place relative to when it is not.

This alternative cost-saving basis for measuring budgetary fiscal incidence is illustrated in Figure II-1.

Figure II-1 Cost-saving Basis for Measuring Budgetary Fiscal Incidence

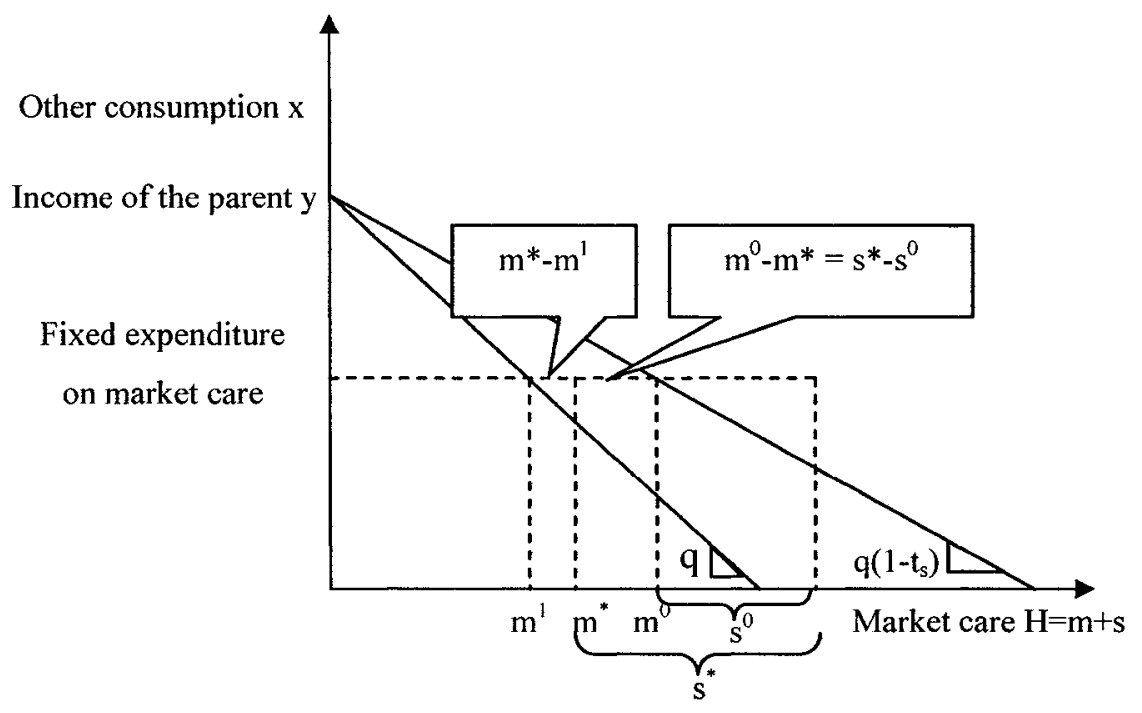

When the subsidy is not in place (state 1), the parent purchases $m^{I}$ units of market care. When the subsidy is in place (state 0 ), with the same expenditure, the parent demands $m^{0}$ units in the short run and the child demands $s^{0}$ units, as indicated. In the long run, due to behavioral adjustments, some of the benefit shifts from the parent to the child and finally the parent purchases $m^{*}$, and the child provide $s^{*}$.

The total benefit from the subsidy, if measured by the extra hours of market care that the parent could purchase, is $m^{0}-m^{l}$, in which the parent shares $m^{*}-m^{l}$ hours and the child shares $m^{0}-m^{*}$ hours. If we allocate budgetary benefits according to the extent of costsavings on market care purchased, the net benefit to the parent and the child then are, 
respectively

$$
\begin{gathered}
N B_{p}{ }^{0}=T R_{p}-T_{p}=t_{s} q m \cdot\left(m^{*}-m^{l}\right) /\left(m^{0}-m^{l}\right)-t^{L R} Y_{p}, \\
\text { and } \\
N B_{c}{ }^{0}=T R_{c}-T_{c}=t_{s} q m \cdot\left(m^{0}-m^{*}\right) /\left(m^{0}-m^{l}\right)-t^{L R} Y_{c} .
\end{gathered}
$$

Compared with (14a) and (15a), this method may be more consistent with the "change of wellbeing" basis of welfare incidence. However, it turns out that in the simulations, this method does not perform better than the traditional budgetary method outlined earlier in reducing the inconsistency between BFI and WFI. (Interested reader may check the Appendix for more detailed information on this point.). In the first place, the family's total hours of purchased market care in the presence of the subsidy and before the behavioral adjustments will generally not be equal to the total hours after the adjustments, as is assumed in Figure II-1. Second, this method does not measure the marginal welfare benefit of market care to the parent or the child.

\subsection{Welfare-based incidence}

Now we assume the post-fisc situation to be baseline situation (state 0 ), and assume away the subsidy in a counterfactual balanced budget experiment, again returning the extra tax revenue to taxpayers via lump-sum transfers, $R_{i}$, to maintain government budget balance in state 1.

To obtain the equivalent variation, we equalize the indirect utilities at state 0 and state 1 and see how much income has to be taken from the citizen when the subsidy in place to make him as well off as when the subsidy is assumed away. A positive (negative) EV 
implies a net welfare gain (loss) from the subsidy.

The budget-balanced $\mathrm{EV}$ for the parent in the long run defined by $V_{p}^{0}\left[q\left(1-t_{s}\right), Y_{p}-E V_{p}\right]=$ $V_{p}^{l}\left[q, Y_{p}+R_{p}\right]$ is

$E V p=[w T(1-t L R)(1-t s)+y(1-t L R)]-(1-t s)(b+c)[y(1-t L R)+t L R y+w T(1-t L R)]$

Similarly, the child's' EV from the subsidy in the long run defined by $V_{c}^{0}\left[q\left(1-t_{s}\right), Y_{c}-E V_{c}\right]$ $=V_{c}^{l}\left[q, Y_{c}+R_{c}\right]$ is

$$
E V_{c}=\left[w T\left(1-t^{L R}\right)+y\left(1-t^{L R}\right) /\left(1-t_{s}\right)\right]-\left(1-t_{s}\right)^{-r a(l+r)}\left[w T\left(1-t^{L R}\right)+y\left(1-t^{L R}\right)+t^{L R} Y_{c}\right]
$$

Using post-fisc income as the benchmark income for the distribution of net benefits, the welfare fiscal incidence indexes for the parent and the child then are

$W F I_{p}^{L R}=\frac{E V_{p}}{Y_{p}}=\frac{\left[w T\left(1-t^{L R}\right)\left(1-t_{s}\right)+y\left(1-t^{L R}\right)\right]-\left(1-t_{s}\right)^{(b+c)}\left[w T\left(1-t^{L R}\right)+y\left(1-t^{L R}\right)+t^{L R} y\right]}{Y_{p}^{p o s t-f i s c}}$

and

$W F I_{c}^{I R}=\frac{E V_{c}}{Y_{c}}=\frac{\left[w T\left(1-t^{L R}\right)+y\left(1-t^{L R}\right) /\left(1-t_{s}\right)\right]-\left(1-t_{s}\right)^{[-r a /(1+r)]}\left[w T\left(1-t^{L R}\right)+t^{L R} Y_{c}+y\left(1-t^{L R}\right)\right]}{Y_{c}^{p o s i-f i s c}}$

Here we can see the roles of the subsidy rate for home care, $t_{s}$, the tax rate in the long run situation, $t^{L R}$, the child's degree of altruism towards the parent, $r$, the parent's taste parameters, $a, b$, and $c$, and the income measures of the parent and the child, $y, w T$, and $Y_{c}$.

The changes in welfare are the outcome of the child's adjustments of time use in labor, 
leisure, and home care, when the parent's purchase of market care is subsidized. The parent's welfare change is a result of the subsidization of consumption and the trade-off between market care and attention by the child. The equilibrium tax rate in a balanced government budget is also result of these adjustments.

\subsection{A comparison of incidence indexes}

The differences between BFI and WFI over both horizons, though easy to derive, are quite complicated. (They are not presented here and can be found in the Appendix). With the exception of one special case, which is presented analytically below, it proves useful to explore these indexes using simulations. The one case we exhibit analytically is motivated by the search for situations in which welfare incidence can be approximated by budgetary incidence. While it will be seen that generally BFI and WFI measures for the program in question differ for both groups over all horizons, as do the measures of shifting. But consider the special case when the degree of altruism is zero, so that the child does not contribute any formal or informal care to his parent. ${ }^{46}$ In that case, the child does not interact with the parent over any horizon, and there is no difference in short and long run incidence for the child or the parent.

The differences between budgetary and welfare incidence when $r=0$ in both the long run and the short run, for the two generations are then:

$$
W F I_{p}^{r=0}-B F I_{p}^{r=0}=\frac{\left[1-b t_{s} /\left(1-t_{s}\right)\right] y(1-t)+t y-\left(1-t_{s}\right)^{b} y}{Y_{p}^{p o s t-f i s c}} \neq 0
$$

\footnotetext{
${ }^{46}$ When degree of altruism is zero, the family is effectively dissolved.
} 


$$
W F I_{c}^{r=0}-B F I_{c}^{r=0}=\frac{-t Y_{c}-\left(-t Y_{c}\right)}{Y_{c}^{p o s t-f i s c}}=0 .
$$

We state this result as proposition 1:

Proposition 1: For the home-care subsidy program, a BFI index is equivalent to a WFI index only when there is no altruism, and then only for the child.

The reason for the equivalence of BFI and WFI is simply that, with no behavioural adjustments by child (when there is no altruism), changes in income due to the payment of taxes are equivalent to changes in welfare in terms of the equivalent variation. ${ }^{47}$ Whenever there is a behavioural adjustment to a program or tax, there is a divergence between the incidence based on a budgetary metric and that using welfare. Thus, for example, the BFI index for the parent is different from the WFI index even when $r=0$, because the parent always respond to the price subsidy.

We now use simulation to explore the differences between WFI and BFI. In our hypothetical, simulated family, we assume initially that the child is altruistic towards to the parent to the degree of $r=0.3$. (This is varied later on). The child earns a wage of 25 dollars per hour and his total available time in a day is 12 hours. The parent earns a fixed pension income of 50 dollars per day. The parent's preference for numéraire consumption, for formal care, and for informal care are represented by coefficients $a=0.5, b=0.3$, and

\footnotetext{
${ }^{47}$ Even when $r=0$, the child responds to tax, but this adjustment only reduces his income. His consumption pattern does not change. When utility is Cobb-Douglas and the marginal utility of income is one, WFI equals BFI.
} 
$c=0.2$. The government grants the parent a subsidy at the rate of $t_{s}=0.2$, which requires a tax rate of 0.0209 in the long run, 0.0142 in the short run for a non-cooperative family, and 0.0595 for a cooperative family. The price of formal care is 10 dollars per hour.

Next we compute incidence for the hypothetical family when family members are non cooperative and the child can adjust to the subsidy. ${ }^{48}$ The relationship between degree of altruism and fiscal incidence when different degrees of altruism are assumed is shown in the following Figure II-2a, $2 \mathrm{~b}$ and $2 \mathrm{c}$. Here a positive (negative) BFI represents a gain (loss) from the subsidy-tax program in terms of budgetary benefit, and a positive (negative) WFI represents a gain (loss) in terms of welfare change.

${ }^{48}$ Altruism and shifting do not matter in a cooperative family. 


\section{Figure II-2 Net Fiscal Incidence and Altruism}
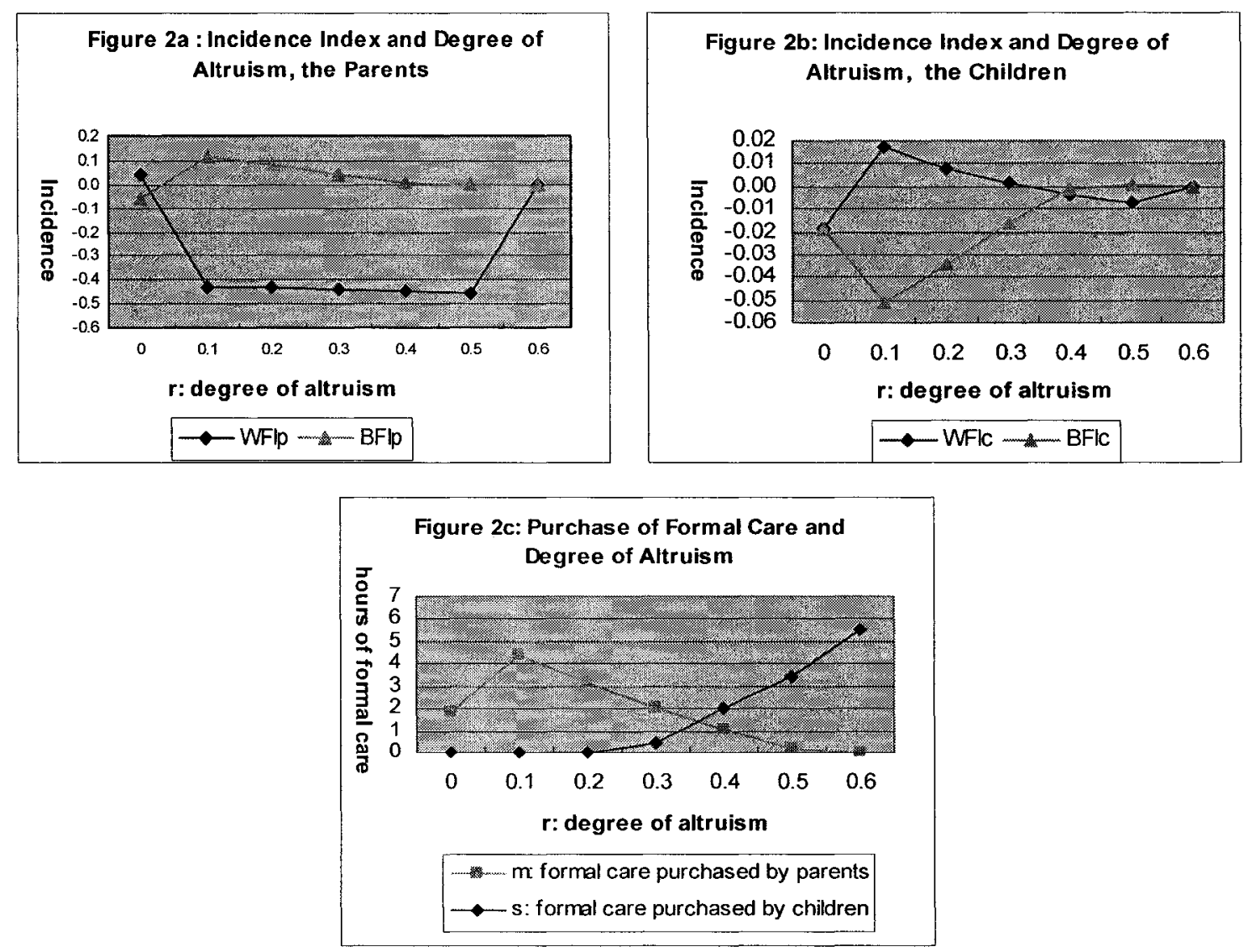

Figure II-2a and Figure II-2b show the incidence indexes of the two generations when $r$ changes within the range of 0 to 0.6 . The divergence between WFI and BFI is most dramatic when $r$ is not close to either end of the range.

From the figure, we can see that WFI and BFI indexes are quite different. We can see that while the parent usually loses and the child gains from the subsidy in terms of welfare, the distribution of net benefits in budgetary amounts is the opposite: for example, when $\mathrm{r}=0.3, \mathrm{WFI}_{\mathrm{p}}{ }^{\mathrm{LR}}<0, \mathrm{WFI}_{\mathrm{c}}^{\mathrm{LR}}>0$, while $\mathrm{BFI}_{\mathrm{p}}^{\mathrm{LR}}>0$, and $\mathrm{BFI}_{\mathrm{c}}^{\mathrm{LR}}<0$. This difference is due to the effect of the child's adjustment on the parent's decision. 
The figures also illustrates proposition 1 , that when $r=0$, WFI and BFI are equivalent for the child (but not for the parent). It has to be kept in mind that when the child is not altruistic, they do not contribute any formal or informal care, and the two generations make independent decisions ${ }^{49}$. In this special case, the child pays tax without receiving any benefit from the government.

On the other hand, when altruism is very high $(r>0.5)$, the parent do not purchase any formal care (as illustrated in Figure II-2c). In this special situation, both government expenditure and tax collection are essentially zero, and nobody benefits from the very small fiscal system: as shown in Figure II-2a and $2 \mathrm{~b}, \mathrm{BFI}=\mathrm{WFI}=0$ when $r>0.5 .^{50}$

\subsection{Shifting}

To define shifting, we require a distinction between longer and shorter horizons. As noted earlier, we assume that in the short run, the child cannot or do not adjust his behavior to incorporate the effect of the subsidy, and still provides home care as if there were no the subsidy program. This implies that in the short run, the child do not respond to the subsidy and thus do not benefit from the subsidy directly. This is an assumption that is analogous to one of a fixed capital stock in the short run analysis of the incidence of a corporate income tax on factors of production.

\footnotetext{
${ }^{49}$ Even when $r$ is not zero but very low, the child buys essentially no more than when $r=0$. This is because the child makes a trade-off between giving money to the parent to gain a warm-glow and using the money on his own consumption. When the degree of altruism is very low, the income effect dominates the warmglow effect and the child chooses not to give any money at all.

${ }^{50}$ As can be seen in Figure II-2, $m$ is highly correlated with $\mathrm{WFI}_{\mathrm{c}}{ }^{\mathrm{LR}}$ and " $1 / m^{\prime \prime}$ is highly correlated with $\mathrm{WFI}_{\mathrm{p}}^{\mathrm{LR}}$. The reasoning is that, $m$ determines size of government subsidy which is important for welfare of both the generations.
} 
In the short run, the parent's problem is the same as in the long run:

$$
\begin{gathered}
\operatorname{Max} U\left(x_{p}, H=m+s, h\right)=a \log \left(x_{p}\right)+b \log (m+s)+c \log (h), \\
\text { subject to } y(1-t)=x_{p}+q\left(1-t_{s}\right) m .
\end{gathered}
$$

The child now maximizes his utility function as if his parent was not subsidized. The parent's budget constraint is regarded as $\mathrm{y}(1-t)=x_{p}+q m$, instead of $\mathrm{y}(1-t)=x_{p}+q\left(1-t_{s}\right) m$.

The child's problem in the short run is:

$\operatorname{Max} U\left(x_{c}, l, x_{p}, m, h, s\right)=[(1-d) \log [w(T-h-l)(1-t)-q s]+d \log (l)]+r U_{p}\left(x_{p}, m, h, s\right)$,

$$
\text { where } x_{p}=y(1-t)-q m \text {. }
$$

Repeating the first four conceptual steps outlined earlier, we then obtain the budgetary incidence indexes of the parent and the child in the short run as:

$$
B F I_{p}^{S R}=\frac{N B_{p}}{Y_{p}}=\frac{t_{s} q m^{S R}-t^{\mathrm{SR}} y}{Y_{p}^{\text {poss - fssc }}},
$$

where, $Y_{p}{ }^{\text {post-fisc }}=y_{p}\left(1-t^{S R}\right)+t_{s} q m^{S R}$

$$
\begin{gathered}
\text { and } \\
B F I_{c}^{S R}=\frac{N B_{c}}{Y_{c}}=\frac{-t^{S R} Y_{c}}{Y_{c}^{\text {pou }-f_{\text {sic }}}},
\end{gathered}
$$

where, $Y_{c}=w T-(r c+d)(w T+y) /(1+r)$, and $Y_{c}^{\text {post-fisc }}=w T\left(1-t^{S R}\right)-\left(1-t^{S R}\right)(r c+d)(w T+y) /$ $(1+r)$

The welfare incidence index in the short run is: 
$W F I_{p}^{S R}=\frac{\left[y\left(1-t^{S R}\right)+q\left(1-t_{s}\right) s^{S R}\right]-\left(1-t_{s}\right)^{b /(a+b)}\left[y+q s^{S R}\right]}{Y_{p}^{\text {pass }-f_{s c}}}$

and

$W F I_{c}^{S R}=\frac{(w T+y)\left(1-t^{S R}\right)-\left(1-t_{s}\right)^{r b} \times\left\{\frac{\left[y\left(1-t^{S R}\right)+q s^{S R}\right]}{\left[y\left(1-t^{S R}\right)+q\left(1-t_{s}\right) s^{S R}\right]}\right\}^{r(a+b)} \times\left[(w T+y)\left(1-t^{S R}\right)+t^{S R} * Y_{c}\right]}{Y_{c}^{\text {post-fise }}}$

where $_{s}{ }^{S R}=\frac{w T\left(1-t^{S R}\right)}{q}-\frac{(1+r c)(w T+y)\left(1-t^{S R}\right)}{(1+r) q}$, and

$m^{S R}=\frac{b y\left(1-t^{S R}\right)}{(a+b) q\left(1-t_{s}\right)}-\frac{a s^{S R}}{(\mathrm{a}+b)}=\frac{b y\left(1-t^{S R}\right)}{(a+b) q\left(1-t_{s}\right)}-\frac{a}{(a+b)} \frac{w T\left(1-t^{S R}\right)}{q}+\frac{a}{(a+b)} \frac{(1+r c)(w T+y)\left(1-t^{S R}\right)}{(1+r) q}$

The formulas of the incidence in the short and longer run show that shifting depends importantly on the income of the parent, $y$, the potential and actual gross income of the child, $w T$ and $Y_{c}$, the degree of altruism, $r$, the parent's taste coefficients, and the policy parameters, $t^{L R}, t^{S R}$ and $t_{s}$.

Figure II-3a and Figure II-3b illustrate shifting of net benefits in terms of welfare for different degrees of altruism (Budgetary shifting is considered below). We see that both the generations are worse off in the longer run compared with the short run, except in some special cases: when $r=0, r=0.1$, or $r>0.5$. This is another outcome of the behavioural adjustments of the child. It is important to keep in mind that the sum of the EVs (and thus the sum of WFIs) need not be zero. It is possible that both the parent and the child gain or lose in terms of welfare, depending on the nature of the family.

As shown by Figure II-3, at a low degree of altruism - for example, at $r=0.1$ - the parent 
are worse off while the child are better off in the longer run, implying a shifting of net benefits from the parent to the child. The gain for the child may not necessarily be equal to the loss for the parent in welfare terms. This shifting is due to the child's ability to respond to the subsidy through a reduced contribution of formal care.

In a family with child who are altruistic, with $r>0.1$, the welfare-based incidence for the child is basically neutral across horizons, the parent faces a worse situation in the longer run, and no shifting of net benefits across generations is observed. The reason is that the child now substitutes the parent's purchase of formal care with his own contributions, which is not efficient in terms of the allocation of family resources. ${ }^{51}$

Figure II-3 Shifting of Program Benefits Using Welfare Indexes
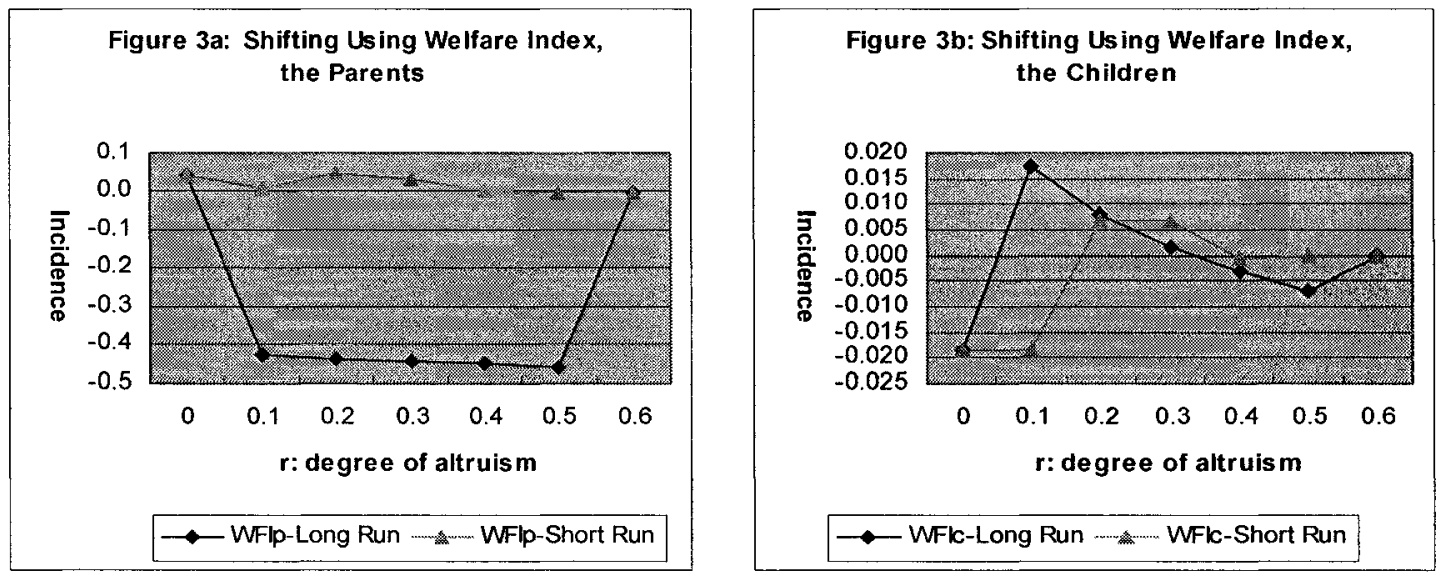

Shifting of net benefits in budgetary terms when different degrees of altruism are assumed is recorded in Figure II-4.

\footnotetext{
${ }^{51}$ When the purchase of the parent is cheaper than that of the child, it is advantageous for the family if the child gives money to his parent and let him purchase all the formal care. This is exactly what a cooperative family does.
} 
Figure II-4 Shifting of Program Benefits Using Budgetary Indexes
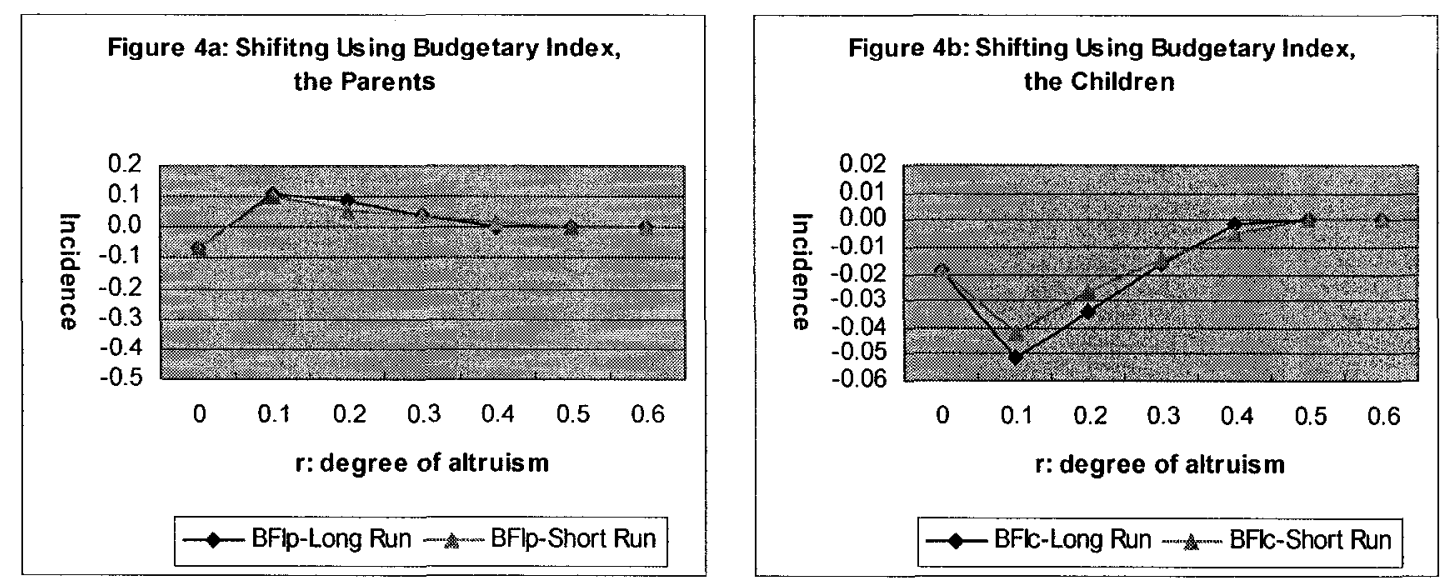

In contrast to shifting measured using individual welfare, not much shifting is observed when it is calculated using budgetary amounts. This is as expected, since behavioural adjustments play a smaller role in the calculations of net incidence when the budget instead of welfare is used as a metric. However, BFI still does depend on the degree of altruism, as shown in Figure II-4.

\section{A Cooperative Family, and Simulation of Incidence Indexes for}

\section{Both Family Types}

Under different behavioural assumptions, the distribution of the benefits from an expenditure policy would also be different, just as different assumptions about model structure lead to alternative conclusions about the burden of taxation. Assume, for example, that the family in question is cooperative instead of non - cooperative so that the parent and the child jointly make a decision which benefits the family as an entity.

Browning and Chiappori (1998) argue that one can use a "collective model" to 
approximate the outcome of cooperative bargaining. Apps and Rees (2007) also propose a generalized household welfare function, based on Samuelson's idea that households can be modeled as if they maximized a form of social welfare function. We shall assume then that a bargaining weights $B$ and $(1-B), 0<B<1$, are put on the parent and the child respectively in the family welfare function and regard the problem faced by the parent and the child when they are cooperative as:

$\left.\operatorname{Max}\left[B U_{p}+(1-B) U_{c}\right]=B\left[a \log \left(x_{p}\right)+b \log (m+s)+c \log (h)\right]+(1-B)\left[(1-d) \log \left(x_{c}\right)+d \log (l)\right]\right]$ $\left(x_{p}, x_{c}, m, h\right)$

subject to the joint budget constraint $y(l-t)+w(T-h-l)(l-t)=q\left(1-t_{s}\right)(m+s)+x_{p}+x_{c}$. As indicated by the joint budget constraint, the family pools their resources and jointly purchases market care at the subsidized rate. The solutions to the cooperative game (C) include

$$
\begin{aligned}
& H^{C}=\left(m^{C}+s^{C}\right)=B b(w T+y)\left(1-t^{C}\right) /\left[q\left(1-t_{s}\right)\right] \\
& h^{C}=B c(w T+y) / w \\
& t^{C}=(1-B) d(w T+y) / w \\
& Y_{c}^{C}=w T\left(1-t^{C}\right)-[B c+(1-B) d](w T+y)\left(1-t^{C}\right) \\
& x_{p}{ }^{C}=B a(w T+y)\left(1-t^{C}\right) \\
& x_{c}{ }^{C}=(1-B)(1-d)(w T+y)\left(1-t^{C}\right)
\end{aligned}
$$

Because the parent's purchase of formal care is cheaper than that of the child, the child does not purchase any formal care directly but transfers some money to pay for part of the formal care. Using individual budget constraints, we derive the family member's share of purchase of market care for later use. 
The budget constraint of the child is $x_{c}^{C}+\left[q\left(1-t_{s}\right)\right] s^{C}=Y_{c}^{C}\left(1-t^{C}\right)$, so $s^{C}=\{w T-[B c+(1-$ $B)](w T+y)\}\left(1-t^{C}\right) /\left[q\left(1-t_{s}\right)\right]$. The budget constraint of the parent is $x_{p}{ }^{C}+\left[q\left(1-t_{s}\right)\right] m^{C}=y$ $\left(1-t^{C}\right)$, so $m^{C}=[y-B a(w T+y)]\left(1-t^{C}\right) /\left[q\left(1-t_{s}\right)\right]$.

The equilibrium tax rate is defined by the balanced government budget:

$$
t_{s} q\left(m^{C}+s^{C}\right)=t^{C}\left(Y_{c}^{C}+y\right) \rightarrow t^{C}=\left[B b^{*} t_{s}\left(1-t_{s}\right)\right] /\left\{\left[B b^{*} t_{s} /\left(1-t_{s}\right)\right]+1-B c-(1-B) d\right\}
$$

When the family collectively makes choices, the family members adjust to the subsidy program simultaneously. Thus there is no difference between short and longer horizons based on the ability to incorporate the subsidy into the child's decision making, and there is no cross-generational shifting when the family acts as a unit. Following the steps outlined above, we then have the following budgetary incidence indexes for a cooperative family, assuming that calculation of separate benefits for each generation still makes sense in this context. In the calculation of BFIs, if we apply a rule of allocating benefits in proportion to contributions, the child and the parent share the benefit according to their share of market care purchased. This is so over both horizons:

$$
\begin{gathered}
B F I_{p}^{C}=\frac{t_{s} q m^{C}-t^{C} y}{Y_{p}^{\text {post-fisc }}}, \\
\text { and } \\
B F I_{c}^{C}=\frac{t_{s} q s^{C}-t^{C} Y_{c}^{C}}{Y_{c}^{\text {post }- \text { fisc }}} .
\end{gathered}
$$

In contrast, using welfare as a metric we have: 


$$
W F I_{p}^{C}=\frac{\left[w T\left(1-t^{C}\right)+y\left(1-t^{C}\right)\right]-\left(1-t_{s}\right)^{b}\left[w T\left(1-t^{C}\right)+y\left(1-t^{C}\right)+t^{C} y\right]}{Y_{p}^{\text {post }- \text { fisc }}},
$$

and

$$
W F I_{c}^{C}=\frac{\left[w T\left(1-t^{C}\right)+y\left(1-t^{C}\right)\right]-\left(1-t_{s}\right)^{[r b /(1+r)]}\left[w T\left(1-t^{C}\right)++t^{C} Y_{c}^{C}+y\left(1-t^{C}\right)\right]}{Y_{c}^{\text {post-fisc }}},
$$

where

$$
\begin{aligned}
& H^{C=}\left(1-t^{C}\right) B b(w T+y) /\left[q\left(1-t_{s}\right)\right] \\
& s^{C}=\left(1-t^{C}\right)^{*}\{w T-[B c+(1-B)](w T+y)\} /\left[q\left(1-t_{s}\right)\right] \\
& m^{C}=\left(1-t^{C}\right)^{*}[y-B a(w T+y)] /\left[q\left(1-t_{s}\right)\right] . \\
& Y_{p}^{p o s t-f i s c}=y\left(1-t^{C}\right)+t_{s} q m^{C}, \\
& Y_{c}^{C}=w T-[B c+(1-B) d](w T+y), \\
& Y_{i}^{p o s t-f i s c}=Y_{c}^{C}\left(1-t^{C}\right), \\
& t^{C}=\left[B b^{*} t_{s} /\left(1-t_{s}\right)\right] /\left\{\left[B b^{*} t_{s} /\left(1-t_{s}\right)\right]+1-B c-(1-B) d\right\} .
\end{aligned}
$$

Again, the difference between the WFIs in a non-cooperative and a collective family is complex because of the difference in the equilibrium tax rate, and it proves revealing to explore these differences in simulations in what follows. ${ }^{52}$

In the simulations, the parent's weight $B$ and the child's weight (1-B) in the family

\footnotetext{
${ }^{52}$ The incidence indexes in a non-cooperative and a cooperative game look similar. As shown by Anderberg and Balestrino (2003), altruism towards household members makes the non-cooperative game solution less inefficient compared with the solution in a cooperative game. In this example, no matter if the family is cooperative or non-cooperative, the child are taking the wellbeing of his parent into account, though different weights are put on the utility of the parent in each case. However, the equilibrium tax rates are very different in the two cases; for example, when $r=0.3$, the equilibrium tax rate for a non-cooperative family is 0.0209 while the tax rate for a cooperative family is 0.0595 .
} 
welfare function are defined as the ratio of the coefficient of his own utility to the total of the family, $B=(1+r) /(2+r)$, and $1-B=1 /(2+r)$. We do this because we want to study the role of the degree of altruism ${ }^{53}$. When $\mathrm{r}=0, \mathrm{~B}$ is effectively $1 / 2 . \mathrm{B}$ is always equal to or higher than half because of the existence of the child's altruism.

The effects of family structure on welfare based incidence indexes are shown in Figure II-5.

Figure II-5 Net Fiscal Incidence and Family Structure
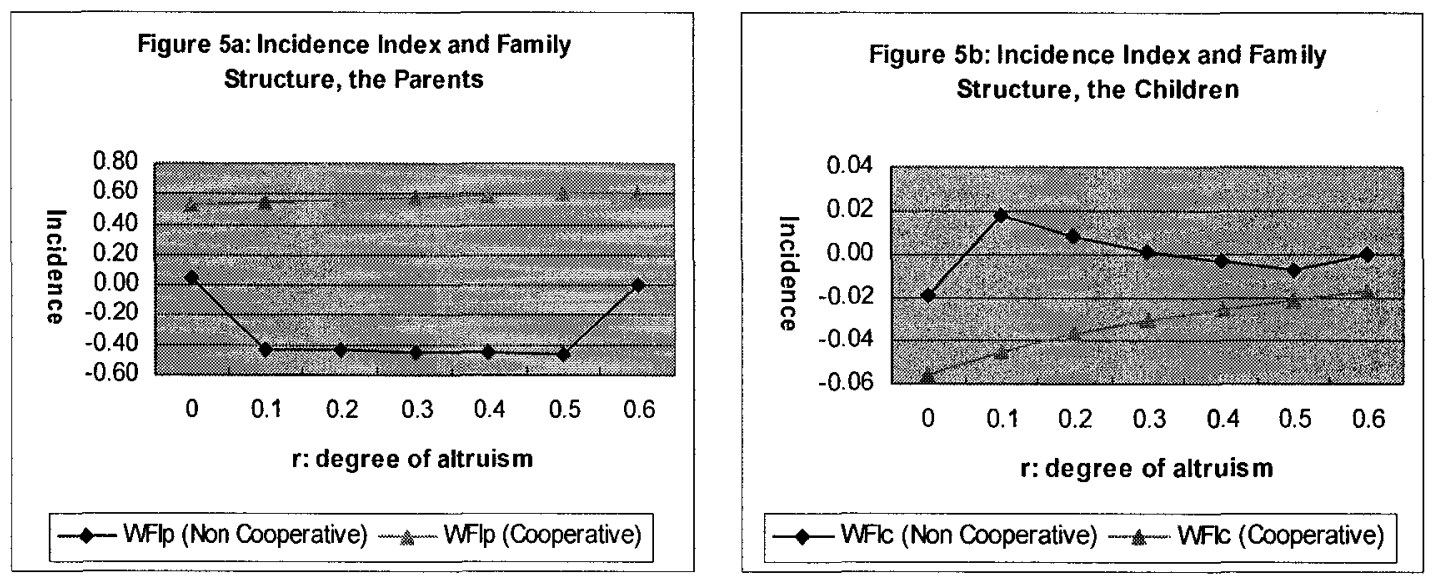

It is clear from these figures that incidences under different family decision structures are not the same. The parent is better off when the family is cooperative rather than noncooperative. In contrast, the child is usually worse off when the family is cooperative. The intuition for this pattern is that a higher weight on the parent in a cooperative family, $(1+r) /(2+r)$ rather than $r /(1+r)$, induces a greater total formal care purchase, while the

\footnotetext{
${ }^{53}$ The weights of individual utility in Browning and Chiaporri (1998)'s collective model depend on wage rates and total household income (Apps and Rees, 2007), though Pollak (2005) suggests that bargaining power in a family depends on three components: exogenous non-labor income, wage rates or earnings, and productivity in household production.
} 
liability of financing the subsidy of formal care is mostly born by the child through adjustment of his work hours under a higher tax rate.

\section{Concluding Remarks}

While some recent work has analyzed the optimal structure of public policies for longterm care of the elderly, there is very little work on the distributional impact of such programs. In this paper, we investigate analytically and with simulation the measurement of the net fiscal incidence of a policy that subsidizes home care, when both individual welfare and family structure matter.

We began with a short overview of the analytical steps required in any incidence study when welfare matters. The existing literature is enormously diverse, and we hope that this review will be useful in aiding those who wish to pursue analytical or empirical net incidence work. The five basic steps we outlined have been applied to consider the grammar of the welfare incidence of a price subsidy for the home care of elderly parents when children are altruistic.

We have used both analytical derivation and simulations to explore the effects on incidence of changes in the structure of the family, in a manner analogous to studies that explore the role of assumptions about economic structure in determining tax shifting. It turns out that welfare and budgetary incidence are identical only for the child, and then only when there is no altruism (or interaction between the parent and the child). WFI and BFI indexes are always different for the parent over both short and long run horizons in the both types of families, with the pattern of differences between incidence indexes, and 
the degree of net benefit shifting, each depending importantly on the degree of altruism of the child.

We have not been able to find a short hand method of calculating welfare indexes for the expenditure program considered using budgetary amounts except for one group (children) in a very special situation. The message here for policy makers and analysts seems clear: incidence analysis based on budgetary amounts in general will most likely be a poor predictor of the distribution of benefits from a program that works through family structure.

The analysis in this paper also conveys a general message for the study of net fiscal incidence: to incorporate the expenditure side of the budget into incidence calculations, a separate analysis for each major type of public service will have to be developed. Such work will parallel the development of tax incidence theory, which has been built up over time on the basis of study of each of the major types of taxes. This paper is an initial contribution to this body of work for the class of public expenditure programs that depend importantly on family structure. Much remains to be done before net incidence analysis of expenditure programs attains the status achieved by the incidence analysis of taxation. 


\section{References}

Aaron, Henry and Martin McGuire (Nov., 1970) "Public Goods and Income Distribution" Econometrica, Vol. 38, No. 6, pp. 907-920.

Anderberg, Dan and Alessandro Balestrino (2003) "Public Spending with Noncooperative Families", in "Taxation and the Family", edited by Alessandro Cigno, Pierre Pestieau, and Ray Rees, CESifo Economic Studies, MIT Press.

Atkinson, A. B. and Joseph E. Stiglitz (1980) "Lectures on Public Economics", McGrawHill Education.

Apps, Patricia and Ray Rees (2007) "Household Models: An Historical Perspective", CESifo Working Paper No. 2172.

Auerbach, J. Alan and Laurence J. Kotlikoff (1987) "Dynamic Fiscal Policy", Cambridge University Press.

Auerbach, J. Alan and Laurence J. Kotlikoff (1999) "The Methodology of Generational Accounting", in Generational Accounting Around the World, edited by Auerbach, J. Alan, Laurence J. Kotlikoff, and Willi Leibfritz, Chicago: the University of Chicago Press.

Balestrino, Alessandro (2004) "Revisiting the Equity-Efficiency Trade-off: Taxation with Noncooperative Families" FinanzArchiv Vol. 60, No. 4, pp. 515-531.

Baum, S. R. (1987) "On the Measurement of Tax Progressivity: Relative Share Adjustment" Public Finance Quarterly 15, pp. 166-187.

Brennan, Geoffrey (1976)"Public Goods and Income Distribution: A Rejoinder to the Aaron-McGuire Reply "Econometrica Vol. 44, No. 2, pp. 405-407.

Browning, Edgar K. (1985) "Tax Incidence, Indirect Taxes, and Transfers" National Tax Journal Vol. 38, No. 4, pp. 525-33.

Browning, Edgar K. and William R. Johnson (1979) "The Distribution of the Tax Burden", 
Washington D. C.: American Enterprise Institute for Public Policy Research

Browning, Edgar K. (1978) "The Burden of Taxation" Journal of Political Econom 86, pp. 649-671.

Browning, M. and P. A. Chiappori (1998) "Efficient Intra-household Allocation: a

Characterization and Tests" Econometrica Vol. 66, No. 6, pp. 1241-1278.

Chamberlain, Andrew and Gerald Prante (2007) "Who Pays Taxes and Who Receives Government Spending? An Analysis of Federal, State and Local Tax and Spending Distributions, 1991-2004" Tax Foundation Working Paper No. 1.

Dyck, Dagmar. (2005) "Fiscal Redistribution in Canada, 1994-2000"Canadian Tax Journal Vol. 53, No. 4, pp. 974-1006.

Gillespie, W. Irwin (1964) "The Incidence of Taxes and Public Expenditure in the Canadian Economy", Studies of the Royal Commission on Taxation, No. 2, Ottawa: Queen's Printer.

Gillespie, W. Irwin (1980) The redistribution of income in Canada, Ottawa: Gage Publishing Limited in association with the Institute of Canadian Studies, Carleton University.

Harberger, Arnold C. (1962)"The Corporation Income Tax" The Journal of Political Economy Vol. 70, No. 3, pp. 215-240.

Hollander, M. and N. Chappell. (2002) "Final Report of the National Evaluation of the Cost-Effectiveness of Home Care: Synthesis Report", available at www.homecarestudy.ca. Huber, Manfred (2005) "OECD health project: Long-term care for older people", OECD. Just, Richard E., Darrell L. Hueth, and Andrew Schmitz (2004) "The Welfare Economics of Public Policy: A Practical Approach to Project and Policy Evaluation", Northampton, MA: Edward Elgar. 
Kakwani, Nanak C. (1977) "Measurement of Tax Progressivity: An International Comparison", Economic Journal, 87, pp. 71-80.

Kakwani, Nanak C. (1984) "On the Measurement of Tax Progressivity and Redistributive Effect of Taxes with Applications to Horizontal and Vertical Equity", Advances in Econometrics 3, pp. 149-168.

Kesselman, Jonathan R. and Ron Cheung (2004) "Tax Incidence, Progressivity, and Inequality in Canada" Canadian Tax Journal Vol. 52, No. 3, pp. 709-789.

Kim, Kinam and Peter J. Lambert (2009) "Redistributive Effect of U.S. Taxes and Public Transfers, 1994-2004" Public Finance Review Vol. 37, No. 1, pp. 3-26.

Knoef, Marike, Peter Kooreman, and Matthijs Kalmijn (2007) "Aging Parent, Long-Term Care, and the Family" IZA-workshop on Long-Term Care.

Maital, Shlomo (1973) "Public Goods and Income Distribution: Some Further Results" Econometrica Vol. 41, No. 3, pp. 561-568.

Martinez-Vazquez, Jorge (1982)"Fiscal Incidence at the Local Level" Econometrica Vol. 50, No. 5, pp. 1207-1218.

Martinez-Vazquez, Jorge (2001) "The Impact of Budgets on the Poor: Tax and Benefit", International Studies Program Working Paper Series at International Studies Program, Andrew Young School of Policy Studies, Georgia State University.

Mas-Colell, Andreu, Michael D. Whinston, and Jerry R. Green (1995) "Microeconomic Theory", Oxford University Press.

Meerman, Jacob (1980) "The Incidence of Sales and Excise Taxes, or Where Do We Put the Transfers?" The Journal of Political Economy, Vol. 88, No. 6, pp. 1242-1248.

Musgrave, Richard A. and Peggy B. Musgrave (1980) "Public Finance in Theory and Practice" third edition, New York: McGraw-Hill. 
Okner, A. Benjamin and Joseph A. Pechman (1974) "Who Bears the Tax Burden?", Washington: Brookings Institution.

Pechman, A. Joseph (1985) "Who Paid the Taxes, 1966-1985", Washington: Brookings Institution.

Pestieau, Pierre and Motohiro Sato (2004) "Long Term Care: The State, the Market and the Family" CORE Discussion Paper No. 82.

Pezzin, Liliana E., Robert A. Pollak, and Barbara S. Schone (2006) "Efficiency in Family Bargaining: Living Arrangements and Care giving Decisions of Adult Child and Disabled Elderly Parent" NBER Working Paper No.12358.

Piggott, John and John Whalley (1987) "Interpreting Net Fiscal Incidence Calculations" The Review of Economics and Statistics Vol. 69, No. 4, pp. 685-694.

Pollak, Robert A (2005) "Family Bargaining and Taxes: A prolegomenon to the Analysis of Joint Taxation", in Taxation and the Family, edited by Alessandro Cigno, Pierre Pestieau, and Ray Rees, MIT Press.

Ruggeri, Giuseppe C. (2003) "Public Expenditure Incidence Analysis", in Bringing Civility in Governance, Vol. 3 of Handbook on Public Sector Performance Reviews, edited by Anwar Shah, Washington D. C.: The World Bank.

Ruggeri, Giuseppe C., D. Van Wart, and R. Howard (1996) "The Government as Robin Hood: Exploring the Myth", Co-published by the School of Policy Studies at Queens University and the Caledon Institute of Social Policy.

Rosen, Harvey S. (2001) "Public Finance", McGraw-Hill/Irwin, 6th edition.

Shoup, Carl S. (1988) "Distribution of Benefits from Government Services: Horizontal Equity" Public Finance Vol. 43, No. 1, pp. 1-18.

Suits, B. Daniel (1977) "Measurement of Tax Progressivity" The American Economic Review Vol. 67, No. 4, pp. 747-752. 
Vermaeten, Arndt (1997) "Expenditure Incidence: Conceptual and Methodological Issues?", unpublished manuscript.

Vermaeten, Arndt, W. Irwin Gillespie, and Frank Vermaeten (1995) "Who Paid the Taxes in Canada, 1951-1988?" Canadian Public Policy Vol. 21, No. 3, pp. 317-343.

Zodrow, George R. (2005) "Tax Incidence", in Encyclopedia of Taxation and Tax Policy, 2nd Edition, edited by Joseph Cordes, Robert Ebel, and Jane Gravelle, Urban Institute and National Tax Association, pp. 186-190. 


\section{$7 \quad$ Appendix}

\subsection{The cost-saving method of calculating budgetary fiscal incidence}

Table II-1 illustrates the cost-saving method of calculating BFI referred to in the main text.

\section{Table II-1 The Cost-Saving Measurement of Budgetary Fiscal Incidence}

\begin{tabular}{|l|l|l|l|l|l|l|l|}
\hline $\mathbf{r}$ & $\mathbf{0}$ & $\mathbf{0 . 1}$ & $\mathbf{0 . 2}$ & $\mathbf{0 . 3}$ & $\mathbf{0 . 4}$ & $\mathbf{0 . 5}$ & $\mathbf{0 . 6}$ \\
\hline $\mathrm{m}^{1}$ & 1.47 & 3.19 & 1.91 & 0.80 & 0.00 & 0.00 & 0.00 \\
\hline $\mathrm{m}^{0}$ & 1.84 & 3.72 & 2.17 & 1.41 & 0.47 & 0.00 & 0.00 \\
\hline $\mathrm{m}^{*}$ & 1.84 & 4.38 & 3.12 & 2.02 & 1.06 & 0.21 & 0.00 \\
\hline $\mathrm{m}^{0}-\mathrm{m}^{1}$ & 0.37 & 0.53 & 0.26 & 0.61 & 0.47 & 0.00 & 0.00 \\
\hline $\mathrm{m}^{*}-\mathrm{m}^{\prime}$ & 0.37 & 1.19 & 1.21 & 1.22 & 1.06 & 0.21 & 0.00 \\
\hline $\mathrm{m}^{0}-\mathrm{m}^{*}$ & 0.00 & -0.66 & -0.95 & -0.61 & -0.59 & -0.21 & 0.00 \\
\hline $\mathrm{t}^{\mathrm{LR}}$ & 0.0184 & 0.0490 & 0.0330 & 0.0209 & 0.0106 & 0.0020 & 0.00 \\
\hline $\mathrm{y}$ & 50.00 & 50.00 & 50.00 & 50.00 & 50.00 & 50.00 & 50.00 \\
\hline $\mathrm{Y}_{\mathrm{c}}$ & 150.00 & 128.64 & 136.88 & 143.85 & 149.82 & 155.00 & 164.38 \\
\hline $\mathrm{Y}_{\mathrm{p}}^{\text {post-fisc }}$ & 52.76 & 56.30 & 54.57 & 53.00 & 51.59 & 50.31 & 50.00 \\
\hline $\mathrm{Y}_{\mathrm{c}}^{\mathrm{post}-\text { fisc }}$ & 147.24 & 122.33 & 132.30 & 140.84 & 148.23 & 154.69 & 164.38 \\
\hline $\mathrm{BFI}_{\mathrm{p}}$ & 0.0523 & 0.3037 & 0.5118 & 0.1336 & 0.0831 & N.A. & N.A. \\
\hline $\mathrm{BFI}_{\mathrm{c}}$ & -0.0187 & -0.1398 & -0.2105 & -0.0503 & N.A. & N.A. & N.A. \\
\hline
\end{tabular}

Figure II-6 shows the incidence indexes as the degree of altruism varies from 0 to 0.6 .

Figure II-6 Fiscal Incidence Index Based on the Cost-saving Measurement
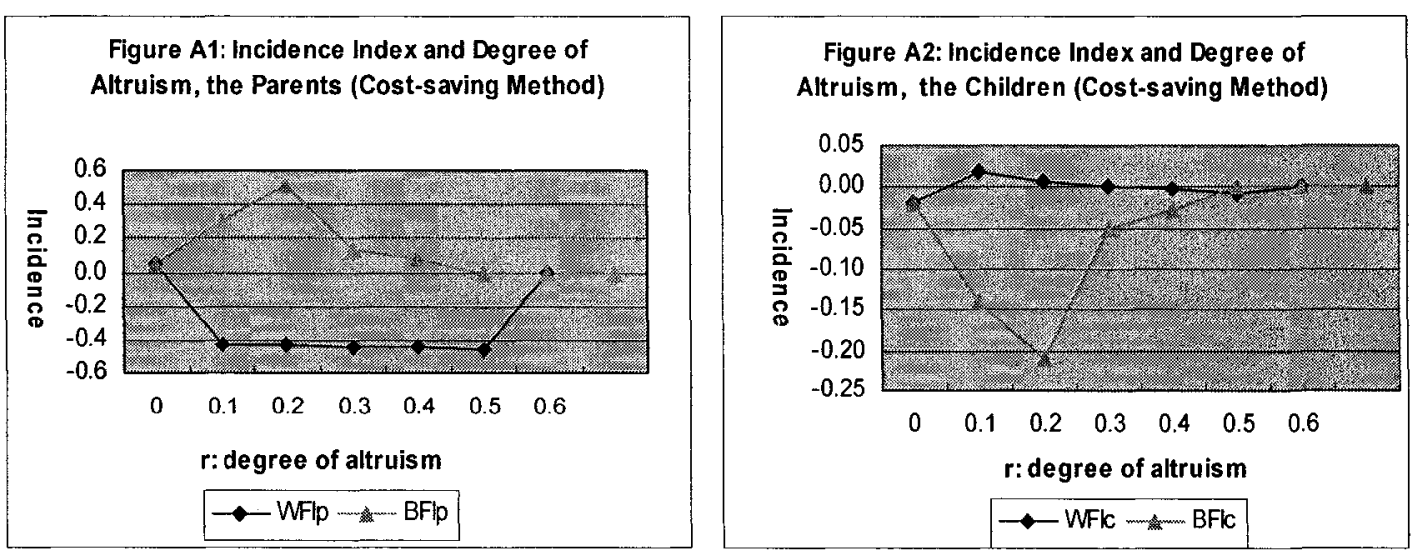

As indicated by Figure II-6, when the cost-saving method is used to calculate BFI, it is 89 
still inconsistent with WFI. The difference between WFI and BFI does not appear smaller than it is when a traditional definition of BFI is used.

\subsection{Differences between BFI and WFI over long and short horizons}

The differences between BFI and WFI for a non-cooperative family in the long run are:

$B F I_{p}^{L R}-W F I_{p}^{L R}=\frac{t_{s} q m^{L R} \times m^{L R} /\left(m^{L R}+s^{L R}\right)-t^{L R} y-\left[w T\left(1-t^{L R}\right)\left(1-t_{s}\right)+y\left(1-t^{L R}\right)\right]+\left(1-t_{s}\right)^{(b+c)}\left[w T\left(1-t^{L R}\right)+y\left(1-t^{L R}\right)+t^{L R} y\right]}{Y_{p}^{p o s t-f i s c}}$ and

$B F I_{c}^{L R}-W F I_{c}^{L R}=\frac{t_{s} q m^{L R} \times s^{L R} /\left(m^{L R}+s^{L R}\right)-t^{L R} Y_{c}-\left[w T\left(1-t^{L R}\right)+y\left(1-t^{L R}\right) /\left(1-t_{s}\right)\right]+\left(1-t_{s}\right)^{[-r a /(1+r)]}\left[w T\left(1-t^{L R}\right)+t Y_{c}+y\left(1-t^{L R}\right)\right]}{Y_{c}^{p o s i-f i s c}}$ where,

$m^{L R}=\left[y\left(1-t^{L R}\right) /\left[q\left(1-t_{s}\right)\right]-r a\left(1-t^{L R}\right)\left[w T+y /\left(1-t_{s}\right)\right] /[(1+r) q]\right.$

$s^{L R}=r(a+b)\left(1-t^{L R}\right)\left[w T+y /\left(1-t_{s}\right)\right] /[(1+r) q]-y\left(1-t^{L R}\right) /\left[q\left(1-t_{s}\right)\right]$, and

$m^{L R}+s^{L R}=r b\left(1-t^{L R}\right)\left[w T+y /\left(1-t_{s}\right)\right] /[(1+r) q]$.

The differences between WFI and BFI in the short run are

$B F I_{p}^{S R}-W F I_{p}^{S R}=\frac{\left[\left(1-t_{s}\right)^{b /(a+b)}+t_{s} \frac{b}{(a+b)}-1\right]^{*} q s^{S R}+\left[\frac{t_{s}}{\left(1-t_{s}\right)} \frac{b}{(a+b)}\left(1-t^{S R}\right)+\left(1-t_{s}\right)^{b /(a+b)}-1\right]^{*} y_{p}}{Y_{p}^{\text {poss-fisc }}}$,

and

$B F I_{c}^{S R}-W F I_{c}^{S R}=\frac{-t^{S R} * Y_{c}-t\left(w T+y_{p}\right)\left(1-t^{S R}\right)+\left(1-t_{s}\right)^{r b} *\left\{\frac{\left[y_{p}\left(1-t^{S R}\right)+q s^{S R}\right]}{\left[y_{p}\left(1-t^{S R}\right)+q\left(1-t_{s}\right) s^{S R}\right]}\right\}^{r(a+b) *\left[(w T+y)\left(1-t^{S R}\right)+t^{S R} * Y_{c}\right]}}{Y_{c}^{\text {post-fssc }}}$ where, $s^{S R}=\frac{w T\left(1-t^{S R}\right)}{q}-\frac{(1+r c)(w T+y)\left(1-t^{S R}\right)}{(1+r) q}$. 


\title{
PART III
}

\section{The Public-Private Mix in Health Care Expenditure in OECD Countries: An Empirical Investigation}

\begin{abstract}
This study investigates the determinants of the public-private mix in health care expenditure in OECD countries over the 1981 - 2005 period. Estimating equations are based on an extension of Usher (1977)'s model of the collective decision to socialize private goods. In the framework we develop, the extent of public health care is a result of the interplay of the incentive to redistribute through the fiscal system (which tends to increase public expenditure on health care) and the losses some citizens in a diverse society experience when a private good is socialized (which leads to reduced public expenditure). In addition, we allow for the fact that government policies towards the health care market change the boundary between public and private care by altering the relative price of private care. We also allow for the general role played by ideological views of voters about public versus private health expenditure.
\end{abstract}

The estimation results verify Usher's theory concerning the roles of incentives to redistribute and the losses from socialization of health care when preferences are diverse. In addition, we find that the general right-left ideological views of citizens play an important role in defining the boundary between public care and private care. Finally, the results indicate that population aging is likely to lead to increased spending on the public health care system rather than to greater relative reliance on private care. 


\section{Introduction}

Aging populations coupled with and the rising cost of medical technologies are changing health care systems in many developed countries. Some countries like Canada are considering allowing more private practice, while in the United States extending public coverage to a larger group of citizens is at the center of debate. What determines the mix of public and private expenditure in OECD countries during 1981-2005? In this paper we investigate this question using a political economy framework. The basic framework employed is based on the work of Usher (1977).

Following Newhouse (1977), there have been many cross-country surveys of health care systems in OECD countries. These include Sanz and Velázquez (2007) on the relationship between aging and social welfare spending, Dreger and Reimers (2005) and Atella and Marini (2006) on the elasticity of health expenditures with respect to GDP, and Shelton (2007) and Gerdtham et al. (1992) on the determinants of health care expenditure in general. More recently, the growth in private care sector has led scholars to study the role of private health insurance; for example, Pearson and Martin (2005), Colombo and Tapay (2004), and Lundsgaard (2002).

Only a few papers have investigated the determinants of the public-private mix of expenditure. Usher (1977) modeled the decision to socialize a commodity in a majority voting setting. He predicted that this decision depends positively on inequality in incomes and negatively on diversity in tastes for the commodity. Besley and Gouveia (1994) applied Usher's theory to health care using OECD data. Wilson and Katz (1983) extended 
Usher's model by considering in greater detail the roles of the elasticity of the demand for the commodity to be socialized, the skewness of the income distribution, and the progressivity of the tax system,. Wilson (1985) applied Usher's model to spending of provincial governments in Canada, confirming that the incentive to redistribute income (measured by the ratio of mean to median income) is an important determinant of the decision to socialize medical services in Canada. Finally, Globerman and Vining (1998) analyzed the relationship between public care and private care by attempting to test whether private financing erodes public support for government health expenditure.

This study of the public-private health care mix begins by informally extending Usher's model to include private alternatives in the collective decision concerning public health expenditure, and then empirically tests the resulting model. Public care and private care are assumed to coexist, and we model the boundary between public care and private care as a political equilibrium in which citizens' demands for public and private care are reflected in public health decisions. Through the political process, the scale of public health provision and government policies towards the private care market are determined simultaneously.

This paper is organized as follows. Section 2 discusses the theory underlying our estimating equations. Section 3 reviews the debates concerning the appropriate methodologies for conducting comparative research using panel data from a wide variety of developed countries. Section 4 describes the data set we use in our estimation and discusses our estimation strategy. Section 5 presents the estimation results and sensitivity tests. Section 6 concludes. 


\section{The Analytical Framework}

\subsection{The Theory}

In a seminal paper, Usher (1977) argues that the decision concerning socialized a commodity depends on a political balancing of interests among voters with different incomes and tastes for medical service. If wealth is unequally distributed across voters, the government has an incentive to redistribute from the rich to the poor through the provision of goods and services funded by progressive taxation. As a result, countries where incentives to redistribute are greater, that is, where there is greater inequality in incomes, should have a larger public sector. Since health care is always an important component of the public sector, we should also expect that public expenditure on health care will be larger. On the other hand, heterogeneity in voters' tastes for services, including medical services, makes any public service expenditure plan harder to agree on. So, given the incentives to redistribute, socialization of medical services is more likely to happen when citizens exhibit relatively homogenous preferences for public care.

According to Usher (1977), and for the reasons indicated above, these two factors income inequality and homogeneity of tastes - work in opposite direction to shape the collective decision about the socialization of medical services. Besley and Gouveia (1994) conducted a rough test of Usher's model applied to health care using OECD data for 1980. A measure of income tax progressivity and a measure of demographic diversity are used to represent the two factors driving decisions on public health expenditure. They find that both the motives work in the right direction, though neither is statistically significant. 
In this study, we will investigate the determinants of public-private mix of health expenditures following the logic of Usher (1977), but with some important extensions. First, we shall take into account that fact that in most developed countries, private care and public care coexist. On average, private health expenditure was $26.8 \%$ of total health expenditure in OECD countries in 2005 , with the highest share of $54.9 \%$ in the United States and the lowest share of $9.8 \%$ in Luxemburg. Accordingly we modify Usher's model to include a private alternative in citizens' demands for health care. This modification is of particular interest as the populations of developed countries age, because we might expect that more seniors will seek care in private markets as public systems come under increasing pressure.

Our second modification of Usher's model is to allow for the fact that public policy choices concerning the private care market and public health expenditure are simultaneously determined in a political equilibrium ${ }^{54}$. Here public health expenditures are not a passive response to a government's tax or regulation policies concerning private care, or vice versa. Instead, we think of government policies as jointly-determined instruments that a government chooses to maximize political support. Politicians are able to garner more votes through carefully-designed complex policies compared with onedimensional ones.

The simultaneity of policy choices inevitably leads to endogeneity problems in the estimation we conduct later, a problem that will be addressed by using instrumental

\footnotetext{
${ }^{54}$ OECD (2004) discusses the interdependence between public health care, government regulation on the private insurance market, and tax incentives for private insurance. The focus of the OECD study is equity and efficiency, not the study of political equilibrium.
} 
variables. It should be noted that, because of the difficulties in dealing with endogenous variables, the endogeneity problem is often ignored and sometimes even not acknowledged in the literature. In this paper, we do not want to ignore the problem even if, as we shall see, it is difficult to deal with.

Third, we think that health care policies are also shaped by the ideological position of the electorate. For example, Nordic countries have a long tradition of government involvement in welfare programs while the citizens in the United States hold a strong antipathy towards the socialization of any private good. The right-left ideological positioning of voters varies widely across OECD countries, and influences the size of the fiscal system ${ }^{55}$. Accordingly, we will study the role of ideological positioning of voters in the decisions concerning the health care market using the recently available Manifesto data provided by Budge et al. (2001) and Klingemann et al. (2006).

We shall include a right-left ideology index directly in our estimation equations. Other aspects of ideological positioning will serve as instrumental variables for endogenous policy instruments in a manner to be discussed in detail below in Section 4 .

Finally, we refine Usher's model further by including a simple medical service production function into the explanation of public health expenditures. We introduce a number of supply side factors including the total number of doctors, the number of hospital beds,

\footnotetext{
${ }^{55}$ From 1950 to 1995 , the average left-right ideological positioning of median voters in OECD countries is -5.69 , with a standard deviation of 12.96. Among the OECD countries, Norway led a left-wing attitude of 23.33 while the United States has the most "right-wing" ideological positioning of 10.10. Canada shares a left-wing ideology of -1.32 . Klingemann et al. argue that, during the period 1950 to 1995 , government policies in eighteen out of twenty-one democracies they investigated are responsive to changes in median voters' ideological positioning. (Klingemann et al. , 2006, p.129)
} 
and an indicator of medical technology into our estimation equations.

In the following section, we outline a model which features the coexistence of public and private care, a supply side to the health care market, and the endogenous choice of multiple policy instruments in a political equilibrium. A basic estimating equation that is consistent with this framework is also stated.

\subsection{A Model and Basic Estimating Equation}

We assume an economy composed of $I$ groups of citizens of different incomes $y_{i}$ and diverse tastes for medical service $b_{i}$, where $i$ denotes the $i^{\text {th }}$ citizen group. The income of the population follows a distribution of $f(y)$ and their tastes for medical care follows a distribution of $f(b) .^{56}$ There are two types of commodities: numeraire consumption, $x$, and medical service, $h$. Each citizen is entitled to some units of public health care and opts for $m_{i}$ units of private care. We use $g$ to represent the average public health expenditure spent on every citizen. It is assumed that the amount of public care consumption is uniform across individuals.

Assume then that a representative citizen in citizen group $i$ maximizes his utility subject to his budget constraint.

$$
\operatorname{Max} u_{i}=u\left(x_{i}, g, m_{i}, b_{i}\right) \text { s.t. } y_{i}\left(1-t_{i}\right)=x_{i}+p m_{i}
$$

where, $t_{i}$ is income tax rate varying across income classes, and $p$ is the market price of private care. By solving (1), we obtain the optimal demand for private care of the citizen

\footnotetext{
${ }^{56}$ At the beginning, we assume there is no correlation between income and tastes for medical service. This assumption will be released in Section Six.
} 
in group $i$.

$$
m_{i}^{*}=m_{i}\left(y_{i}, b_{i}, t_{i}, p, g\right)
$$

After substituting $m_{i}^{*}$ back into the utility function, we obtain the indirect utility of the citizen in group $i$.

$$
v_{i}=v_{i}\left(y_{i}, b_{i}, t_{i}, p, g\right)
$$

Governments sometimes use policies to stimulate the take-up of private social insurance coverage by individuals or employers. For example, tax subsidies to private insurance plans reduce the effective price of private insurance. As a result, the purchaser faces a price that is not solely based on his or her individual risk-profile. This type of tax break is important in Germany, for example, where about $18 \%$ of the population is covered by private health insurance. Similarly for the United States, the exclusion of employer contributions for medical insurance premiums and medical care amounted to 101.9 billion U.S. dollars in 2003, equivalent to $0.9 \%$ of GDP (OECD 2007, p.38).

Besides using tax incentives, governments often use regulation to steer private insurance markets. For example, Canada outlaws duplicate private health insurance ${ }^{57}$. Regulation arises in relation to premium setting in private insurance plans. Some countries allow private insurers to calculate premiums based on health risks of consumers while others totally forbid differential premiums. In some states, risk sharing or risk adjustments are required to smooth costs across insured groups. These regulations are designed to foster a

\footnotetext{
${ }^{57}$ Private health insurances can be duplicative, complementary, substitute/primary, or supplementary to the public health plans. Please see OECD (2004) for a detailed discussion.
} 
level playing ground for the insurers and promote risk pooling among the insured. In Ireland and Australia, regulations have encouraged a large proportion of private health insurance (Colombo and Tapay 2004). (Table III-6 and Table III-7 in the Appendix provide a summary of recent policy practices concerning private care markets in selected OECD countries.)

These government policy interventions modify the effective market price faced by insurance recipients. If $c$ is the cost of providing one unit of private care, and $s$ measures the government policies towards private care market, we can state that the effective market price of private care $p$ is a function of the cost of provision and of government policies towards private care market:

$$
p \approx p(c, s)
$$

To provide further detail concerning the determinants of the market price of private care, we turn to the supply side of the health care market. Assume a medical production function $H=F(L, K, a)$, where $H$ is the total output of health care provision, $L$ is the number of practicing doctors, $K$ is the number of hospital beds, and $a$ represents the level of medical technology. The cost of providing one unit of private care is determined by the supply side of the health care market. We then have

$$
c \approx c(L, K, a)
$$

Substituting equation (5) into equation (4) to replace $c$, and then substituting equation (4) back into equation (3), we have that:

$$
v_{i}=v_{i}\left(y_{i}, b_{i}, t_{i} p(s, L, K, a), g\right)
$$


Now, suppose the major competing political parties in a country optimize a political support function by choosing a bundle of policy instruments, subject to a government budget constraint. The result of the ensuing political competition may be summarized using the Representation Theorem, which shows that the equilibrium in a competitive political economy like that outlined here may be represented by maximizing a suitably defined weighted sum of voter utilities ${ }^{58}$. This synthetic optimization problem can be stated as:

$$
\begin{gathered}
\operatorname{Max} S=\iint v_{i}\left(y_{i}, b_{i}, t_{i}, p(s, L, K, a), g\right) f(y) f(b) d y d b, \\
\text { subject to } N g+s=\iint t_{i} y_{i} f(y) f(b) d y d b .
\end{gathered}
$$

where $N$ is the size of population.

The solutions for policy instruments $g, t$ and $s$ to the problem defined by (7) and (8) are

$$
\begin{aligned}
g^{*} & =g\left(\left\{y_{i}\right\},\left\{b_{i}\right\}, f(y), f(b), N, L, K, a, p\right) . \\
t^{*} & =t\left(\left\{y_{i}\right\},\left\{b_{i}\right\}, f(y), f(b), N, L, K, a, p\right) . \\
s^{*} & =s\left(\left\{y_{i}\right\},\left\{b_{i}\right\}, f(y), f(b), N, L, K, a, p\right) .
\end{aligned}
$$

Here, $g^{*}$ is the equilibrium per capita public health expenditure, $t^{*}$ is an indicator of the structure of the entire income tax schedule, and $s^{*}$ is measurement of the government policies towards private insurance market.

It follows that the share of public health expenditure in total health expenditure can be

\footnotetext{
${ }^{58}$ See Hettich and Winer (1999, Chap. 4) and Coughlin and Nitzan (1981). In the political support function (7), equal political weights across voter groups are assumed. This may be relaxed without affecting the estimating equations.
} 
stated as:

$S h g=N g^{*} /\left(N g^{*}+\iint_{p m_{i}}^{*} f(y) f(b) d y d b\right)=\operatorname{Shg}\left(\left\{y_{i}\right\},\left\{b_{i}\right\}, f(y), f(b), N, L, K, a, p, t, s\right)$,

where $S h g$ is the share of public health expenditure in total health expenditure, $\mathrm{Ng}$ is the total public health expenditure, and $\iint p m_{i}{ }^{*} f(y) f(b) d y d b$ is the aggregated private health expenditure.

Equation (12) is the basis for our estimations. It differs from the equation implied by the model of Usher (1977) in that in our framework, public and private care coexist, and government policies concerning the private care market modify the boundary between public and private care through alterations in the relative price of private care.

Our basic estimation equation, a simple linear version of (12), is:

Shg $=\beta_{0}+\beta_{1} G D P+\beta_{2}$ Demography $+\beta_{3}$ TaxProg $+\beta_{4}$ Mean_Median $+\beta_{5}$ Population

$+\beta_{6}$ Share_PrvIns $+\beta_{7}$ Doctor $+\beta_{8}$ Bed $+\beta_{9}$ Technology $+\varepsilon$.

Here the dependent variable, Shg, is defined as the share of public health expenditure in total health expenditure, i.e. Shg = public expenditure on health / total expenditure on health. To be more precise, total expenditure on health is defined as the sum of expenditure on activities that - through application of medical, paramedical, and nursing knowledge and technology - has the goals of: promoting health and preventing disease; curing illness and reducing premature mortality; caring for persons affected by chronic illness who require nursing care; caring for persons with health-related impairments, disability, and handicaps who require nursing care; assisting patients to die with dignity; 
providing and administering public health; providing and administering health programs, health insurance and other funding arrangements. (See, OECD Health Data 2008)

Public expenditure on health care is the health expenditure incurred using public funds, both current and for capital. Public funds are those of state, regional and local government bodies and social security schemes. Public capital formation for health includes publicly financed investment in health facilities plus capital transfers to the private sector for hospital construction and equipment. (Source, OECD Health Data 2008)

Private expenditure on health care is the privately funded part of total health expenditure. Private sources of funds include out-of-pocket payments, both over-the-counter and costsharing, private insurance programs, charities and occupational health care. (Again, see our data source, OECD Health Data 2008)

The right-hand side variables in estimating equation (13) are defined as follows, where, unless specified, all data are from OECD Health Data (available for 1960-2007) and the definitions of variables are from OECD Health Data 2008, Definitions, Sources, and Methods: Following these concise definitions, we discuss the choice of these variables at greater length.

$G D P \quad$ GDP per capita, current price, in U.S. dollars, at purchasing power parity.

Mean_Median Ratio of real mean income to real median income of individuals for total population. Source: OECD.Stat, Social and Welfare Statistics, 1975-2005.

Demography Ratio of the population over the age of 65 to the population aged 0-64.

Population Total population, in thousands. 
Doctor Number of practicing physicians per 1000 population.

Bed $^{59} \quad$ Number of hospital beds per 1000 population.

Technology Number of MRI, CT, Radiation, Lithotriptors, and Mammographs machines per million population.

TaxProg ${ }^{60} \quad$ Year to year income elasticity of individual income tax revenues.

TaxProg $=\left[\left(\operatorname{Tax}_{t}-\operatorname{Tax}_{t-1}\right) / \operatorname{Tax}_{t-1}\right] /\left[\left(G D P T_{t}-G D P T_{t-1}\right) / G D P T_{t-1}\right]$,

where $\operatorname{Tax}=$ Total tax revenue on individual income and profits, in

millions of national currency. GDP_T = GDP for tax reporting years at

market prices, in millions of national currency. $t$ and $t-1$ denote the

current and the lagged tax reporting year respectively. Source:

OECD.Stat, Revenue Statistics, 1960-2005.

Share_PrvIns Share of voluntary private insurance financing in private health

expenditure. Share_PrvIns = private health expenditure covered by

private insurance / total private expenditure on health.

It may be noted that GDP is our measure of income $\left\{y_{i}\right\}$ and Mean_Median measures the income distribution $f(y)$ in model equations (9) to (12). As usual, a higher ratio of mean income to median income implies that there is greater income inequality. Personal income or personal disposable income may be better measures of the income levels of citizens. But here we use GDP (per capita) because GDP data is widely available on a comparable basis for many countries.

\footnotetext{
${ }^{59}$ Total hospital beds are all hospital beds which are regularly maintained and staffed and immediately available for the care of admitted patients. Inclusion: Beds in all hospitals, including general hospitals, mental health and substance abuse hospitals, and other specialty hospitals; occupied and unoccupied beds. Exclusion: Surgical tables, recovery trolleys, emergency stretchers, beds for same-day care, cots for healthy infants; beds in wards which were closed for any reason; provisional and temporary beds; and beds in nursing and residential care facilities. (OECD Health Data 2008)

${ }^{60}$ We use income tax progressivity following the convention of Besley and Gouveia (1994). The tax progressivity measurement in our paper is rough due to data limitation problem. A better measurement is discussed in Section 5.
} 
Demography represents morbidity $\left\{b_{i}\right\}$ and the morbidity distribution $f(b)$ in equations (9) to (12). Elderly citizens usually have a poorer than average health status and require more health care consumption relative to the others. Accordingly, we may construct a variable that reflecting homogeneity (or heterogeneity) of tastes for heath care using the ratio of the number of seniors (65 years and older) to the number of younger people (0-64 years old). A higher ratio of seniors to young implies tastes for medical services are more homogeneous.

Doctor, Bed and Technology represent the factors in medical production, $L, K$, and $a$, respectively.

Data limitations require us to use proxies for government policies in our estimating equation. TaxProg, the year to year income elasticity of income tax revenues, approximates the progressivity of the income tax system and the structure of the income tax schedule. The idea here is that the more progressive is the tax system, the higher will be its income elasticity, as taxpayers are moved up into higher tax brackets.

Share of voluntary private health insurance financing in private health expenditure, Share_PrvIns, reflect the generosity of the government policies toward the private care market $\left(s^{*}\right.$ in equation 11). These government policies include tax incentives for the purchase of private care and regulations concerning the private care market, as discussed before.

Spending on voluntary private health insurance, although made by private individuals and 
companies, is promoted by tax breaks ${ }^{61}$. A higher share of voluntary private health insurance expenditure in private health expenditure implies a more generous tax subsidy for the purchase of private care. A good regulatory system boosts consumers' confidence and encourages take-ups of private insurance plans. A higher share of private insurance also reflects a more mature private insurance market and more generous government regulations concerning private insurance market. Accordingly, we use the share of private insurance coverage in total private health expenditure to represent the generosity of government policies towards the private care market.

TaxProg and Share_PrvIns are the endogenous policy variables determined simultaneously with the share of public health expenditure. As noted earlier, the resulting endogeneity problem will be addressed by the use of instrumental variables, as discussed in Section 4 below.

\section{A Brief Review of Issues in Empirical Comparative Research}

Before we turn to details of our estimation methodology and estimation results, it is useful to consider general approaches to empirical comparative social research of the kind we are undertaking.

\footnotetext{
61 This is the reason why OECD Social Expenditure Database includes "Voluntary Private Health Expenditure" as part of social expenditures that involves income redistribution. Voluntary private social expenditure: benefits accruing from privately operated programs that involve the redistribution of resources across households and include benefits provided by NGOs, and benefit accruing from tax advantaged individual plans and collective (often employment-related) support arrangements, such as for example, pensions, childcare support, and, in the US, employment-related health plans. ( Social Expenditure 19802003 Interpretative Guide of SOCX, OECD 2007)

The data of the voluntary private health expenditure in the OECD Social Expenditure Database is obtained from OECD Health Data, Health expenditure by source of funding, private insurance. The definition of voluntary private health expenditure is illustrated in Table III- 8 in the Appendix.
} 
Shalev $(2007 a, b)$ contributes to what has become an extensive debate on the use of multiple regression (MR) versus case studies in comparative research. His views appear in an issue of Comparative Social Research (Volume 24, 2007) devoted entirely to this issue. According to Shalev, one of the main drawbacks of MR is the formidable difficulties with the use of pooling technique in time-series-cross-section data (TSCS), as we shall do here.

The entire second issue of the $15^{\text {th }}$ volume of Political Analysis (2007) is also devoted to a detailed discussion of the methods of dealing with the problems of TSCS data. In the following remarks, we shall briefly summarize the main points in the debate as represented by the two journal issues referenced above, in which support is provided for the use of regressions using panel data, as well as important criticisms.

In the debate about use of MR, Shalev is the only one who is strongly against the use of MR in comparative research, arguing instead for the conventional case study approach. We first discuss Shalev's arguments and then summarize the opinions of those on the other side.

Shalev (2007a)'s opposition to the use of MR approach is based on the fact that MR approach tends to generalize specific cases and to over simplify the complicated relationship among observations. His major arguments against the use of MR approach include the following:

1. The MR approach is variable-oriented and it treats the particular cases as being invisible;

2. It is difficult to define variables clearly and measure variables precisely. 
3. It is improper to put a complicated social process into a simple linear model;

4. MR estimates the marginal effect of one variable conditional on other factors, but people are often interested in the marginal effect with or without the conditions.

5. MR summarizes the associations among variables but does not directly testing causal hypotheses. A description can better reveal causal relationships, possible interactions between variables, and implication of outliers than MR does.

6. The MR approach cannot easily deal with heterogeneity because of the "too many variables and not enough cases" problem in cross-national quantitative analysis.

In particular, Shalev believes that the pooling technique is inappropriate in comparative research. He thinks that $\mathrm{MR}$ with pooling requires heroic assumptions about causal patterns across time and across units, yielding unreliable or incorrect results. His arguments against MR with pooling include:

1. Extending cross-sectional analysis to time-series-cross-sectional data only make the problems of MR worse because of the complexity in the causal patterns across time and the small number of available cases.

2. Pooling observations in different periods assume stability in the casual relationship across time, which sometimes is not true. Variation across sub-periods should be considered.

3. Pooling cannot distinguish between variations across time and across sectionals. Including a dummy variable captures merely different slopes or baseline values instead of the different slopes with various units or periods.

4. Pooling suffers from the serial correlation problem. 
In conclusion, Shalev thinks that we should treat the results of MR approach tentatively and as a guide to alternative analyses. A convergence of the results from different methodologies is more trustworthy than that of MR approach. He proposes three alternatives to MR approach including refinement, triangulation, and substitution.

Many if not most other scholars in the debate think the benefits of MR outweigh its technical problems. They believe that going back to the case study method, often used in past decades in political science especially, is a retreat from social science, and that a combination of MR with qualitative analysis (not necessarily or usually in the same paper) should be a better alternative to MR.

More specifically, Esping-Anderson (2007) believes that diagnostic testing may provide support for some of the strong assumptions made by MR. He thinks that a close examination of the residuals gives important insights.

Rubinson and Ragin (2007) suggest that the analytical methods based on Boolean or fuzzy-test algebra are better alternatives to the conventional case studies.

Pontusson (2007) and Swank (2007) suggest that carefully designed pooling regressions can lead to reliable results, despite of the existence of the variations in causal patterns over time or across units. Pontusson argues that pooling actually allows researchers to solve many of the interesting questions that arise in comparative research that involve variations occurring both within and across countries.

Kenworthy (2007) and Scruggs (2007) strongly believe in the power of MR approach but suggest that MR should be used with caution. Scruggs defends the MR approach by 
arguing that the complaints of MR are mainly due to improper statistical practices. According to Scruggs, MR helps identify the most important factors at play, and that generalization through formal statistical analyses is much preferable to the arbitrary judgments that necessarily are required when doing case studies.

Beck (2007) recognizes the importance and growing popularity of time-series-crosssection data (TSCS) in political economy and leads a very useful discussion on the issues raised in the operations of TSCS.

In the ensuing discussion, Wilson and Butler (2007) suggest that unit heterogeneity and dynamics should be taken into account seriously before using the Beck and Katz (1995, 1996) recipe of handling pooled data. They suggest that researchers should detect unit heterogeneity by use of a fixed effects model and test for different types of autocorrelation structures before pooling data.

Plumper and Troeger (2007) proposes a three-stage procedure to capture the effects of the time-invariant and slowly changing covariates while accounting for unit heterogeneity. Franzese and Hays (2007) discuss the importance of the interdependence among units and the econometrics issues related to the interdependence.

Shore et al. (2007) support the use of Bayesian multilevel analysis in dealing with unit heterogeneity, and Beck and Katz (2007) discuss the advantage of using maximum likelihood estimation of random coefficients models.

In a summary of the discussion, Beck (2007) confirms that the use of TSCS data raise important issues, and argues that scholars should not be afraid to use such data because of 
the technical difficulties of doing so.

In conclusion, some scholars such as Shalev hold a philosophically different view on the use of MR in comparative research, while many other scholars think that despite of the problems with MR, we should not 'throw the baby out with the bathwater'.

We agree with the views of most of the scholars in the debate, and believe that MR is useful in testing the comparative theory that we are interested in, despite difficulties involved in MR.

In this paper, we use multiple regression as the basic technique and use descriptive table and charts to make the cases as visible as possible. TSCS data is used, and tests of the main assumptions relied upon are provided as far as is possible.

Finally, it should be noted that the issue of what determines the public-private mix in health care in OECD countries is an important and widely discussed matter about which there has been little (perhaps too little) empirical research. We think it is essential to move forward by making the most of the available theory and data, despite the difficulties that may arise in doing so. We think that at the very least, this work will provide a good basis for others who will be able to make further progress once more or better data becomes available.

\section{The Data and Estimation Strategy}

Most of the data for the variables described in Section 2 are from the databases of 
"OECD.Stat" for 1981-2005 ${ }^{62}$. The ideology indexes used as the instrumental variables are from Budge et al. (2001) and Klingemann et al. (2006). The use of instrumental variables will be discussed below. We use five-year simple arithmetic averages of all data to remove business cycle effects.

\subsection{Basic characteristics of the countries included in the estimation sample}

The sample is based on OECD countries. If any of the ten regressors in equation (13) was missing through the period 1981-2005, that country was excluded from the final dataset. Accordingly, fourteen OECD countries are retained in the sample: Australia, Austria, Canada, Denmark, Finland, France, Germany, lreland, Japan, Luxembourg, Netherlands, Spain, United Kingdom, and United States.

Table III-1 gives means of the variables used in equation (13) for the fourteen countries. More detailed summary statistics can be found in Table III-9 in the Appendix ${ }^{63}$. Figure III-1 below the table shows the share of public expenditure in total health expenditure in the fourteen OECD countries during 1981-2005. In most OECD countries, shares of public health expenditure are around $70 \%-80 \%$ of total health expenditure, except in the United States where the share of public expenditure is below $50 \%$, and in Luxemburg where the share of public expenditure is more than $90 \%$ most of the time.

\footnotetext{
${ }^{62}$ OECD.Stat provides around 300 datasets included in SourceOECD Statistics. OECD.Stat is available online at http:/puck.sourceoecd.org $/ \mathrm{vl}=672722 / \mathrm{cl}=18 / \mathrm{nw}=1 / \mathrm{rpsv} / \mathrm{dotstat}$.htm. Information of the databases used in the paper is provided in Section 2.

63 Table III 3 in the Appendix shows the simple correlations among the nine independent variables. We find that only one of the correlation coefficients is higher than 0.5 in terms of absolute value, which is 0.57 , between Bed and Technology. At first glance, there does not appear to be a serious multicollinearity problem.
} 
Table III-1 Summary of Main Variables for 1981-2005 (five-year averages)

\begin{tabular}{|c|c|c|c|c|c|c|c|c|c|c|}
\hline $\begin{array}{c}\text { Variable } \\
\text { (unit) }\end{array}$ & $\begin{array}{l}\text { Shg } \\
\text { (ratio) }\end{array}$ & $\begin{array}{l}G D P \\
\text { (US\$, } \\
P P P)\end{array}$ & $\begin{array}{l}\text { Mean- } \\
\text { Median } \\
\text { (ratio) }\end{array}$ & $\begin{array}{l}\text { Demo- } \\
\text { graphy } \\
\text { (ratio) }\end{array}$ & $\begin{array}{l}\text { Popu- } \\
\text { lation } \\
\text { (in } \\
1000 \text { s) }\end{array}$ & $\begin{array}{l}\text { TaxProg } \\
\text { (elastic- } \\
\text { city) }\end{array}$ & $\begin{array}{l}\text { Share } \\
\text { PrvIns } \\
\text { (ratio) }\end{array}$ & $\begin{array}{l}\text { Doctor } \\
\text { (No. } \\
\text { per } \\
1000)\end{array}$ & $\begin{array}{l}\text { Bed } \\
\text { (No. } \\
\text { per } \\
1000)\end{array}$ & $\begin{array}{l}\text { Tech- } \\
\text { nology } \\
\text { (No. per } \\
\text { Million) }\end{array}$ \\
\hline Australia & 0.66 & 20926 & 1.14 & 0.13 & 17637 & 0.93 & 0.33 & 2.28 & 5.10 & 23.94 \\
\hline Austria & 0.75 & 21968 & 1.09 & 0.18 & 7872 & 1.21 & 0.30 & 2.53 & 9.61 & 27.93 \\
\hline Canada & 0.73 & 22042 & 1.13 & 0.13 & 28543 & 1.19 & 0.36 & 2.04 & 5.28 & 10.05 \\
\hline Denmark & 0.84 & 21689 & 1.05 & 0.18 & 5225 & 1.13 & 0.74 & 2.59 & 5.40 & 10.45 \\
\hline Finland & 0.77 & 19157 & 1.09 & 0.16 & 5047 & 1.13 & 0.61 & 2.37 & 7.60 & 46.33 \\
\hline France & 0.78 & 19394 & 1.15 & 0.17 & 57405 & 1.85 & 0.50 & 2.99 & 9.25 & 34.27 \\
\hline Germany & 0.79 & 21411 & 1.12 & 0.19 & 73722 & 0.26 & 0.37 & 3.15 & 9.29 & 22.17 \\
\hline Ireland & 0.75 & 18523 & 1.17 & 0.13 & 3656 & 0.98 & 0.31 & 2.26 & 7.33 & 12.08 \\
\hline Japan & 0.78 & 20192 & 1.14 & 0.16 & 124189 & 2.40 & 0.18 & 1.72 & 14.91 & 69.64 \\
\hline Luxembourg & 0.91 & 37031 & 1.12 & 0.16 & 404 & 0.86 & 0.33 & 2.08 & 6.19 & 35.09 \\
\hline Netherlands & 0.67 & 21124 & 1.12 & 0.15 & 15265 & 0.79 & 0.46 & 2.73 & 5.31 & 7.53 \\
\hline Spain & 0.76 & 15729 & 1.21 & 0.17 & 39561 & 1.12 & 0.16 & 2.88 & 4.32 & 15.33 \\
\hline United Kingdom & 0.84 & 19038 & 1.25 & 0.19 & 57833 & 1.06 & 0.19 & 1.73 & 4.32 & 11.64 \\
\hline United States & 0.43 & 26261 & 1.17 & 0.14 & 260972 & 0.87 & 0.59 & 2.26 & 4.46 & 34.62 \\
\hline Average & 0.75 & 21749 & 1.14 & 0.16 & 49809 & 1.13 & 0.40 & 2.37 & 6.82 & 26.50 \\
\hline $\begin{array}{l}\text { Average_without } \\
\text { US }\end{array}$ & 0.77 & 21402 & 1.14 & 0.16 & 33567 & 1.15 & 0.38 & 2.38 & 7.05 & 26.08 \\
\hline
\end{tabular}

Figure III-1 Share of Public Health Expenditure in Total Health Expenditure

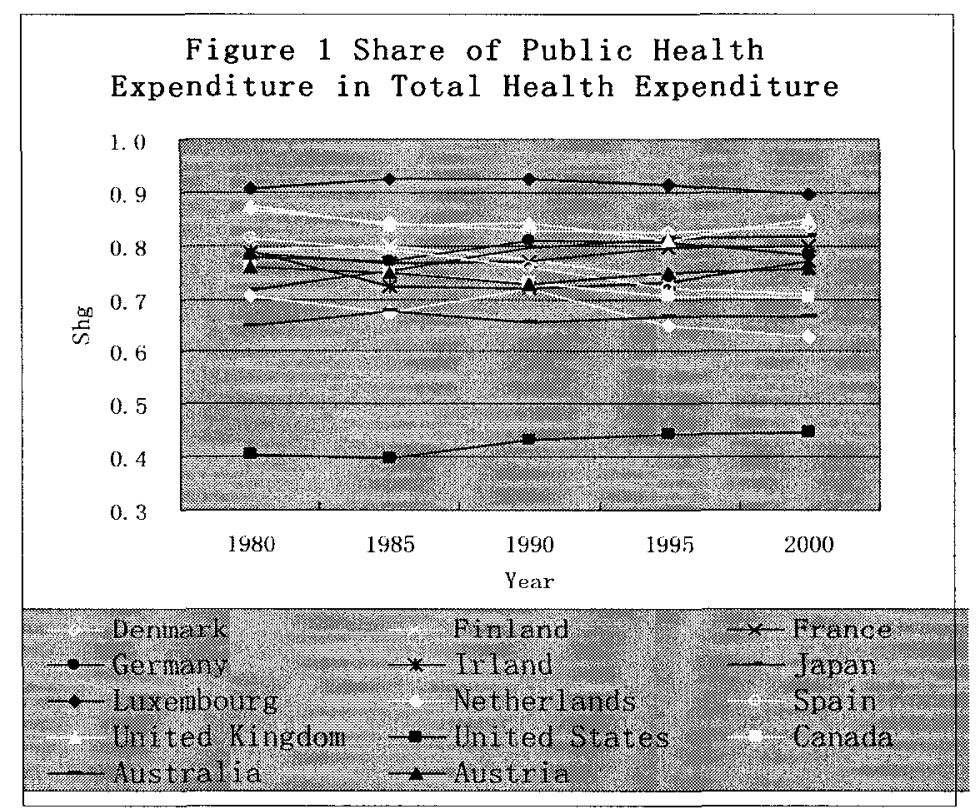

112 


\subsection{The structure of the time-series, cross-section data}

In our sample, after averaging there are five five-year periods, and so there are 70 observations for 14 countries. Before we perform any estimation, it is important to know about the structure of the data we are analyzing.

Figure III-2 Patterns of Variations Across Units and Over Time
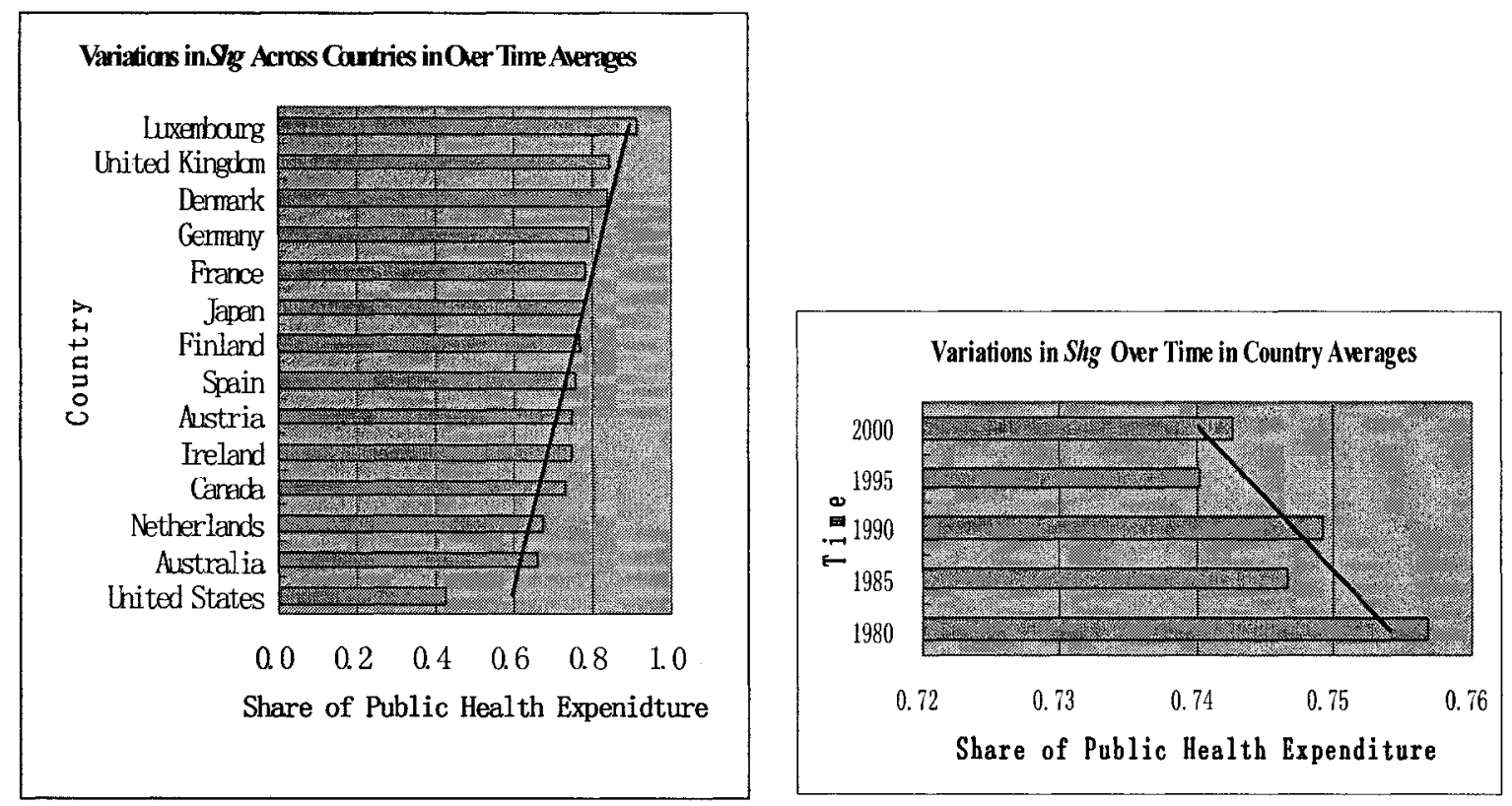

The trendlines in Figure III-2 illustrate the pattern of variation across countries and across time periods for the dependent variable. In the following paragraphs, we will test if there is heterogeneity or time trend in this pooled data. We use the estimation model in equation (13) as our baseline model. The detailed test statistics can be found in the Appendix.

We first test whether there is significant fixed effect of country groups. In an OLS estimation, when a dummy for country groups is added, the dummy is significant at $10 \%$ level, implying the presence of fixed effects. In a panel data setting, a Breusch and Pagan 
Lagrange multiplier test for fixed effects of country group rejects the null that there is no fixed effect. We speculate that the presence of fixed effect arises because of the diverse institutional settings in the health care systems across countries. For example, Gerdtham et al. (1991) find that the compensation scheme of physicians contribute significantly to variations in public health expenditures, while institutional factors are omitted in our model. We will take the heteroscedasticity problem into account in our estimation.

We then test for a time trend. When a dummy for time periods is added, the OLS estimation result for (13) shows that the dummy for years is not significant. In a panel data setting, a Breusch-Pagan Lagrange multiplier test for a time trend confirms that there is no such trend. However, there is possibly serial correlation between the dependent variables in different time periods. We will correct for autocorrelation in the error terms in our estimation.

\subsection{Choice of instrumental variables}

In the estimating equations outlined earlier, tax progressivity and government policies towards the private care market are endogenous. Hence, we use instrumental variables as one of the estimation strategies. We consider ideological positioning indexes as the instrumental variable for the endogenous policies because voter opinions influence government policies in democratic states (Budge et al. 2001 and Klingemann et al. 2006). In the following, we will introduce the measurements of ideological positioning on different policy dimensions.

Three indexes of ideological positioning are of interest to the problem we are analyzing. 
They are called I_RightLeft, I_Incentive, and I_Regulation. The first index, I_RightLeft, measures the general politically right-left ideology of the electorate, and the last two indexes measure the attitude of the electorate towards development of private markets. These ideological positioning indexes are described in more detail below. These data are from Budge et al. (2001) and Klingemann et al. (2006), which are massive studies of ideology that are only recently completed.

I_RightLeft is defined as the average right-left ideological positioning of the electorate. The average ideology of voters is represented by weighted average of the ideology of the major political parties in a country. The weight for each political party is its vote share in a general election ${ }^{64}$. Table III-11 in the Appendix illustrates the formula for computing the right-left ideology of political parties based on their policy preferences on various policy issues. The major policy issues in question include national defence, social welfare expansion, economic policy, and so on. In a measurement centered at 0 for the right-left ideology, a negative number implies strong preferences for welfare and government interventions, and a positive number represents ideologically-based supports for strong defence, free enterprise, and traditional morality.

I_Incentive is the average ideological positioning of the electorate on the issue of providing financial incentives to private businesses. Again, we use the weighted average of the ideology of the major political parties to approximate the electorate's ideological positioning on this issue. This ideology of political parties on this issue is obtained by

\footnotetext{
${ }^{64}$ The right-left ideological positioning of the major political parties in Canada and in the United States and their weighted averages are illustrated in Figure III-5 in the Appendix.
} 
counting the number of positive statements of political parties on the issue of financial incentives and then computing the proportion of the positive statements in all the statements on this issue. A Positive statement on this issue means favourable mentions of need for wage and tax policies to induce enterprise; encouragement to start enterprises; need for financial and other incentives.

I_Regulation is the average ideological positioning of the electorate on the issue of using regulations to make the private market work better. Similar to I_Incentive, I_Regulation is the weighted average of the ideology of political parties, and the ideology of political parties is calculated as the proportion of the positive statements in the total number of statements on the issue of regulation. Here, a positive statement means favourable mentions of need for regulations designed to make private enterprises work better; actions against monopolies and trusts, and in defence of consumers and small business; encouraging economic competition; and social market economy. By definition, I_Incentive and I_Regulation are always positive and a higher number of the indexes implies more ideology-based supports for the development of private businesses.

Table III-2 provides the average ideology (as defined above) of the voters in different dimensions. Figure III-2 depicts the average right-left ideological positioning of the electorate in the fourteen countries during 1981-2005 and Table III-3 provides the simple correlation among the ideology indexes and the related endogenous regressors. 
Table III-2 Average Ideological Positioning of the Electorate in 1981-2005

\begin{tabular}{|l|l|l|l|}
\hline Country & I RightLeft & I_Incentive & I_Regulation \\
\hline Australia & 15.26 & 6.76 & 0.97 \\
\hline Austria & 5.07 & 2.22 & 1.57 \\
\hline Canada & -0.78 & 5.34 & 2.09 \\
\hline Denmark & 4.85 & 2.57 & 0.84 \\
\hline Finland & -9.34 & 2.85 & 1.80 \\
\hline France & -2.04 & 3.00 & 1.29 \\
\hline Germany & 1.02 & 3.05 & 2.30 \\
\hline Ireland & -5.67 & 4.40 & 1.90 \\
\hline Japan & -9.87 & 1.07 & 1.61 \\
\hline Luxembourg & -10.40 & 3.11 & 2.36 \\
\hline Netherlands & -4.76 & 2.19 & 1.65 \\
\hline Spain & -6.90 & 2.43 & 1.79 \\
\hline United Kingdom & 3.56 & 3.14 & 1.98 \\
\hline United States & 12.24 & 2.32 & 0.89 \\
\hline Average & -0.55 & 3.17 & 1.65 \\
\hline Average without US & 1.54 & 3.24 & 1.70 \\
\hline
\end{tabular}

Figure III-3 Average Right-left Ideological Positioning of the Electorate in 1981-2005

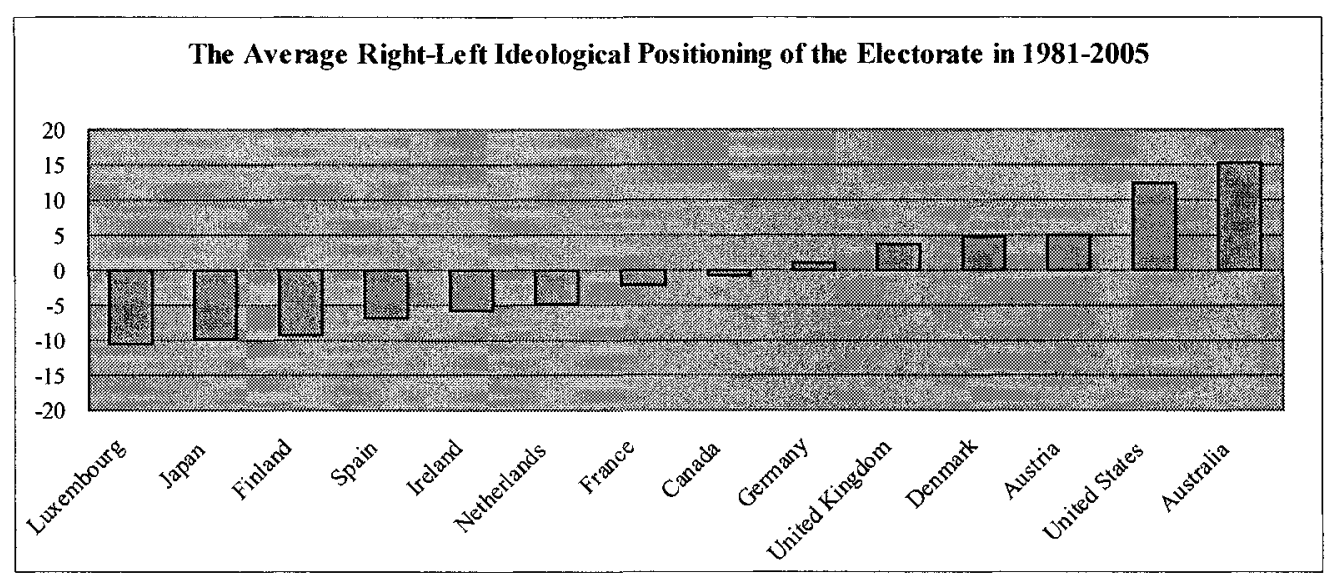

Table III-3 Simple Correlation of Ideological Indexes and Related Regressors

\begin{tabular}{|c|lccccc|}
\hline & I RightLeft & I Incentive & I Regulation & Shg & TaxProg Share PrvIns \\
\hline I RightLeft & 1.00 & & & & & \\
\hline I Incentive & 0.26 & 1.00 & & & & \\
\hline I Regulation & -0.47 & -0.02 & 1.00 & & & \\
\hline Shg & -0.45 & -0.12 & 0.29 & 1.00 & & \\
\hline TaxProg & -0.03 & -0.19 & 0.03 & 0.11 & 1.00 & \\
\hline Share PrvIns & 0.11 & 0.01 & -0.17 & -0.19 & -0.12 & 1.00 \\
\hline
\end{tabular}

Because of the endogeneity problem with the endogenous policies in our estimation equation (13), we will consider the three ideology indexes as potential instrumental 117 
variables. In the following, we will first list the characteristics of a valid instrument and then discuss our reasons for using an ideology index as an instrumental variable.

A valid instrument variable is one which can explain the endogenous variable in question, but is exogenous or predetermined with respect to the dependent variable. There are two formal criteria for a valid instrumental variable:

1. Instrument exogeneity, i.e. the instruments are uncorrelated with the error term in the equation to be estimated.

2. Instrument relevance, i.e. endogenous regressors can be predicted by the instruments and the included exogenous regressors. If the correlation between the instruments and the endogenous regressors are small, the instruments are 'weak'.

We will consider our three potential instrumental variables according to the two criteria.

We first consider the possibility of the right-left ideology as the instrumental variable for the measurement of the tax progressivity, TaxProg. I_RightLeft is not likely to be an instrumental variable for TaxProg, because the right-left ideology likely influences both the endogenous regressor, tax policies, and the dependent variable, the health care mix.

We will include the right-left index directly in our estimation equation as an independent regressor. Since we cannot find any better instrumental variable for tax progressivity because structure of tax systems is generally closely related to the spending on public health care, we shall have to exclude TaxProg from the instrumental variable two-stage least square analysis. 
Next we consider the validity of I_Incentive and I_Regulation as instrumental variables for the measurement of government policies to private care market, Share_PrvIns. These indexes are possible candidates for the instrumental variables because they are likely determined in a process exogenous to the one underlying the public-private mix of health care expenditure. We will formally test the two ideology indexes against the two criteria for a valid instrumental variable. The detailed test statistics are available in the Appendix.

First, we test the exogeneity of the instrumental variables. Since there are two potential instrumental variables for one endogenous regressor, we use the Sargan test of overidentifying restrictions. The Chi-square of the Sargan test is around zero, implying that the instrumental variables are uncorrelated with the error term. Second, we test for the strength of the instrumental variables in explaining the endogenous regressor. Because we have only one endogenous regressor to consider, we use the $F$-statistics in the first stage of the two-stage least square estimation to judge the explanatory power of the instrumental variables. The null of the $F$-test is that the excluded instruments are irrelevant in the first-stage regression. In this test, the $F$-statistics of 1.02 implies that the two ideology indexes are weak as instrumental variables.

In spite of the weak instrument problem, we still estimate with instrumental variables techniques because of the importance of this type of work. In this estimation, we will include I_RightLeft directly in our estimation equation and exclude TaxProg in the instrumental variable regressions. Here I_Incentive and I_Regulation serve as the instrumental variables for Share_PrvIns. 


\section{Estimation Result and Sensitivity Tests}

\subsection{Re-estimating Besley and Gouveia's test of Usher Model}

We begin by estimating the Besley and Gouveia model using our own data for 1980 , the year they looked at, but with a somewhat different selection of countries ${ }^{65}$. The OLS estimation result for the Besley and Gouveia (1994) model is ${ }^{66}$

$$
\begin{aligned}
& \text { Shg }=2.39-0.22 \log (G D P)+2.59 \text { Demography65 }+0.03 \text { TaxProg } \\
& \text { (1.39) (1.10) (1.77) (0.33) }
\end{aligned}
$$

$R^{2}=0.28,14$ observations, absolute values of $t$-statistics in parentheses.

where Demography 65 is the proportion of the population over the age of 65 to the total population. This result is very similar to that of Besley and Gouveia in terms of signs and significance levels of coefficients.

We then modify and test the Besley and Gouveia model using the expanded data for 1981-2005. We perform OLS estimation with robust errors and the estimation result is given in the Column A1 of Table III-4. We also perform Generalized Least Square (GLS) estimation with heteroscedastic and autocorrelated errors to take into account of the unit heterogeneity and dynamics in the pooled data. This estimation result is given in the Column A2 of Table III-4. We shall not describe these results here in order to focus on

\footnotetext{
${ }^{65}$ Besley and Gouveia (1994) includes 17 countries in their estimation, but their listed data source for tax progressivity, OECD (1984), has only 15 countries. We do not know exactly what countries are included in their regression. We use the country set in our sample to estimate their model.

${ }^{66}$ The estimation result in Besley and Gouveia (1994) is Shg $=\beta_{0}-0.20 \log (G D P)+0.02$ Dem65 +0.18 TaxProg $R^{2}=0.52,17$ observations, $t$-statistics in parentheses. Demo65 is the proportion of the population over the age of 65 to the total population.
} 
the results of estimating our more preferred equations.

\subsection{Extensions of Usher model to allow for private alternatives and supply side}

Next, we extend Besley and Gouveia's test of the Usher model in the manner described above. We start with Usher's theory about the role of income distribution and diversity in tastes, then incorporate government policies towards private care markets and ideology, and finally include supply side factors. In what follows we describe the estimating equations that gradually evolve with these considerations, keeping a discussion of the estimation results for the last. At that point, we consider the results taking all of the various equations estimated into account. In a following section, we attempt to uncover a best fitting model searching over all of the possibilities that we have considered.

Our first set of extensions or modifications to the simple Besley and Gouveia model is to add the ratio of mean income to median income, Mean Median. We also add population to the model. Alesina and Waczarg (1998) argue that a larger population leads to a cheaper provision of public goods because of the economies of scale. But also, a larger population exhibits more heterogeneous preferences for public goods, so adding population allows a better consideration of Usher's hypothesis about diversity of tastes. We expect a positive sign on Mean_Median, but cannot predict the sign on Population because economies of scale and diversity effects represented by Population act in different directions on government spending.

These extensions allow us to study the role of incentives for redistribution and diversity of tastes more fully than does the Besley and Gouveia equation. The estimation model 
now becomes

Shg $=\beta_{0}+\beta_{1} \log (G D P)+\beta_{2}$ Demography $+\beta_{3}$ TaxProg $+\beta_{4}$ Mean_Median $+\beta_{5}$

$\log ($ Population $)+\varepsilon$,

Results of estimating this model are recorded in Column B of Table III-4.

Our second extension is to add the right-left ideology of the electorate, I_RightLeft because in a general manner, overall left-right ideology of an electorate is likely to influence the incentive to redistribute. The estimation model then becomes

Shg $=\beta_{0}+\beta_{1} \log (G D P)+\beta_{2}$ Demography $+\beta_{3}$ TaxProg $+\beta_{4}$ Mean_Median $+\beta_{5}$

$\log ($ Population $)+\beta_{6} I$ RightLeft $+\varepsilon$.

and the estimation result based on this model is recorded in the Column C of Table III- 4 .

Because a democratic state with more "left-wing" attitude should favour more generous fiscal redistribution, we expect a negative correlation between the right-left ideology of electorates and the share of public health expenditure.

Our third extension to the Usher model is to allow for the presence of private care market and to add government policies towards private care, Share_PrvIns. The estimation model now becomes

Shg $=\beta_{0}+\beta_{1} \log (G D P)+\beta_{2}$ Demography $+\beta_{3}$ TaxProg $+\beta_{4}$ Mean_Median $+\beta_{5}$

$\log ($ Population $)+\beta_{6} I$ RightLeft $+\beta_{7}$ Share_PrvIns $+\varepsilon$.

and the estimation result based on this model is recorded in the Column D of Table III-4.

Favourable tax incentives and regulations for private care promote consumption of 
private care, and reduce the share of public health expenditure. On the other side, using private care may allow the rich citizens to skip the public plan and attenuate the progressivity of the fiscal system, leading them to offer less resistance to the public sector. It will be interesting to see how the share of the public health care sector responds to the government policies towards the private care market.

Finally, we add the supply side factors, Doctor, Bed, and Technology into the estimation. The estimation model now appears in equation (18) and the estimation results are presented in the Column E of Table III-4:

$$
\begin{aligned}
& \text { Shg }=\beta_{0}+\beta_{1} \log (G D P)+\beta_{2} \text { Demography }+\beta_{3} \text { TaxProg }+\beta_{4} \text { Mean_Median }+\beta_{5} \\
& \log (\text { Population })++\beta_{6} I \text { RightLeft }+\beta_{7} \text { Share_PrvIns }+\beta_{8} \log (\text { Doctor })+\beta_{9} \log (\text { Bed }) \\
& +\beta_{10} \log (\text { Technology })+\varepsilon .
\end{aligned}
$$

On the supply side of the health care market, we expect that a country with more practicing doctors and more hospital beds will also have a relatively larger public health care system because the cost of the public system will be lower. Recently, there has been a rising concern that technological advancements make public health systems unsustainable and make private health care more popular. We shall see if there is a negative correlation between technology and the share of public expenditure.

To estimate all of the equations specified above, we use OLS estimation with robust errors and GLS estimation with heteroscedastic and autocorrelated errors. The autocorrelation structure is assumed to be AR1 for all the panels.

Two-stage least square (2SLS) regressions are also provided. The instruments used in the 2SLS regressions include ideology indexes I_Incentive and I Regulation. These 
instruments were discussed earlier.

We note again that the dependent variable in all models is Shg, i.e. the share of public health expenditure in total health expenditure. Since the dependent variable, Shg, is a ratio, the scalar regressors, GDP, Population, Doctor, Bed, and Technology are used in logarithm form.

All the estimation results are reported in the columns of Table III-4 noted above with $t$ statistics in parenthesis. Number of observations, adjusted $R$-square and $F$-statistics for OLS regressions, and Chi-square statistics for GLS and 2SLS regressions are all provided at the end of the table. 
Table III-4 Estimation Results of Alternative Model Specifications

\begin{tabular}{|c|c|c|c|c|c|c|c|c|c|c|c|c|}
\hline \multirow{3}{*}{ Regressor } & \multicolumn{2}{|c|}{$\begin{array}{l}\text { Besley \& Gouveia } \\
\text { replicated }\end{array}$} & \multicolumn{2}{|c|}{$\begin{array}{l}\text { Incentive to } \\
\text { redistribute measured } \\
\text { more accurately }\end{array}$} & \multicolumn{2}{|c|}{$\begin{array}{l}\text { Right-left ideology } \\
\text { added }\end{array}$} & \multicolumn{3}{|c|}{$\begin{array}{l}\text { Policies towards private care } \\
\text { market added }\end{array}$} & \multicolumn{3}{|c|}{ Supply side factors included } \\
\hline & A1 & $\mathbf{A 2}$ & B1 & B2 & $\mathrm{C1}$ & $\mathrm{C} 2$ & D1 & D2 & D3 & E1 & E2 & $\mathbf{E 3}$ \\
\hline & OLS & GLS & OLS & GLS & OLS & GLS & OLS & GLS & 2SLS & OLS & GLS & 2SLS \\
\hline \multirow[t]{2}{*}{$\log (G D P)$} & -0.06 & -0.04 & -0.10 & -0.04 & -0.08 & -0.05 & -0.08 & -0.07 & 0.01 & -0.06 & -0.06 & 0.10 \\
\hline & $(1.27)$ & $(2.78)^{* * *}$ & $(4.32)^{* * *}$ & $(2.76) * * *$ & $(3.70)^{* * *}$ & $(2.67)^{* * *}$ & $(3.97)^{* * *}$ & $(3.57)^{* * *}$ & $(0.26)$ & $(1.25)$ & $(1.48)$ & $(1.88)^{*}$ \\
\hline \multirow[t]{2}{*}{ Demography } & 1.84 & 0.83 & 2.50 & 0.76 & 2.36 & 1.04 & 2.61 & 2.52 & -0.30 & 1.83 & 0.99 & 0.05 \\
\hline & $(4.02)^{* * *}$ & $(3.45)^{* * *}$ & $(5.36)^{* * *}$ & $(2.34)^{* *}$ & $(5.45)^{* * *}$ & $(3.17)^{* * *}$ & $(5.87)^{* * *}$ & $(7.37)^{* * *}$ & $(0.94)$ & $(4.14)^{* * *}$ & $(3.00)^{* * *}$ & $(0.16)$ \\
\hline \multirow[t]{2}{*}{ TaxProg } & 0.0003 & \begin{tabular}{|c|}
-0.0004 \\
\end{tabular} & 0.002 & 0.0002 & 0.002 & 0.001 & -0.0003 & 0.002 & & -0.001 & 0.001 & \\
\hline & $(0.05)$ & $(0.20)$ & $(0.18)$ & $(0.07)$ & $(0.22)$ & $(0.35)$ & $(0.03)$ & $(0.24)$ & & $(0.13)$ & $(0.58)$ & \\
\hline \multirow[t]{2}{*}{ Mean Median } & & & 0.36 & 0.12 & 0.30 & 0.12 & 0.27 & 0.37 & 0.19 & 0.19 & 0.13 & 0.19 \\
\hline & & & $(2.23)^{* *}$ & $(0.77)$ & $(1.74)^{*}$ & $(0.72)$ & $(1.25)$ & $(2.27)^{* *}$ & $(1.26)$ & $(0.65)$ & $(0.71)$ & $(1.19)$ \\
\hline \multirow[t]{2}{*}{ Log(Population) } & & & -0.05 & -0.03 & -0.05 & -0.03 & -0.05 & -0.05 & -0.01 & -0.05 & -0.02 & -0.03 \\
\hline & & & $(6.06)^{* * *}$ & $(4.25)^{* * *}$ & $(5.58)^{* * *}$ & $(4.38)^{* * *}$ & $(5.15)^{* * *}$ & $(7.12)^{* * *}$ & $(0.32)$ & $(4.06)^{* * *}$ & $(1.62)$ & $(1.30)$ \\
\hline \multirow[t]{2}{*}{ I RightLeft } & & & & & -0.003 & -0.001 & -0.002 & -0.001 & -0.001 & -0.002 & -0.001 & -0.001 \\
\hline & & & & & $(2.63)^{* * *}$ & $(1.18)$ & $(2.06)^{* *}$ & $(1.90)^{*}$ & $(1.17)$ & $(1.95)^{*}$ & $(1.45)$ & $(1.41)$ \\
\hline \multirow[t]{2}{*}{ Share Prvins } & & & & & & & -0.06 & -0.03 & -0.10 & -0.0001 & 0.05 & -0.07 \\
\hline & & & & & & & $(0.97)$ & $(0.60)$ & $(1.21)$ & $(0.00)$ & $(1.04)$ & $(1.14)$ \\
\hline \multirow[t]{2}{*}{$\log ($ Doctor $)$} & & & & & & & & & & -0.07 & -0.08 & -0.05 \\
\hline & & & & & & & & & & $(1.36)$ & $(1.52)$ & $(0.87)$ \\
\hline \multirow[t]{2}{*}{$\log (\mathrm{Bed})$} & & & & & & & & & & 0.07 & 0.06 & 0.15 \\
\hline & & & & & & & & & & $(2.24)^{* *}$ & $(2.04)^{* *}$ & $(2.68)^{* * *}$ \\
\hline \multirow[t]{2}{*}{$\log ($ Technology $)$} & & & & & & & & & & -0.01 & 0.01 & 0.003 \\
\hline & & & & & & & & & & $(0.37)$ & $(1.07)$ & $(0.31)$ \\
\hline \multirow[t]{2}{*}{ Constant } & 1.01 & 1.04 & 1.43 & 1.26 & 1.25 & 1.23 & 1.39 & 1.15 & 0.64 & 1.27 & 1.13 & -0.43 \\
\hline & $(2.61)^{* * *}$ & $(8.10)^{* * *}$ & $(4.52)^{* * *}$ & $(6.26)^{* * * *}$ & $(4.32)^{* * * *}$ & $(5.49)^{* * *}$ & $(4.76)^{* * *}$ & $(3.89)^{* * *}$ & $(2.08)^{* *}$ & $(2.20)^{* *}$ & $(2.43)^{* *}$ & $(0.65)$ \\
\hline $\mathrm{N}$ & 70 & 70 & 59 & 59 & 59 & 59 & 53 & 53 & 53 & 39 & 37 & 39 \\
\hline F or (Chi2) & 6.72 & $(12.71)$ & 10.54 & $(24.37)$ & 11.43 & (31.41) & 13.53 & $(138.66)$ & $(7.83)$ & 10.01 & $(36.67)$ & $(18.03)$ \\
\hline Adjusted $\mathrm{R}^{2}$ & 0.14 & & 0.59 & & 0.62 & & 0.65 & & & 0.66 & & \\
\hline
\end{tabular}


Looking across Table III-4, we see that the ratio of seniors to young is among the most significant and robust regressors. A higher ratio of seniors leads to a larger share of public care in total health expenditure. The ratio of mean income to median income also works in the expected direction, i.e. a more unequal distribution of income is associated with more redistribution. This result is consistent with Meltzer and Richard (1981)'s theory about the positive relationship between degree of public redistribution and the skewness of the income distribution ${ }^{67}$. The positive correlation between the ratio of seniors to young and the share of public health expenditure implies that an aging population does not lead to reduced public support for public health care. Although seniors may prefer more private options, it appears that most of the political pressure generated by seniors is accommodated by an increasing government budget on public health care systems.

Population size exhibits a robust negative correlation with the share of public health expenditure. This implies that, in our model, the loss in welfare due to socializing a private good dominates the economies of scale effect. Here, population is more like a proxy for the heterogeneous preferences of citizens for public goods based on factors other than age or income. The factors contributing to the heterogeneity in preferences can be from, for example, ethnic fragmentation, language, or religion ${ }^{68}$. Citizens in a smaller

\footnotetext{
${ }^{67}$ Meltzer and Richard argue that when a uniform benefit is financed by linear tax rate, the benefit is proportional to the mean income while the cost of tax burden is according to the median income for a median voter. Therefore, when the median voter is decisive, the degree of redistribution is positively correlated with the ratio of mean income to median income.

${ }^{68}$ Easterly and Levine (1997) find that ethnic fragmentation reduces expenditures on public goods. Some of the evidences supporting this theory include the fact that Canada and United States are slow in adopting social security systems, and the fact that Quebec and the rest of Canada have separate old-age insurance systems (Cutler and Johnson 2004).
} 
country are more likely to reach consensus about how to allocate public resources because they share similar cultural backgrounds. The contrast between Luxemburg and United States in terms of population size and share of public health expenditure may serve as a good example (see Table III-1).

The logarithm of GDP enters with a negative coefficient and is significant in most of the estimation models. This implies that private health insurance is a luxury good. A richer country has relatively higher share of private care ${ }^{69}$. This conclusion must be seen in the light of the fact that all the countries included in our sample are developed economies and almost all of them have a universal public health care plan. Given the supporting role of private insurance in OECD countries, we do not interpret this result as implying a growing substitution of private care for public care that is driven by wealth accumulation. Instead, we think the rising share of private care reflects the increasing demand for comprehensive medical coverage and desire for a better quality of medical service for some groups of citizens ${ }^{70}$.

The index of right-left ideology enters with a negative sign and it is significant in four of the eight cases where it appears. As predicted, left-wing governments prefer a relatively larger public health care system. This implies that the general right-left ideological positioning of voters can be another important factor in explaining redistributive policies, in addition to the commonly considered factors such as income or demographic

\footnotetext{
${ }^{69}$ This does not violate Wagner's law. We are looking at the ratio of public health expenditure in total expenditure instead of the size of public health expenditure.

${ }^{70}$ The survey of Colombo and Tapay (2004) provides evidences that wealthier citizen groups are more likely to purchase private health coverage in most OECD countries.
} 
characteristics. Despite the use of different datasets, the study of Iverson and Soskice (2006) also finds that the right-left ideology of political parties has a similarly strong effect on the degree of redistribution in democratic countries.

We find that in most of the equations, endogenous government policies are not significant in explaining share of public health expenditure, though their coefficients almost always have the expected signs. Perhaps this is due to our use of rough proxies and use of weak instruments $^{71}$.

The $F$-statistics and the Chi-square statistics in the end of Table III-4 indicate that the supply side does not improve the estimation. Although almost all the factors are present with the expected sign, only the number of hospital beds is statistically significant. We suspect that the supply side factors used here suffer from an endogeneity problem.

\subsection{A best fitting model}

In the following section, we attempt to find a "best fitting" model based on Table III-4.

To begin, we start from Model C and ignore model D1, D2, and D3 because including supply side factors does not improve the estimation in terms of $F$-statistics and Chisquare statistics, and number of hospital beds is likely to be endogenous in the model. Starting from model $\mathrm{C}$ we gradually drop the insignificant independent variables to search for the most parsimonious specification. In moving from the general to more specific specification, $F$-statistics and Chi-square statistics are used as guidelines.

\footnotetext{
71 The testing in Section Five reveals a weak instrument problem.
} 
The best fitting model based on this strategy using OLS estimations is:

$$
\text { Shg }=\underset{(4.34)^{* * *}(3.73)^{* * *}}{1.25-0.08 \log (G D P)}+\underset{(5.67)^{* * *}}{2.38 \text { Demography }}+\underset{(1.76)^{*}}{0.30 \text { Mean Median }}
$$

- 0.05 Log (Population) - 0.002 I_RightLeft $+\varepsilon$.

$$
(5.69)^{* * *} \quad(2.69)^{* * *}
$$

$R^{2}=0.66, F$-statistics $=13.84,59$ observations.

The best fitting reduced-form model based on the GLS estimations is:

$$
\begin{aligned}
& \text { Shg }=1.26-0.03 \log (G D P)+0.90 \text { Demography }-0.03 \log (\text { Population) } \\
& (8.11)^{* * *}(2.20)^{* *} \quad(3.07)^{* * *} \quad(5.22)^{* * *} \\
& -0.0007 \text { I_RightLeft }+\varepsilon \text {. } \\
& (1.78)^{*}
\end{aligned}
$$

Wald chi $2=38.47,70$ observations.

The models in equation (19) and (20) imply that income distribution, demographic distribution, the right-left ideology of voters, and the size of population matter in determining the share of public health expenditure. We will use the most parsimonious model, the model in equation (20), as our baseline model in the following sensitivity tests.

\subsection{Sensitivity test on sample selection}

We first drop some outliers to see whether the immediate preceding estimation results are sensitive to sample selection. The United States is the only country in our sample that does not have a public health care system and the country with a dramatically lower share of public health expenditure. We first drop United States from our sample and run a regression based on our model in equation (20).

The estimation result is: 
Shg $=1.16-0.04 \log (G D P)+0.77$ Demography -0.02 Log (Population) $(7.94)^{* * *}(2.47)^{* *} \quad(3.22)^{* * *} \quad(2.67)^{* * *}$

-0.0006 I_RightLeft $+\varepsilon$.

$(1.88)^{*}$

Wald chi2 $=18.52,65$ observations.

This result shows that all our estimators are robust even when United States is excluded from the sample. This confirms that the negative relationship between GDP and the share of public health expenditure is not because of the presence of the United States in the sample. We conclude that among the countries with a universal public health care plan, citizens in richer countries purchase more private care to supplement their entitlements to public care.

We then put back the United States, and drop Luxemburg, the country with a relatively higher share of public health expenditure from the sample.

The estimation result based on equation (20) is:

$$
\begin{aligned}
& \text { Shg }=1.24-0.05 \log (G D P)+0.77 \text { Demography }-0.01 \log (\text { Population) } \\
& (7.37)^{* * *}(2.95)^{* * *} \quad(2.66)^{* * *} \quad(1.19) \\
& -0.0006 \text { I_RightLeft }+\varepsilon \text {. } \\
& (1.91)^{*}
\end{aligned}
$$

Wald chi $2=15.24,65$ observations.

We find that population is no longer a significant estimator and the other results still hold. This implies that the negative relationship between population and the share of public expenditure may be partially due to the presence of Luxembourg as an outlier.

\subsection{Testing for the effects of health care systems}

Esping-Anderson's influential book "The Three Worlds of Welfare Capitalism" clusters 130 
the developed capitalist countries into three major groups: Liberal (for example, the United States), Conservative (for example, Germany), and Social Democratic (for example, Sweden). In our context however, it makes more sense to us to group countries according to the type of health care system directly, since these types are well-identified in the data. This will also help to deal with the case of the U.S. which is an outlier in the data set with respect to its public-private mix.

In OECD countries, there are three major types of health care systems including National Health Service systems (NHS), social insurance systems, and fully private insurance systems (Auer et al. 1995 and Attella and Marini 2006). The first two systems are universal public health care plans, and the last one is a private health care system.

The NHS model (or Beveridge model) is characterized by tax financing, universal coverage, and public provision of health care. The social insurance model (or Bismarck model) is characterized by compulsory universal coverage within a social security framework, employment-based contributions through non-profit insurance funds, and mixed public-private provision of health care. The private insurance model is characterized by individual or employer-based purchase of private health insurance coverage, employer and individual contributions, and private provision of health care (Auer et al. 1995, p.19-22.).

According to this categorization, we divide the countries in our sample into three 
groups $^{72}$.

NHS countries ( 7 countries): Australia, Canada, Denmark, Finland, Ireland, Spain, the United Kingdom;

Social insurance countries (6 countries): Austria, France, Germany, Japan, Luxembourg, the Netherlands;

and

Private insurance countries (1 country): the United States.

Attella and Marini (2006) think that private health expenditures either substitute or complement public health expenditures, depending on the health care systems. They argue that in National Health Service (NHS) system, public and private health expenditures are substitutes because more tax-financed public health care means less disposable income to be spent on private care. In social insurance based health systems public expenditure and private care are complements, they argue, because individual contributions cover individual needs and public expenditure covers health needs of the poor.

In this section, we will use our data to see if there exists a systematic difference between the health care systems in terms of the determinants of the public-private mix. Figure

\footnotetext{
${ }^{72}$ There are differences among countries within NHS or Social Insurance systems. Please see Table 2.3. "Cost-sharing Policies in Public Schemes for Basic Health Coverage" on page 36 and Table 2.2. "Permitted Role of Private Health Insurance" on page 35 of OECD (2007) for detailed information. Interested readers may also refer to the "Country diagram: charts on health care systems" in OECD Health Data 2008 for the structure of the health care systems in each country.
} 
III-4 below suggests that there is no systematic difference between the two public health care systems in terms of share of public health expenditure, but there is significant difference between the public systems and the private one.

Figure III-4 Health Care System and Share of Public Health Expenditure

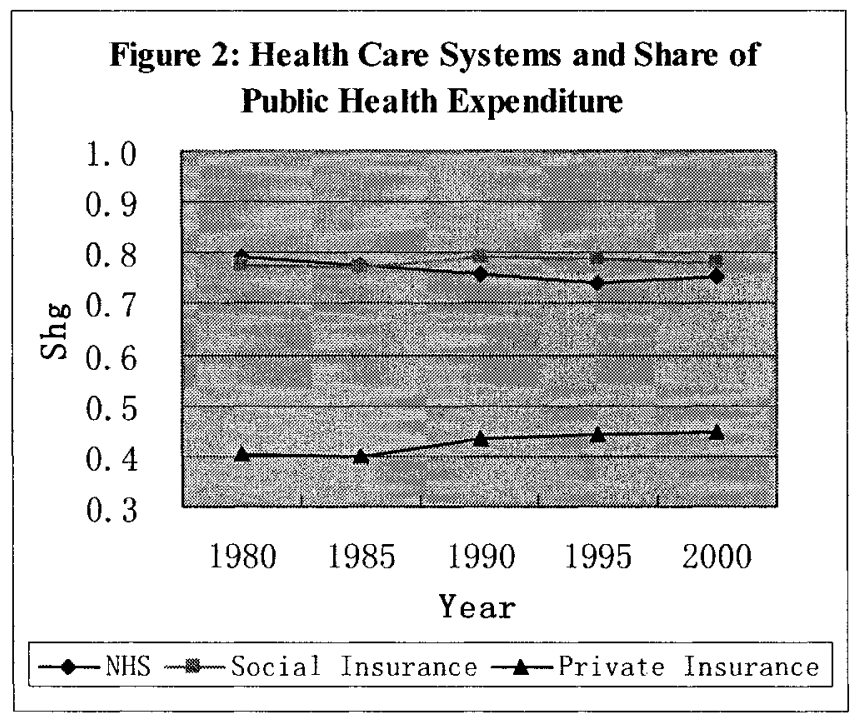

To test the significance of systems statistically, we include a dummy for the health care systems, System, in the preferred model, equation (20). When a country has a private insurance system, System $=0$. An NHS system is denoted with System $=1$, and social insurance system is with System $=2$. We sequentially run regressions using a sample of all the countries, and a sample excluding the United States. These estimation results are in column A and B of Table III-5. We then estimate the model with the countries that have a NHS system, or a social insurance system separately. These estimation results are reported in column $\mathrm{C} 1$ and $\mathrm{C} 2$ of Table III-5. 
Table III-5 Summary of Estimation Results about Health Care Systems

\begin{tabular}{|l|l|l|l|l|}
\hline \multirow{2}{*}{ Model } & \multicolumn{1}{|c|}{ A } & \multicolumn{1}{c|}{ B } & \multicolumn{1}{c|}{ C2 } \\
\cline { 2 - 5 } Regressor & $\begin{array}{l}\text { All the countries with } \\
\text { a dummy for health } \\
\text { care systems }\end{array}$ & $\begin{array}{l}\text { Excluding United } \\
\text { States and with a } \\
\text { system dummy }\end{array}$ & $\begin{array}{l}\text { Countries with a } \\
\text { NHS system only }\end{array}$ & $\begin{array}{l}\text { Countries with a } \\
\text { Social Insurance } \\
\text { system only }\end{array}$ \\
\hline Log(GDP) & -0.03 & -0.03 & -0.03 & 0.01 \\
& $(1.95)^{* *}$ & $(2.26)^{* *}$ & $(1.77)^{* *}$ & $(0.39)$ \\
\hline Demography & 0.70 & 0.67 & -0.47 & 0.52 \\
& $(2.72)^{* * *}$ & $(2.68)^{* * *}$ & $(1.20)$ & $(1.48)$ \\
\hline Log(Population) & -0.03 & -0.02 & -0.01 & -0.02 \\
& $(6.16)^{* * *}$ & $(2.93)^{* * *}$ & $(0.53)$ & $(3.32)^{* * *}$ \\
\hline I_RightLeft & -0.001 & -0.001 & -0.001 & -0.001 \\
& $(2.33)^{* *}$ & $(1.80)^{*}$ & $(3.52)^{* * *}$ & $(1.61)$ \\
\hline System & 0.07 & 0.02 & & \\
\hline Constant & $(4.77)^{* * *}$ & $(1.26)$ & 1.25 & 0.79 \\
& 1.10 & 1.14 & $(6.62)^{* * *}$ & $(3.17)^{* * * *}$ \\
\hline $\mathrm{N}$ & $(7.87)^{* * *}$ & $(7.74)^{* * *}$ & 35 & 30 \\
\hline Chi2 & 70 & 65 & 35.45 & 22.04 \\
\hline legend: $* \mathrm{p}<0.05 ; * * \mathrm{p}<0.01 ; * * *$ & 0.001 & & \\
\hline
\end{tabular}

The dummy for health care system is significant in Model A (all countries), but not significant in Model B (excluding the U.S.). This confirms that there is significant difference between the public and private systems. Be comparing model $\mathrm{C} 1$ and $\mathrm{C} 2$, we find different determinants for the public-private mix between the countries with a NHS system and the countries with a social insurance system, especially with respect to the roles of income and age structure.

\subsection{Further considerations concerning how the model may be improved}

There are probably better alternatives to our "best fitting" model. In this section, we discuss how our model might be improved if the data were fully available. This section largely points towards future statistical research.

First, we consider possible interaction terms. One may suspect that population size may be correlated with income inequality. We include an interaction term of Population and 
the ratio of mean income to median income in our model (20) and run a trial regression. The estimation result shows that the interaction term is not significant.

The interaction of the ratio of seniors to young and the ratio of mean to median income is not significant either, confirming that there is no joint effect from the distribution of income and the distribution of tastes for medical care.

Second, we are not able to include some interesting endogenous variables in our model because of the limitations of the data. For example, health care prices are important endogenous variables but they are available only in a small set of countries. The pre-fisc Gini index may be a better indicator of income inequality than the ratio of mean to median income, and the change in the Gini index before and after fiscal redistribution may better represent incentives to redistribute than the tax progressivity does. Interested readers may check Table III-12 in the Appendix for preliminary estimation using these alternative specifications.

Third, better proxies of government policies may be necessary. The definition of tax progressivity used in Besley and Gouveia (1997) is more precise than the year-to-year elasticity of income tax revenue that we use. The actual amount of tax deductions or credits for purchase of private care may be a better indicator of tax incentives than share of private health insurance used in our model. But data for tax deduction and credits only became available for the years 2001, 2003, and 2005 in OECD Social Expenditure Database (SOCX 2008) $)^{73}$.

\footnotetext{
${ }^{73}$ See "Country detailed information on the impact of the tax system on social expenditure. pdf", available at http://www.oecd.org/document/9/0,3343,en $2649 \quad 34637 \quad 38141385 \quad 1 \quad 1 \quad 1 \quad 1.00$ html.
} 
In addition to the above variables, other forces influencing fiscal redistribution could be included in the estimation model. For example, unionization, female labour participation rate, and unemployment rate are believed to affect the scale and degree of fiscal redistribution. Political institutions such as the election system and size of coalition may also be important explanatory variables (Iverson and Soskice 2006).

\section{Conclusion}

Population aging and the increasing cost of medical technology have provoked a policy debate on the trend of public-private mixed health care system. This study investigates the determinants of the public-private mix of health care expenditure, based on extensions of Usher's (1977) seminal model concerning decisions about socializing medical service. An empirical test is performed to examine our extension of Usher's model using data on selected OECD countries for 1981-2005.

In our analysis, the public-private mix of health expenditure is determined as a political equilibrium in which citizens exhibit diverse preferences for public care. Public provision of health care is motivated by the incentive to redistribute across income classes, and is influenced by the composition of the citizens by age structure or other heterogeneous characteristics. Our estimation results generally verify Usher's hypothesis that the size of public health expenditure is positively correlated with the inequality of income distribution, and negatively correlated with the heterogeneity of tastes for medical care. The right-left ideological positioning of citizens is also shown to play an important role in shaping government policies concerning the health care market. 
It has been speculated that the boundary between public care and private care will be modified as population ages. Our estimation results imply that an aging population is more likely to lead the government to increase spending on public health systems, rather than to cut back to leave room for private alternatives. On the other hand, the results indicate that private care will become more prominent when countries get wealthier.

The implication of the study is that the public-private mix of health expenditure is a complicated political economy issue, but one which is meaningful to empirical research. To understand the cross-country variations in the public-private mix of health expenditure, one has to take into account a number of factors including incentives to redistribute, heterogeneity in preferences for public care, and the left-right ideological positioning of citizens. In future studies, a more complete model should also incorporate institutional arrangements and political systems. 


\section{Reference}

Alesina, Alberto and Romain Waczarg (1998) "Openness, Country Size and Government" Journal of Public Economics Vol. 69 No. 3, pp. 305-321.

Atella, Vincenzo and Giorgia Marini (2006) "Is Health Care Expenditure Really a Luxury Good? Re-Assessment and New Evidence Based on OECD Data" Available at SSRN: http://ssrn.com/abstract $=383004$.

Auer, Ludwig, Douglas E. Angus, J. Eden Cloutier, and Janet Comis (1995), CostEffectiveness of Canadian Health Care, Queens-University of Ottawa Economic Projects Beck, Nathaniel (2007a) "From Statistical Nuisances to Serious Modeling: Changing How We Think About the Analysis of Time-Series-Cross-Section Data" Political Analysis Vol. 15 No. 2, pp. 97-100.

Beck, Nathaniel and Jonathan N. Katz (2007b) "Random Coefficient Models for TimeSeries-Cross-Section Data: Monte Carlo Experiments" Political Analysis Vol. 15 No. 2, pp. 182-195.

Besley, Timothy J. and Miguel Gouveia (1994) "Alternative Systems of Health Care Provision" Economic Policy Vol. 9 No. 2, pp. 200-258.

Budge, Ian, Hans-Dieter Klingemann, Andrea Volkens, Judith Bara and Eric Tanenbaum (2001), Mapping Policy Preferences: Estimates for Parties, Electors, and Governments 1945-1998, Oxford University Press.

Colombo, Francesca and Nicole Tapay (2004) "Private Health Insurance in OECD Countries: The Benefits and Costs for Individuals and Health Systems" OECD Health Working Papers

Coughlin, Peter and Shmuel Nitzan(1981) "Electoral Outcomes with Probabilistic Voting and Nash Social Welfare Maxima"Journal of Public Economics Vol.15, No.1, pp.113-121. 
Cutler, David M. and Richard Johnson (2004) "The Birth and Growth of the Social Insurance State: Explaining Old Age and Medical Insurance across Countries" Public Choice 120, pp. 87-121.

Dreger, Christian and Hans-Eggert Reimers (2005) "Health Care Expenditures in OECD Countries: A Panel Unit Root and Cointegration Analysis" IZA Discussion Paper No. 1469.

Easterly, W. and R. Levine (1997) "Africa's Growth Tragedy: Polices and Ethnic Divisions" Quarterly Journal of Economics 112, pp.1203-1250.

Esping-Andersen, Gosta (2007) "Multiple Regression in Small-N Comparisons" Comparative Social Research Vol. 24, pp. 335-342.

Esping-Andersen, Gøsta (1990) The Three Worlds of Welfare Capitalism, Princeton University Press.

Franzese, Robert J. Jr and Jude C. Hays (2007) "Spatial Econometric Models of CrossSectional Interdependence in Political Science Panel and Time-Series-Cross-Section Data" Political Analysis Vol. 15 No. 2, pp. 140-164.

Gerdtham, U.-G., J. Snrgaard, F. Andersson, and B. Jonssona (1992) "An Econometric Analysis of Health Care Expenditure: A Cross-Section Study of the OECD Countries" Journal of Health Economics 11, pp. 63-84.

Globerman, Steven and Aidan Vining (1998) "A Policy Perspective on "Mixed" Health Care Financial Systems of Business and Economics" Journal of Risk and Insurance Vol. 65 No. 1 , pp. 57-80.

Hettich, Walter and Stanley L. Winer (1999), Democratic Choice and Taxation---A Theoretical and Empirical Analysis, New York: Cambridge University Press.

Iverson, Torben and David Soskice (2006) "Electoral Institutions and the Politics of Coalitions: Why Some Democracies Redistribute More Than Others" American Political Science Review Vol. 100 No. 2. 
Kenworthy, Lane (2007) "Toward Improved Use of Regression in Macro-Comparative Analysis" Comparative Social Research Vol. 24, pp. 343-350.

Klingemann, Hans-Dieter, Andrea Volkens, Judith Bara and Ian Budge (2006), Mapping Policy Preferences II: Estimates for Parties, Electors and Governments in Central and Eastern Europe, European Union and OECD 1990-2003, Oxford University Press.

Lundsgaard, Jens (2002) "Competition and Efficiency in Publicly Funded Services" OECD Economics Department Working Papers No. 331.

Meltzer, Allan and Scott Richard (1981) "A Rational Theory of the Size of Government" Public Choice Vol. 41 No. 3, pp. 403-418.

Newhouse, J. P. (1977) "Medical-Care Expenditures: A Cross-National Survey" Journal of Human Resources 12, pp. 115-24.

OECD (2008) "OECD Health Data 2008: Definitions, Sources, and Methods", OECD. OECD (2007) "Social Expenditure 1980-2003: Interpretative Guide of SOCX", OECD. OECD (2004) "The OECD Health Project: Private Health Insurance in OECD Countries", available at http://www.oecd.org/document/10/0,3343,en_2649_37407_33913226_1_1_1_1,00.html. OECD (1984) "OECD Studies in Taxation: Tax Elasticities of Central Government Personal Income Tax Systems", OECD.

Pearson, Mark and John P. Martin (2005) "Should We Extend the Role of Private Social Expenditure?" IZA Discussion Paper No. 1544.

Plümper, Thomas and Vera E. Troeger (2007) "Efficient Estimation of Time-Invariant and Rarely Changing Variables in Finite Sample Panel Analyses with Unit Fixed Effects" Political Analysis Vol. 15 No. 2, pp. 124-139.

Pontusson, Jonas (2007) "Methods in Comparative Political Economy" Comparative 
Social Research Vol. 24, pp. 325-333.

Rothstein, Bo (2007) "How to get at Causality in the Social Sciences: Multiple

Regressions Versus Case Studies" Comparative Social Research Vol. 24, pp. 351-360.

Rubinson, Claude and Charles C. Ragin (2007) "New Methods for Comparative

Research?" Comparative Social Research Vol. 24, pp. 373-389.

Scruggs, Lyle (2007) "What's Multiple Regression got to do with it?" Comparative Social Research Vol. 24, pp. 309-323.

Sanz, Ismael and Francisco J. Velázquez (2007) "The Role of Ageing in the Growth of Government and Social Welfare Spending in the OECD" European Journal of Political Economy 23, pp. 917-931.

Shalev, Michael (2007a) "Limits and Alternatives to Multiple Regression in Comparative Research" Comparative Social Research Vol. 24, pp. 261-308.

Shalev, Michael (2007b) "Rejoinder: Affirming Limits and Defending Alternatives to Multiple Regression" Comparative Social Research Vol. 24, pp. 391-409.

Shelton, Cameron A. (2007) "The Size and Composition of Government Expenditure" Journal of Public Economics 91, pp. 2230-2260.

Shor, Boris, Joseph Bafumi, Luke Keele, and David Park (2007) "A Bayesian Multilevel Modeling Approach to Time-Series Cross-Sectional Data" Political Analysis Vol. 15 No. 2, pp. 165-181.

Swank, Duane (2007) "What Comparativists Really do" Comparative Social Research Vol. 24, pp. 361-372.

Usher, Dan (1977) "The Welfare Economics of the Socialization of Commodities" Journal of Public Economics 8, pp. 151-168.

Wilson, L S and Michael L Katz (1983) "The Socialization of Commodities" Journal of 
Public Economics Vol. 20 No. 3, pp. 347-356.

Wilson, L S (1985) "The Socialization of Medical Insurance in Canada" Canadian Journal of Economics Vol. 18 No. 2, pp. 355-376.

Wilson, Sven E. and Daniel M. Butler (2007) "A Lot More to Do: The Sensitivity of Time-Series Cross-Section Analyses to Simple Alternative Specifications" Political Analysis Vol. 15 No. 2, pp. 101-123. 


\section{Appendix}

\subsection{Tables}

\section{Table III-6 Tax and Monetary Incentives for the Purchase of Private Care}

\begin{tabular}{|c|c|}
\hline Australia & $\begin{array}{l}30 \% \text { premium rebate to individual purchasers of private health insurance. } \\
\text { Medicare Levy Surcharge on taxable income of high income earners who do not take out private } \\
\text { health insurance }\end{array}$ \\
\hline Austria & $\begin{array}{l}\text { Single people (deduction limited amount and available up to an income threshold) and sole earners } \\
\text { (subject to limit) can deduct } 25 \% \text { of PHI premiums from their taxable income. } \\
\text { Firms can deduct employer-paid premiums from tax. . }\end{array}$ \\
\hline Canada & Tax credits, allowances, deductions and exclusions. \\
\hline Denmark & Firms can deduct employer paid premiums from tax. \\
\hline Finland & None \\
\hline France & Employees can deduct amount PHI premiums paid by employers from taxable income \\
\hline Germany & $\begin{array}{l}\text { Premiums for PHI as well as contributions for social insurance are deductible up to a limit. Health care } \\
\text { costs that have not been covered by the insurance carrier may be deducted up to a maximum amount } \\
\text { depending on income (For those born after 1957: additional max. amount of EUR } 184 \text { applies to } \\
\text { contributions to a voluntary nursing care insurance). }\end{array}$ \\
\hline Ireland & $\begin{array}{l}\text { Tax allowances: Applicable to all taxpayers, deducted by insurers at the standard tax rate, limited to } \\
\text { health insurance premiums for registered health insurance undertakings. Tax relief is also available for } \\
\text { out-of-pocket medical expenditures not covered by PHI, at the higher "marginal" rate. } \\
\text { Rebates: If not claimed as a tax allowance. } \\
\text { From } 1 \text { January } 2004 \text {, employers are to pay "Employers Pay Related Social Insurance Contributions" } \\
\text { (PRSI) on a broad range of "benefits in kind" provided to employees, including employer-paid health } \\
\text { insurance premiums. }\end{array}$ \\
\hline Luxen & $\begin{array}{l}\text { Individuals can deduct mutual PHI premiums from taxable income up to a ceiling (ceiling for all } \\
\text { insurance premiums) }\end{array}$ \\
\hline $\begin{array}{l}\text { The } \\
\text { Netherlands }\end{array}$ & $\begin{array}{l}\text { Tax Credits: Tax credit for young disabled }(<65) \text {. Credit deducted from tax that persons (entitled } \\
\text { under Wajong law) have to pay = EUR } 500(2002) \text {. } \\
\text { Tax allowances: Healthcare costs are income tax deductible (costs directly related to illness or } \\
\text { invalidity). Must exceed a certain threshold }(11.2 \% \text { of income with a max of EUR } 5594(2002) \text { in } \\
\text { order to become deductible. } \\
\text { Premiums for private (industrial) disability are deductible. }\end{array}$ \\
\hline Spain & $\begin{array}{l}\text { No tax on insurance premiums (re: all policy subscribers). } \\
\text { Employees/workers (Income Tax): The premiums or quotas paid by companies to insurance entities } \\
\text { are not considered as earned in kind up to a limit: Limits: EUR } 360,61 \text { per year (individual); EUR } \\
1.202,02 \text { per year, (if the insurance includes the spouse or dependents). The amount in excess is } \\
\text { considered in kind income. } \\
\text { Employers: (Corporate Tax) premiums paid are considered deductible expenses. } \\
\text { If the taxpayer (in business activities) is the insured: (Income Tax), the amount of the premium is } \\
\text { deductible in the direct estimation regime under the same terms of the Corporate Tax. }\end{array}$ \\
\hline $\begin{array}{l}\text { United } \\
\text { Kingdom }\end{array}$ & None for individuals nor firms (since 1997), although firms can deduct premiums from taxable profits. \\
\hline $\begin{array}{l}\text { United } \\
\text { States }\end{array}$ & $\begin{array}{l}\text { Tax Credits: } 60 \% \text { of premium applicable to trade-displaced persons on Qualified Health Insurance } \\
\text { products (Health Insurers must be licensed). } \\
\text { Tax allowance, deductions or exclusions: } 100 \% \text { deduction for employers and employees for group } \\
\text { health insurance policies; } 85 \% \text { for self-employed; other health care expenses (including premiums) } \\
\text { can be deducted when they exceed a certain income threshold. }\end{array}$ \\
\hline
\end{tabular}

Source of Table III-6: OECD (2004), P. 139. Note: PHI means private health insurance. 
Table III-7 Key Private Health Insurance Related Laws and Regulations

\begin{tabular}{|c|c|c|}
\hline & $\begin{array}{l}\text { Consideration of health-risk-related } \\
\text { factors permitted in premium setting }\end{array}$ & $\begin{array}{l}\text { Risk sharing or risk-adjustment } \\
\text { requirements/mechanisms }\end{array}$ \\
\hline Australia & $\begin{array}{l}\text { Lifetime Health covers permits calculation } \\
\text { based on age of entry. }\end{array}$ & $\begin{array}{l}\text { Yes. Risk equalization scheme funds benefits } \\
\text { for those over } 65 \text { years of age and those } \\
\text { experiencing over } 35 \text { days of hospitalization } \\
\text { per year. }\end{array}$ \\
\hline Austria & Yes & No \\
\hline Canada & No & $\begin{array}{l}\text { In Quebec, for private drug insurance plans } \\
\text { for high drug claims in excess of specified } \\
\text { dollar amounts. }\end{array}$ \\
\hline Germany & $\begin{array}{l}\text { Substitutive cover must be offered on a } \\
\text { lifetime basis; premiums determined by age } \\
\text { of entry and gender (and benefits); health } \\
\text { status risk surcharge may be imposed } \\
\text { (except for civil servants switching from } \\
\text { public cover to standard tariff). New entries } \\
\text { may not be charged less than already insured } \\
\text { of same age (not including ageing reserve). } \\
\text { Premium cap: substitutive coverage. }\end{array}$ & $\begin{array}{l}\text { PHI contracts include an option to impose a } \\
\text { surcharge to pay for premium cap on standard } \\
\text { tariff package, but this option has not been } \\
\text { invoked. } \\
\text { Insurers participate in a risk equalization } \\
\text { scheme for standard tariff policies, as the } \\
\text { number of aged insurees varies across } \\
\text { companies. }\end{array}$ \\
\hline Ireland & $\begin{array}{l}\text { Introduction of premiums differentiated } \\
\text { according to age at policy inception is } \\
\text { permitted by law but regulation is required in } \\
\text { order for it to be implemented. }\end{array}$ & $\begin{array}{l}\text { Yes. Risk equalization system being } \\
\text { implemented. }\end{array}$ \\
\hline $\begin{array}{l}\text { The } \\
\text { Netherlands }\end{array}$ & $\begin{array}{l}\text { Premium for WTZ package subject to } \\
\text { limitation. Limit is above average premium } \\
\text { levels in the PHI market. } \\
\text { No limits for supplemental coverage. }\end{array}$ & $\begin{array}{l}\text { Compensation scheme between social } \\
\text { insurance and PHI where privately insured } \\
\text { pay a contribution to cover for social } \\
\text { insurance covering more of the health care } \\
\text { costs of the elderly. Pooling scheme for WTZ } \\
\text { scheme pools costs exceeding WTZ } \\
\text { premiums, and divides and spreads this cost } \\
\text { through surcharge imposed on all privately } \\
\text { insured. }\end{array}$ \\
\hline Spain & $\begin{array}{l}\text { Yes; some entities set premiums according } \\
\text { to age groups and others base them upon the } \\
\text { criteria for mutuals. }\end{array}$ & No \\
\hline $\begin{array}{l}\text { United } \\
\text { Kingdom } \\
\end{array}$ & Yes & No \\
\hline United States & $\begin{array}{l}\text { Many states restrict health status-based } \\
\text { rating ("experience rating") in small group } \\
\text { market and some require community rating } \\
\text { with varying degrees of permitted variation } \\
\text { by age, gender and geography. Individual } \\
\text { market requirements vary. Some states } \\
\text { require community rating in the Medicare } \\
\text { supplement market. }\end{array}$ & $\begin{array}{l}\text { Many states have voluntary risk equalization } \\
\text { schemes in their small group markets; some } \\
\text { are mandatory. } \\
\text { Some states have risk equalization in } \\
\text { individual markets. } 30 \text { states offer high risk } \\
\text { pools (coverage offered by separate pools, } \\
\text { often subsidized by charges on insurers or } \\
\text { other taxes) (Chollet, 2002). }\end{array}$ \\
\hline
\end{tabular}

Source of Table: OECD (2004) P. 96.

Note: PHI means private health insurance. 
Table III-8 Categorisation of benefits with a social purpose

\begin{tabular}{|l|l|l|l|l|}
\hline \multicolumn{2}{|c|}{ Public } & \multicolumn{2}{c|}{ Private } \\
\hline Mandatory & Voluntary & Mandatory & Voluntary \\
\hline Redistribution & $\begin{array}{l}\text { Means-tested } \\
\text { benefits, social } \\
\text { insurance } \\
\text { benefits }\end{array}$ & $\begin{array}{l}\text { Voluntary } \\
\text { participation in } \\
\text { public } \\
\text { insurance } \\
\text { programs. } \\
\text { Self-employed } \\
\text { opting inc to } \\
\text { obtain } \\
\text { insurance } \\
\text { coverage. }\end{array}$ & $\begin{array}{l}\text { Employer-provided } \\
\text { sickness benefits, } \\
\text { benefits accruing from } \\
\text { mandatory } \\
\text { contributions, to, for } \\
\text { example, pension or } \\
\text { disability insurance. }\end{array}$ & $\begin{array}{l}\text { Tax-advantaged } \\
\text { benefits, e.g. individual } \\
\text { retirement accounts, } \\
\text { occupational pensions, } \\
\text { employer-provided } \\
\text { health plans. }\end{array}$ \\
& $\begin{array}{l}\text { Benefits from } \\
\text { government } \\
\text { managed } \\
\text { individual saving } \\
\text { schemes }\end{array}$ & $\begin{array}{l}\text { Non tax-advantaged } \\
\text { actuarially fair pension } \\
\text { benefits }\end{array}$ & $\begin{array}{l}\text { Exclusively private: } \\
\text { Benefits accruing from } \\
\text { insurance plans bought at } \\
\text { market prices given } \\
\text { individual preferences. }\end{array}$ \\
\hline
\end{tabular}

Source of table: OECD 2007, page 10.

Table III-9 Summary Statistics of Variables in 1981-2005 (5-year averages)

\begin{tabular}{|l|l|l|l|l|l|}
\hline Variable & Observations & Mean & Std. Dev. & \multicolumn{1}{|c|}{ Min } & \multicolumn{1}{c|}{ Max } \\
\hline Shg & 70 & 0.75 & 0.11 & 0.40 & 0.93 \\
\hline GDP & 70 & 21749 & 9151 & 7825 & 61894 \\
\hline Demography & 70 & 0.16 & 0.03 & 0.11 & 0.24 \\
\hline Mean Median & 59 & 1.14 & 0.06 & 1.04 & 1.28 \\
\hline Population & 70 & 49809 & 68349 & 366 & 290859 \\
\hline TaxProg & 70 & 1.13 & 1.21 & -3.05 & 6.83 \\
\hline Share PrvIns & 59 & 0.40 & 0.20 & 0.13 & 0.90 \\
\hline Doctor & 62 & 2.37 & 0.53 & 1.38 & 3.49 \\
\hline Bed & 56 & 6.82 & 2.88 & 3.32 & 15.49 \\
\hline Technology & 61 & 26.50 & 24.52 & 0.14 & 100.52 \\
\hline I RightLeft & 70 & -0.55 & 9.93 & -25.59 & 25.51 \\
\hline I Incentive & 70 & 3.17 & 2.02 & 0.00 & 12.29 \\
\hline I_Regulation & 70 & 1.65 & 1.04 & 0.00 & 4.93 \\
\hline
\end{tabular}

\section{Table III-10 Simple Correlation of Regressors}

\begin{tabular}{|c|c|c|c|c|c|c|c|c|c|}
\hline & \multicolumn{9}{|c|}{ GDP Demography Mean Median Population TaxProg Share PrvIns Doctor Bed Technology } \\
\hline$G D P$ & 1.00 & & & & & & & & \\
\hline Demography & -0.11 & 1.00 & & & & & & & \\
\hline Mean Median & -0.06 & -0.11 & 1.00 & & & & & & \\
\hline Population & 0.10 & -0.08 & 0.48 & 1.00 & & & & & \\
\hline TaxProg & -0.03 & 0.29 & -0.02 & 0.04 & 1.00 & & & & \\
\hline Share PrvIns & 0.17 & -0.09 & -0.44 & 0.07 & -0.14 & 1.00 & & & \\
\hline Doctor & 0.11 & 0.30 & -0.32 & -0.27 & -0.08 & 0.23 & 1.00 & & \\
\hline Bed & -0.21 & 0.40 & -0.15 & 0.08 & 0.28 & -0.24 & -0.09 & 1.00 & \\
\hline Technology & 0.36 & 0.22 & 0.03 & 0.25 & 0.38 & -0.12 & -0.09 & 0.57 & 1.00 \\
\hline
\end{tabular}


Table III-11 Measurement of the Right-left Ideological Positioning of Political Parties

(Scoring a left-right scale on the basis of the manifesto estimates)

\begin{tabular}{|l|l|}
\hline Right emphasis: sum of \%s for $(+)$ & Left emphasis: sum of \%s for $(-)$ \\
\hline Military: positive & Decolonization \\
\hline Freedom, human rights & Military: negative \\
\hline Constitutionalism: positive & Peace \\
\hline Effective authority & Internationalism: positive \\
\hline Free enterprise & Democracy \\
\hline Economic incentive & Regulate capitalism \\
\hline Protectionism: negative & Economic planning \\
\hline Economic orthodoxy & Protectionism: positive \\
\hline Social service: limitation & Social services: expansion \\
\hline National way of life: positive & Education: expansion \\
\hline Traditional morality: positive & Controlled economy \\
\hline Law and order & Nationalization \\
\hline Social harmony & Labor groups: positive \\
\hline
\end{tabular}

Source: Budge et al. (2001), page 22.

Table III-12 Summary of Estimation Results of Models with Alternative Regressors

\begin{tabular}{|c|c|c|c|c|}
\hline & Base & $\mathbf{A}$ & $\mathbf{B}$ & $\mathrm{C}$ \\
\hline Regressor & $\begin{array}{l}\text { "best fitting" } \\
\text { model in } \\
\text { equation (20) }\end{array}$ & $\begin{array}{l}\text { Add } \\
\text { prices }\end{array}$ & $\begin{array}{l}\text { Add Gini_PreFisc } \\
\text { (to } \\
\text { replace } \\
\text { Mean_Median) }\end{array}$ & $\begin{array}{l}\text { Add } \\
\text { GiniChange_Fisc } \\
\text { (to replace } \\
\text { TaxProg) } \\
\end{array}$ \\
\hline \multirow{2}{*}{$\log (G D P)$} & -0.03 & -0.04 & -0.07 & -0.07 \\
\hline & $(2.20)^{* *}$ & $(1.25)$ & $(2.96)^{* * *}$ & $(3.00)^{* * *}$ \\
\hline \multirow{2}{*}{ Demography65 } & 0.90 & 1.79 & 1.28 & 1.33 \\
\hline & $(3.07)^{* * *}$ & $(4.85)^{* * *}$ & $(3.38)^{* * *}$ & $(3.78)^{* * *}$ \\
\hline \multirow{2}{*}{ Log(Population) } & -0.03 & -0.03 & -0.02 & -0.02 \\
\hline & $(5.22)^{* * *}$ & $(7.52)^{* *}$ & $(1.84)^{*}$ & $(1.98)^{* *}$ \\
\hline \multirow{2}{*}{ I RightLeft } & -0.001 & -0.004 & -0.001 & -0.001 \\
\hline & $(1.78)^{*}$ & $(6.01)^{* * *}$ & $(1.56)$ & $(1.44)$ \\
\hline \multirow{2}{*}{ Price PubExp } & & 0.001 & & \\
\hline & & $(0.56)$ & & \\
\hline \multirow{2}{*}{ Price PrvExp } & & -0.001 & & \\
\hline & & $0.52)$ & & \\
\hline \multirow{2}{*}{ Gini PreFisc } & & & 0.15 & \\
\hline & & & $(0.83)$ & \\
\hline \multirow{2}{*}{ GiniChange Fisc } & & & & -0.05 \\
\hline & & & & $(2.03)^{* *}$ \\
\hline \multirow[t]{2}{*}{ Constant } & 1.26 & 1.22 & 1.36 & 1.42 \\
\hline & $(8.11)^{* * *}$ & $(3.78)^{*}$ & $(6.08)^{* * *}$ & $(6.24)^{* * *}$ \\
\hline $\mathrm{N}$ & 70 & 22 & 47 & 47 \\
\hline Chi2 & 38.47 & 444.91 & 19.45 & 19.18 \\
\hline
\end{tabular}


Where,

Price_PubExp Price index $(2000=100)$ : Public expenditure on health.

Price_PrvExp Price index $(2000=100)$ : Private consumption on health.

Gini PreFisc Gini coefficient before taxes and transfers.

GiniChange_Fisc Change in Gini coefficient after taxes and transfers.

GiniChange Fisc $=$ Gini_PostFisc - Gini_PreFisc.

Note: A low Gini coefficient indicates more equal income or wealth distribution, while a high Gini coefficient indicates more unequal distribution. 0 corresponds to perfect equality (everyone having exactly the same income) and 1 corresponds to perfect inequality (where one person has all the income, while everyone else has zero income).

\subsection{Figures}

Figure III-5 illustrates the right-left ideological positioning of the major political parties in Canada and in the United States and their mean ideological positioning weighed by the vote shares of the parties.

Figure III-5 Right-left Ideological Positioning of the Political Parties in Canada and in U.S.A.
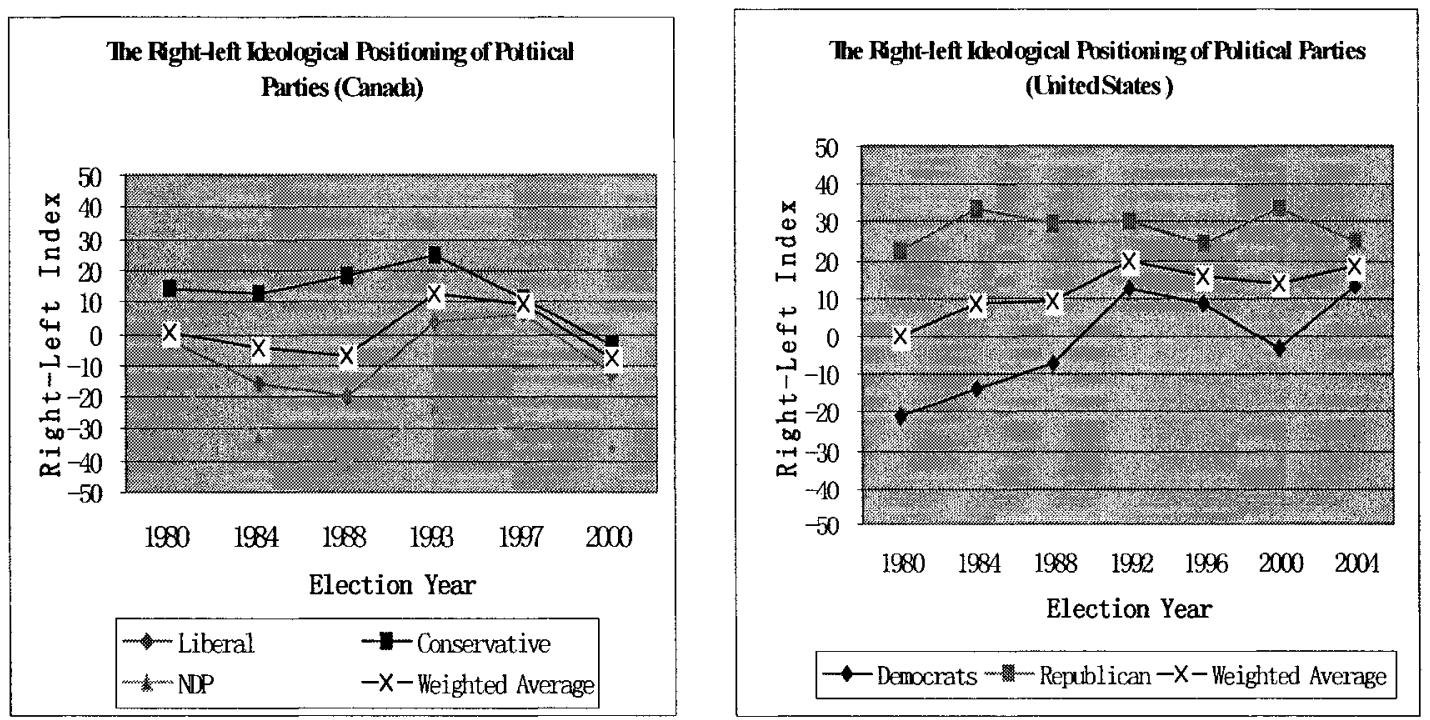

147 


\subsection{Testing for unit heterogeneity and time trend}

Breusch and Pagan Lagrangian multiplier test for random effects shg[countrydum, $t]=x b+u[$ countrydum $]+e[$ countrydum, $t]$ Estimated results:

\begin{tabular}{r|cc} 
& Var & sd $=$ sqrt $(\operatorname{Var})$ \\
shg & .011526 & .1073593 \\
e & .0001915 & .0138401 \\
u & .0055088 & .0742214
\end{tabular}

Test: $\operatorname{Var}(u)=0$

chi2(1) $=12.49 \quad$ Prob $>$ chi2 $=0.0004$

Breusch and Pagan Lagrangian multiplier test for random effects shg $[$ yeardum, $t=\mathrm{Xb}+\mathrm{u}[$ yeardum $]+\mathrm{e}[$ yeardum, $t]$ Estimated results:

\begin{tabular}{r|rr} 
& Var & sd $=$ sqrt(Var) \\
shg & .011526 & .1073593 \\
$e$ & .0046848 & .0684457 \\
u & 0 & 0
\end{tabular}

Test: $\operatorname{Var}(u)=0$

$\operatorname{chi} 2(1)=1.76 \quad$ Prob $>\operatorname{chi} 2=0.1851$

\subsection{Testing for validity of instrumental variables}

Test for relevance of instrumental variables:

First-stage of the 2SLS regression

\begin{tabular}{|c|c|c|c|c|c|c|}
\hline Source 1 & SS & $d f$ & MS & Number of obs & $=$ & 39 \\
\hline 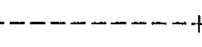 & $=$ & - & - & 29) & $=$ & 1.8 \\
\hline Model | & .62897331 & 9 & .069885923 & Prob $>E$ & $=$ & 0.1054 \\
\hline Residual | & 1.10803729 & 29 & .038208183 & R-squared & $=$ & 0.362 \\
\hline-------+ & - -ーーーーー & --- & -------ー- & Adj R-squared & $=$ & 0.164 \\
\hline Total & 1.7370106 & 38 & .045710805 & RoOt MSE & $=$ & \\
\hline
\end{tabular}

\begin{tabular}{|c|c|c|c|c|c|c|}
\hline share_prvins 1 & Coef. & std. Err & t & $P>|t|$ & {[} & In \\
\hline loggdp । & .2505611 & .1745852 & 1.44 & 0.162 & -.1065057 & .6076279 \\
\hline demography | & -.2282162 & 1.578225 & -0.14 & 0.886 & -3.456048 & 2.999615 \\
\hline mean_median 1 & -1.622164 & .9666459 & -1.68 & 0.104 & -3.599176 & .3548494 \\
\hline logpopulat $\sim$ n & .0214545 & .0317493 & 0.68 & 0.505 & -.04348 & .086389 \\
\hline logdoctor 1 & .1470671 & .1891278 & 0.78 & 0.443 & -.2397426 & .5338769 \\
\hline logbed I & -.0349856 & .1190797 & -0.29 & 0.771 & -.278531 & .2085599 \\
\hline logtechnol y I & -.0689443 & .0572701 & -1.20 & 0.238 & -.1860748 & .0481863 \\
\hline
\end{tabular}

148 


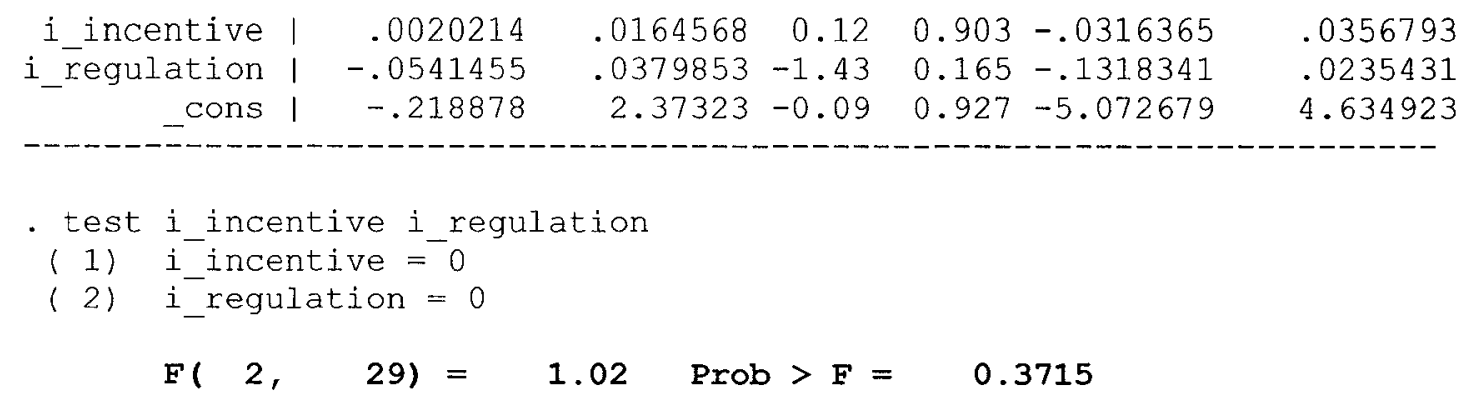

Instrumental variables (2SLS) regression

Source |
Model |

Instrumented: share_prvins

Instruments: loggdp demography mean median logpopulation logdoctor logbed logtechnology i_incentive i_reğulation

Test for exogeneity of instrumental variables:

Tests of overidentifying restrictions

$\begin{array}{lll}\text { Sargan } N{ }^{*} \mathrm{R}-\mathrm{sq} \text { test } & \text { Chi-sq }(1)=0.000 & \text { P-value }=0.9854 \\ \text { Basmann test } & \text { Chi-sq }(1)=0.000 & \text { P-value }=0.9874\end{array}$

